\title{
ELEMENTS OF CONCHOLOGY:
}

\author{
PREPARED FOR THE USE OF
}

SCHOOLS AND COLLEGES,

\section{B X}

W. S. W. RUSCHENBER GER, M.D.

Surgeon in the U. S. Navy ; Fullow of the College of Physicians; Hon. Member of the Philadelphia Medical Society; Member of the Academy of Natural Soiences of Phíladelphia, \&co. \&co,

FROM THE TEXT OF

MILNE EDWARDS, AND ACHILLE COMTÉ, PROFESSORS OF NATURAL HISTORY IN THE COLLEGES OF HENRI IV, AND CHARLEMAGNE.

WITE PIATES.

PHILADELPHIA :

GRIGG \& ELIIOT,

NO. 9 NORTH FOURTP STREET,

1845 . 







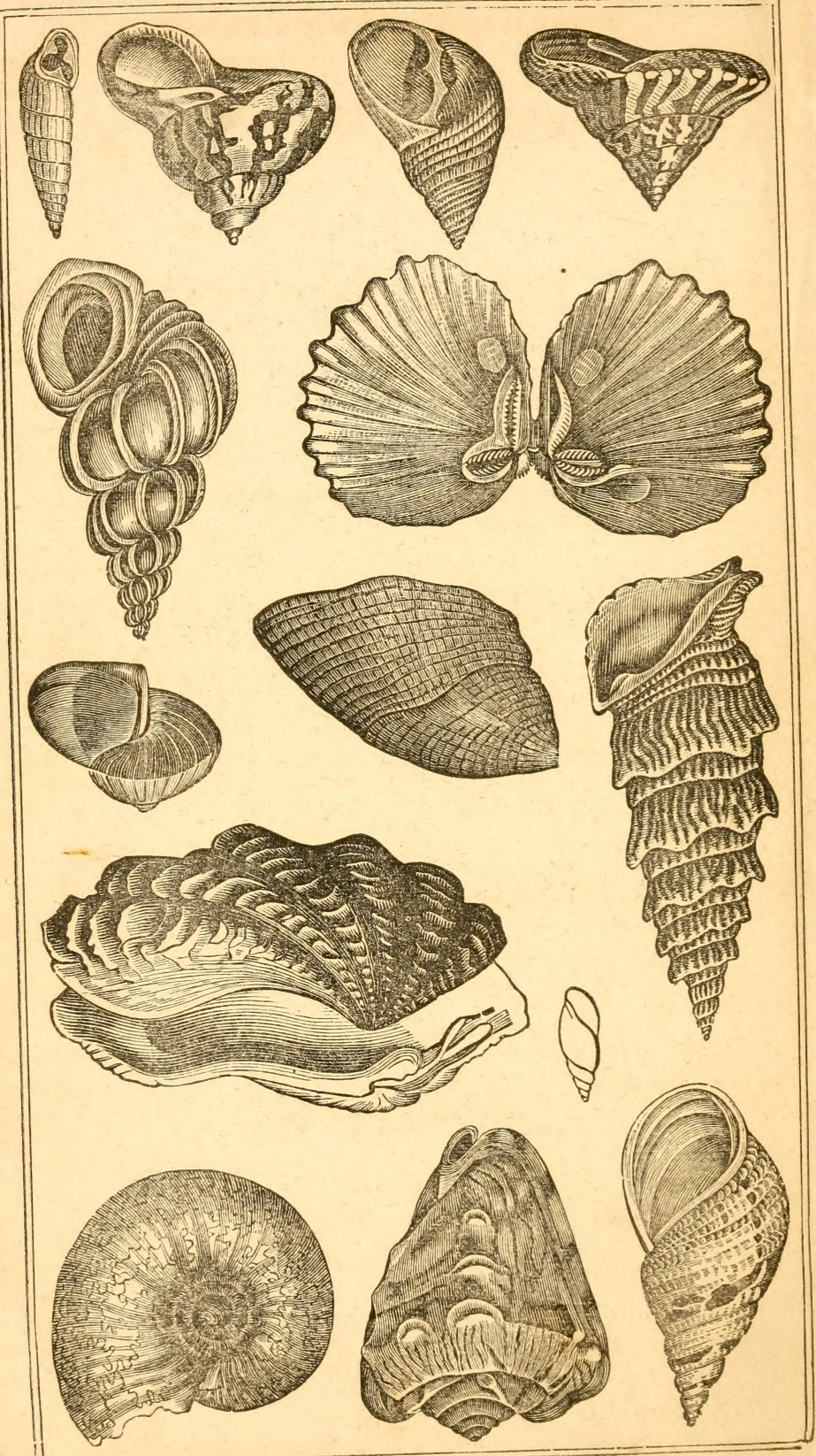




\title{
ELEMENTS OF CONCHOLOGY:
}

\author{
PREPARED FOR THE USE OF
}

\section{SCHOOLS AND COLLEGES,}

B Y

W. S. W. R US CHENBER G ER, M.D.

Surgeon in the U. S. Navy; Fellow of the College of Physicians; Hon, Member of the Philadelphia INedical Society; Member of the Academy of Natural Sciences of Fhiladelphia, \&c. \&ce.

FROM THE TEXT OF

MILNE EDWARDS, AND ACHILLE COMTE,

PROFESSORS OF NATURAL HISTORY IN THE COLLEGES

OF HENRI IV, AND CHARIEMAGNE.

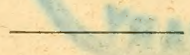

WITH PLATES.

PHILADELPHIA :

GRIGG \& ELLIOT,

NO. 9 NORTH FOURTH STREET,

1845 . 
F nlarod, according to the Act of Congress, in the year 1843, by W. S. W. RUSCHENBERGER, M.D., in the clerk's office of the District Court of the United States in and for the Eastern District of Pennsylvania.

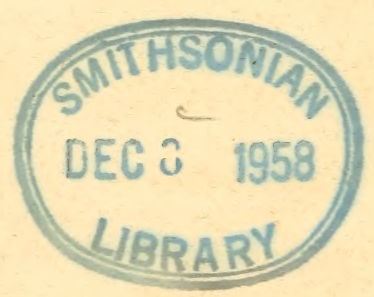

T. K. \& P G. Collins, Printers。 


\section{PREFACE.}

The fifth of the Series of First Books of Natural History, cm. braces that branch of our subject which treats of the Mollusca, or soft animals, and, consequently, includes the Elements of Conchology.

In the beauty and singularity of their forms, the varicty and brilliancy of their colours, shells only yield to flowers. The admiration of these deserted habitations of a very numerons class of animals is very general, if not universal; scarcely a house, at least in sea-port towns, is without a few shells, and in many there are large collections of them. Comparatively, few persons, however, vicw them in connection with animal existence-for the mass, they are merely beautiful things from the seas and rivers, far and near. We care little how they grow, how they live, how they breathe, upon what they feed, or for what use they were created. Who stops to think an oyster has a heart and bloodvessels, a breathing apparatus, a nervous system, or digestive organs? How very few are aware that certain snails possess eyes and lay eggs; nor is it universally known that we are indebted to the organization of soft animals for mother-of-pearl and pearls!

Limited as this little volume is, it may prove a key to stores of information, even more interesting to many than the numerous fictions of the day. "Truth is stranger than fiction," has been often said; and the beautiful truths brought to us by a study of animal life, in its various forms, are certainly more admirable and wonderful than any fiction of man's creation.

Is there any thing produced by the Bulwers or the James' of the day, more worthy of admiration than the habits of a snail, or the movements of a cockle-shell? When at the Sandwich Islands, in 1836, we heard an anecdote which has an application here. The officers of a British ship of war manifested a strong desire to obtain "curiosities:" a young Kanaka, with a view to 
profit, brought to one of these officers a chicken's foot, and offered it for sale; and by way of insisting upon its value, said, as he pulled the tendon which was attached to its toes, "See how nicely it works ;" and was it not more worthy of attention and thought than all the idols of wood and stone that could be collected?

Fictions are the works of man, but the wonderful truths of the universe are the creations of Omnipotence; yet we bestow more time and more interest on the last novel, in many instances, than would be sufficient to lead us to the contemplation of all the beautiful and magnificent productions which it was Adam's duty to name. Whoever reveres his God, should be able to contemplate his works understandingly, and be able to perceive the beauty of design, the adaptation of the organization, the various forms of life, to the circumstances in which life is placed, and perceive the same wise hand in the structure of the snail, as in the complete and perfect animal, man; and learn too, that even an oyster is within the scheme and protection of Providence.

In forming this little volume, besides the works of MM. Edwards and Comte, those of Cuvier, Lamarck, Blainville and Captain Thomas Brown have been consulted and freely used.

Many of the engravings are copied from the works of M. Blainville; and, it is believed, the engraving, which was done by Mr. G. Thomas, (No. 37 South Third Street,) will compare favourably with anything of the kind ever offered to the American public.

The etymology and pronunciation of the technical words have been placed at the foot of the page.

'This little volume offers the means of becoming acquainted with the history of soft animals and conchology, and opens the way to an advantageous perusal of more complete and ample treatises on the subject.

Philadelphia, June 1, 1844. 


\section{CONCHOLOGY.}

\section{CON'TEN'TS.}

\section{LESSON I.}

General Considerations.-Mollusca in general-Organization-Nervous System-General Form-Skin-Mantle-Shell-Formation of ShellDigestive Apparatus-Circulation of the Blood-Respiration-Senses -Eggs-Classification.

\section{LESSON II.}

Class of Cephalopoda.-General Form-Respiration-Circulation-Organs of Digestion-Cephalic Cartilage-Organs of Locomotion-Organs of the Senses-Nervous System-Habits-Division into two Families.

Family of Ceplalopoda Dibranchiata,_Octopus Vulgaris, or Poulpe-Argonaut-Calmaries-Cuttle-fishes.

Family of Cephalopoda Tetrabranchiata.-Nautilus-Ammonites-Belem nites-Foraminifera.

\section{LESSON III.}

Class of Gasteropoda.-General Conformation-Classification.

Order of Gasteropoda Pulmonea.-Organization-Division into two Families, Family of Terrestrial Pulmonea.-Limax-Vaginulus-Helix-BulimusPupa-Chondrus-Clausilia-Achatina.

Family of Aquatic Pulmonea.-Onchidium-Planorbis-Limnæa-PhysaAuricula.

Order of Gasteropoda Pectinibranchiata.-Organization-Classification.

Family of Trochoides,-Trochus-Turbo-Delphinula-Turritella-Cyclo. stoma-Valvata-Paludina-Littorina-Monodon-Phasianella-Am. pullaria-Janthina-Nerita.

\section{LESSON IV.}

Family of Buccinoides.-Buccinum-Buccinum properly so called-Harpa -Purpura-Cassis-Cerithium-Murex - Strombus-Voluta_Ovula Cypræa-Conus.

Family of Pectinibranchiata Capuloida.-Pileopsis-Hipponyx-Crepidula -Calyptræa-Siphonaria-Sigaretus.

Order of Gasteropoda Tubulibranchiata.

Order of Gasteropoda Scutibranchiata.-Haliotis-Fissurella-Emarginula, 
Order of Gasteropoda Cyclobranchiata.-Patella_Chiton.

Order of Gasteropoda Inferobranchiata.

Order of Gasteropodia Tectibranchiata.-Pleurobranchus-Aplysia-Dolabella-Bullea-Bulla.

Order of Gasteropoda Nudibranchiata.-Eolidia-Glaucus.

Order of Gasteropoda Heteropoda.-Carinaria.

Class of Mollusea Pteropoda.-Clio borealis.

\section{LESSON V.}

Class of Mollusea Acephala, or Lamellibranchiata-Organization-C 'lassification.

Family of Ostracea.-Classification-Oysters-Gryphæa-Pecten-LimaMalleus-Anomia - Spondylus-Perna-Etheria-Avicula-Pearls-

Pearl Fishery-Pinna-Arca-Pectunculus-Trigonia.

Family of Mytilacea.-Mussels, (Mytilus)-Modiolus-Anodonta-Unio. Family of Chamacea.-Tridacna-Chama-Isocardia.

\section{JESSON VI.}

Family of Cardiacea-Cardium-Donax-Cyclas-Corbis-Tcllina-Ve. nus-Petricola-Venerupis-Mactra.

Eamily of Inclusa, - Lutraria - Mya-Byssomia-IIiatella-Solen-Sangninolaria-Pholas-Teredo-Fistulana-Gastrochæna-ClavigellaAspergillum.

Class of Mollusea Brachiopoda,-General Characters-Lingula-Terebratula-Orbicula.

Class of Mollusca Tunicata, or Acephala Nuda.-Biphora-Ascidia-BotrylIus-Pyrosoma-Parts of Shells. 


\title{
ELEMENTS OF CONCHOLOGY.
}

\section{SECOND BRANCH OF TFE ANIMAI KINGDON,}

\section{MOLLUSCA :}

\author{
MOLLUSKS, OR SOFT ANIMALS.
}

\section{LESSON I.}

General Considerations.-Mollusca in general-Organiza. tion-Nervous System-General Form - Skin - MantleShell-Formation of Shell-Digestive Apparatus-Circulation of the Blood-Respiration-Senses-Eggs-Classification.

The long series of vertebrate animals, the history of which we have already concluded, forms only a small part of the animal kingdom, and to make the beings we are now about to study as interesting as the vertebrata, we should be obliged to very far exceed the limits of these lessons: but these animals are less useful to us; they attract less attention, and most of them pass unnoticed, except by those who are at the pains of becoming acquainted with them; their faculties are more limited and their structure is less complicated and less perfect.

1. All these lower animals want a spinal marrow and a true internal skeleton; this last character has obtained for them the collective name of invertebrate animals; but in a natural classification, they could not all be placed in the same group, because they are evidently formed after three different types, and therefore should be divided into three distinct branches, namely : the mollusca, the articulata, the radiata, or zoophytes.

2. The branch of zoophytes is composed essentially of the most imperfect animals : according to the classification of Cuvier, which we follow, this branch comprises a certain number of beings which seem, in a manner, to present the first sketch of the mode of organization proper to mollusks and articulate animals; its place is therefore among the lowest grades of the animal series, and passes, by gradual shades, from the type of the radiate animal to that of the two great branches which spring from it. These two latter branches, one equally with the other, present a constantly increasing complication of organization, and form, as it

1. What are inver'tebrate animals? What groups or divisions include the inver'tebrate animals?

2. What are zo'ophytes? Why are the mollus'ca placed before the artic. ulata in the series of animals? 
were, two parallel series. The series of articulate animals seems to be the highest in the scale; but the mollusca, though less perfect in structure, seem to be less remote in their mode of organization from the vertebrata, and for this reason we have determined to place them first.

3. We give the name of Mollusca (from the Latin, mollis, soft) to animals which, in the general features of their organization, resemble snails, oysters, \&c. They have no articulated skeleton nor vertebral canal, like the vertebrate animals; their body is soft, and their skin, which is often corered by a shell, is never hardened so as to form a kind of external skeleton composed of a series of rings, as is the case in insects and the crustacea.

4. The nervous system, an apparatus of so much importance, the action of which regulates all the phenomena of animal life, and the functions of which must necessarily be in harmony with its mode of conformation, differs altogether in the mollusca in its general disposition, from what we observe in the vertebrata. There exists a nervous centre which to a certain extent may be compared to the brain in superior animals; but this ganglionic mass is not continuous with an organ analogous to the spinal marrow ; the other central parts of the nervous system are found on the opposite side of the digestive tube, and hence this canal is always embraced by a sort of medullary collar, from which the different nerves of the body arise. In other respects, this apparatus varies more in its arrangement than in the number of parts composing it.

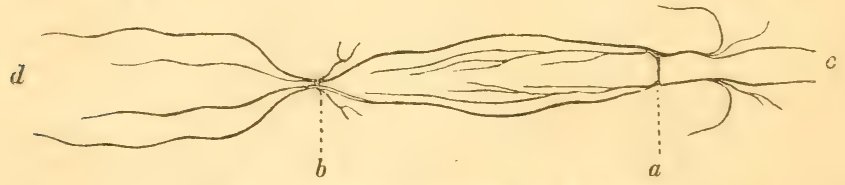

Fig. 1.-NERVOUS SYSTEM OF A SOLEN.

5. In a great many of the least perfect mollusks, such as the Solen and many other acephala, which inhabit bivalve shells, the nervous system is generally composed of but two pairs of ganglia, united by two long inter-ganglionic cords, giving rise to different branches ( $f g .1$ ); the ganglia of the anterior pair

Explanation of Fig. 1. - Nervous system of an acephalous mollusk (Solen) :- $a$, the pair of ganglia which is situate in front of the esophagus representing that portion of the nervous system of these animals, which is

3. What are the general characters of the Mollus'ca?

4. What are the peculiarities of arrangement of the nerves of the Mollus'ca?

5. What are the general characters of the nervous system in acephalous mollusks? What are tine peculiarities of the nervous system of gasteropods? 


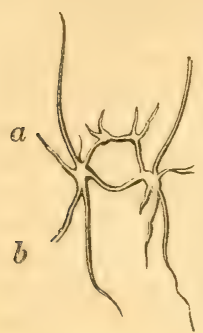

(a) are sometimes considerably separated from each other, and only united by an intermediate cord, and sometimes glued one to the other, or even confounded in a single mass: they are situate above the œsophagus, and far from the posterior ganglia $(b)$, which are placed beneath the intestine towards the posterior part of the body. In some mollusks, the nervous system is still more simple in its composition; but, in general, the ganglia tend to approximate the

Fig. 2. œsophagus more and more ( $f \mathrm{~g}: 2)$, and in most of these animals we find a greater numNERVES OF A ber of small medullary masses, some of which JANTHINA.

form a sort of nervous centre, and the others are distributed in different parts of the body. Thus, in the snails and most mollusks constructed on the same plan, and named gasteropods (from the Greek, gaster, belly, and pous, foot), on account of their mode of crawling on the ventral surface of the body, there exists, above and in front of the $p$ œsophagus, a medullary mass ( $f \mathrm{~g}$. $3, c$.$) , which is the representative d$ of the anterior pair of ganglia above mentioned, and which is re- $\boldsymbol{a}$ garded by most anatomists as the

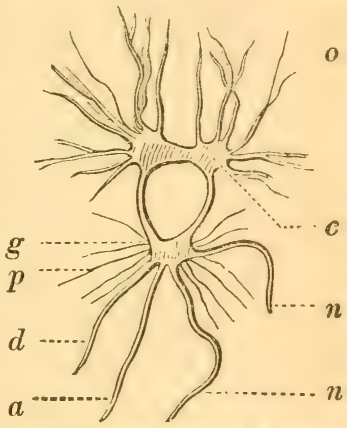

Fig. 3.- NERVES OF A SNAIL.

generally called the brain; here, these two ganglia are considerably separated from each other, and are united by a transverse band; $-c$. nerves which arise anteriorly to be distributed to the tentacula, to the mantle, \&c.; $-b$. ventral pair of ganglia, which are united in a single mass, placed beneath the intestine, and joined to the anterior ganglia by two very long nervous cords; $-d$. nerves which arise from the posterior ganglia to be distributed to the mantle, \&c.

Explanation of Fig. 2.-Nervous system of a Janthina; a gasteropod mollusk, in which the posterior ganglia $(b)$ as well as the anterior ganglia (a) are separated from each other; but they are more approximated to the latter, so that the inter-ganglionic cords are very short, and form a sort of closely fitting collar around the osophagus.

Explanation of Fig. 3.-Central portion of the nervous system of the snail :--c. ganglia situate in front of the œsophagus, and constituting, by thcir union, the mass which is called the brain in mollusca; - 0 . nerves of the anterior parts of the body, the eyes, \&c.; $-g$. the nervous mass formed by the union of the ganglia of the posterior pair ; the cesophagus passes through the collar or ring which unites it to the brain $;-p$. the nerves of the foot; $-n$. nerves which go to the pulmonary cavity, \&c.; $-a$. the nerve which accompanies the principal artery; $--d$. the nerve which goes to the diaphragm, \&c. 
brain of these animals: it furnishes nerves to the organs of the senses as well as to the neighbouring parts $(o)$, and is continued posteriorly by two inter-ganglionic cords, which embrace the œsophagus, and which, at a short distance, unite with a second nervous mass $(g)$, situate beneath the digestive tube, and comparable to the posterior pair of ganglia, which we remarked when speaking of the acephalous

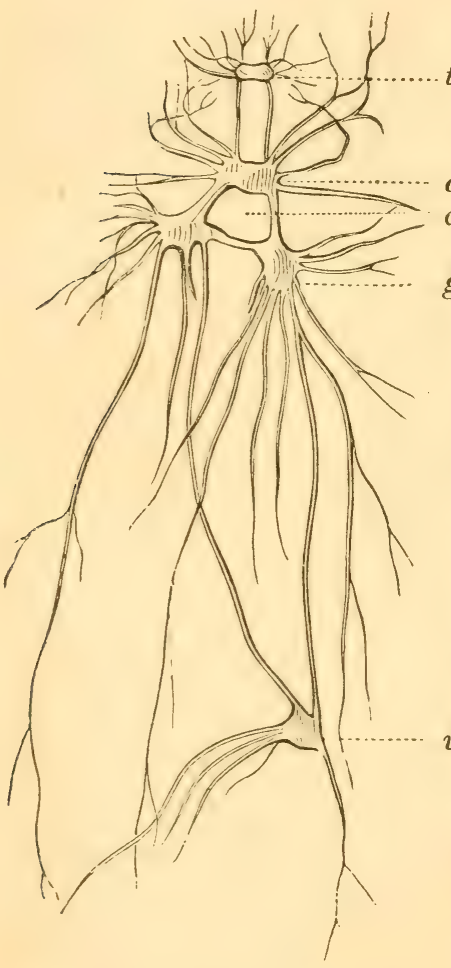

Fig. 4.-NeRves of THE APLYSIA. mollusks; and two small nerves, which arise from the brain, unite to form a third ganglion $(f i g .4, t)$, below the origin of the cosophagus.

c In other gasteropods, the o aplysice or sea-hares, for example, to these ganglia is joined another ( fig. 4,v), situated among the viscera, and united by two communicating threads to the medullary collar which surrounds the cesophagus,. and giving rise to the nerves of the intestines, liver, branchiæ, ovaries, \&c. We also find in these mollusks a fifth ganglion, which is very small, belonging to these latter organs. And, in the poulpes and the cuttle-fish (fig. 5).

$v$ in which this systemacquires its highest degree of development, the ganglionic parts grouped around the œsophagus, are larger and more complicated; for the cephalic and post-œsophageal ganglia, united in a large osophageal collar, present laterally a third

Explanation of Fig. 4.-Nervous system of the aplysia (or sca-hare, as it was called by the ancients), another gasteropod mollusk ; $-c$. the brain ;$o$. the nervous collar which surrounds the csophagus; $-g$. the thoracic or post-oesopluageal ganglia ; - v the visceral ganglion;-t. the buccal ganglion. 
pair of ganglionic swellings, which are lodged in a cartilaginous, cranial cravity ; from them arise the nerves of the feet (Fig. 5).

To recapitulate, sve see that, in this class of animals, the nervous system is essentially composed of a medullary collar, embracing the alimentary tube, and formed by the communicating cords of the two pairs of ganglia, which are widely separated in the acephalous mollusks, but approximate more and more as we ascend in the series, formed by the gasteropods and cepha. lopods; and the

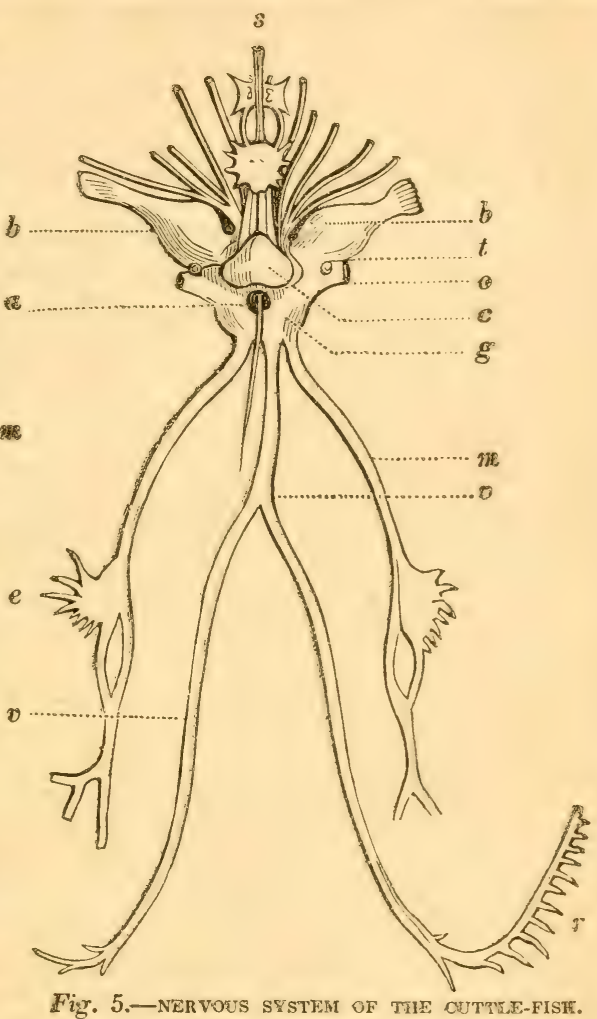

Explanation of Fig. 5.-Nerwous system of the cuttle-fish;-a. the nervous collar which embraces the asophagus, the course of which is indieated by a bristle $(s):-c$. the nervous mass, siruate in frout of the aesophagus, and commonly called the brain : the upper surface is surmounted by a very large cordiform tubercle, and from its anterior part arise two nerves thą soon terminate in a cireular ganglion, which, in its turn gives rise to another pair of nerves, which descend beneath the mouth so as to embrace the oesophagus again, and then form a smasl anterior ganglion from which arise the labial nerves;- $b$. the tentacular ganglia, from which arise the nerves of the arm;- -0 . the optic nerves which arise from the lateral parts of the brain, and soon swell into a large ganglion;-t. smals nervous \{ubercles, situate on the origin of the optic nerves; $-g$. the sub-asophageal or ventral ganglion; - v. the great nerve of the viscera, one branch of which presents an elongated ganglion $(r)$, and penetrates into the branchiæ; - $r$. nerves which also arise from the post-cesophageal ganglia, and which, in their course, present a large star-like ganglion $(e)$, the branches of which are distributed to the mantle. 
nerves which arise from each of these ganglia, to be distributed to the different organs, are at first simple, but very soon pre. sent in different parts of the body ganglionic swellings; bus these ganglia, however numerous they may be, never form a regular longitudinal chain, extending along the middle line of the abdominal face of the body, as is the case in the articulated animals.

6. As we have already said, in this great branch of the animal kingdom, there is neither an internal skeleton, analogous to the solid frame of vertebrate animals, nor an external slieleton, similar to the tegumentary sheath, which envelopes the whole body of articulate animals in a series of rings, and serves the same purposes as the skeleton, properly so called, of the superior animals. 'The general form of mollusks is exiremely variable. Their body is always soft, and in a very small number of them only, there exists internally some solid pieces which are unarticu. lated, and serve rather to protect the viscera than to furnish levers and points of support to the apparatus of locomotion. The muscles are attached directly to the integuments and act but very little beyond their point of insertion; their motions are slow, and in general ill directed. In a small number of these beings, there are elongated and flexible appendages, designed for locomotion ( fig. 7, prge 23); but in most instances the animal can change its place, only by successively contracting difierent points of the inferior sarface of its body, and, even when it possesses extremities, they are united in a group at one end of the body, and never arranged in a symmetrical series, as they are in verte. brate and in articulate animals.

7. The skin of mollusks, always soft and viscid, often forms folds that more or less completely envelope the body, and this disposition has caused the name of mantle to be given to that portion of integument which ordinarily furnishes these expansions. Frequently this mantle or pallium is almast entirely free, and constitutes two large veils which conceal all the rest of the animal, or rather, these two laminæ or membranes unite together so as to form a kind of tube; but at other times, it consists only of a sort of dorsal disk, the edges of which alone are free, or surround the body more exactly under the form of a sack.

8. In general this soft skin is protected by a sort of stony cuirass named shell. It is a secretion having some analogy to

6. What kind of a skeleton have mollusks? What are the general characters of their body? How is locomotion effected in mollwisks?

7. What is the mantle or pallium?

8. What is meant by shell? What is meant by naked mollusks? Whas are testacea? 
that of the epidermis which produces this envelope. The follicles, ordinarily lodged in the edges of the mantle, deposit upon its surface a semi-corncous matter, mixed with a greater or less proportion of carbonate of lime, which moulds itself upon the subjacent parts and solidifies. 'The lamina or layer, thus formed, thickens and grows by successive deposits of new matter. Its superficies is not stony, but in form of a kind of epidermis. Sometimes it preserves a horny consistence throughout its whole thickness. In general, however, the proportion of carbonate of Sime that it contains rapidly increases and imparts to it a stony hardness. The internal surface is often harder than the rest, and possesses a particular structure which renders it vitreous or shining and nacreous. Sometimes the shell always remains enclosed in the thickness of the skin; but, in general, it is external, and extends beyond the mantle, so as to afford the animal perfect protection. Those which are unprovided with shells, or only have an internal sheil, are called naked mollusks, and those in which the sinell is visible are included under the name of con. chifera, or sometimes iesta'cea.

9. The manner in which the shell grows is easy to understand. If we examine the shell of an oyster, for example, we observe that it consists of a multitude of superposed laminæ, the separation of which may be effected by the assistance of heat. These laminæ are formed successively by the mantle of the animal which they cover, and, consequentiy, the most external one must be the oldest; and it is also the smallest, and each new lamina that is added, exceeds the lamina situate above, so that while the shell is augmenting in thickness, it is also increasing in size. In generai, the distinctness of the lamina is less marked, and often the new matter is deposited in such a manner, that its molecules exactly correspond to the molecules of the matter already consolidated, and thus gives to the whole a fibrous structure.

10. Shells are adomed with most diviversified and most agree. ably arranged colours, which often vary with their age. They are almost always entirely superficial, and scem to depend on a sort of a dyeing process performed by the sinin of the animal. which is coloured in a manner corresponding with that of its envelope. The colouring matter seems to be deposited upon the shell at the time of its formation: and its brightness is in proportion to the newness of the latter. It is produced by the edge of the nantle. When a shell happens to be broken and the ani-

9. How does the shell grow?

10. Wow are the colouins of shells produced? 
mal succeeds in repairing the accident, the part newly formed is always white, if it has not been in contact with the edge of the mantle; but if it correspond to this edge, it then assumes the colour that the latter presents at the point touched. For example, when this edge is spotted, we find corresponding spots on the margin of the shell, and, in proportion as the latter is elongated, these spots become confounded with those previously formed, and produce lines perpendicular to crossing strix, or they do not join the latter, but remain isolated, aecordisg as the mantle remains unmoved, and preseryes the same relation to the margins of the shell, or frequently changes its position according to the movements of the animal. Sometimes the seeretion of the colouring matter varies with age; and accidentesl circum stances may also modify it. Light, for example, exests a very remarkable influence on this phenomenom, for not only are shells that are most exposed to the action of this physical agent, ordiarily most brightly coloured, but, when a rollusk lixes fixed to a rock, or in some spot hidden beneath a sponge, or other opaque body, the part of the shell thus placed in dapkness is always dull, and paler than that which is exposed to the contact of tho solar rays.

The duration of shells, and the length of time the animals live which inhabit them, are circumstances not yet determined. When exposed to the action of the air and the vicissitudes of tempera. ture and moisture for some time, shells usually change their colours and gradually become white. The animal matter which enters into its composition is destroyed, and disappears little by Bittle; the lamine separate from each other, particularly ande? the alternate influence of heat and cold, and become finally re. duced to a calcareous powder, which is washed away by currents of water.

11. All mollusks are provided with an alimentary canal, which is more or less folded on itself and open at its two cnds, either as the extreme points of the body, or at points more or less near to each other. There is always a voluminous liver, and we often find them furnished-also with salivary glands and organs of mastication; but the intestines are never held in their place by the assistance of a mesentery.

12. The blood of these animals is cold and colourless or slightly bluish, and circulates in a very complicated vascular appratus, composed of arteries and veins. A heart, formed of a ventricle $(v)$ lusks :

11. What are the gencral characters of the digestive apparatus of mol.

12. Whet is the nature of the blood of mollusks? Flow is it circulated ? 
and one or two auricles (o) is found in the track of the arterial blood, and sends this liquid to all parts of the body, from which it re. turns to the organs of respiration. Sometimes we also find, at the base of the vessels which enter this latter apparatus, vennus reservoirs, erroneously cailled pulmonary hearts; for, having, nothing in their structure resembling muscle, they cannot set the blood in motion, and consequently do not merit this name. (See fig. 9, Page 21.)

13. The organs of respiration vary so much that they cannot be well described at this place: we will merely mention that they are some- $r$ times in the form of lungs, and at others, in that of branchire or gills.

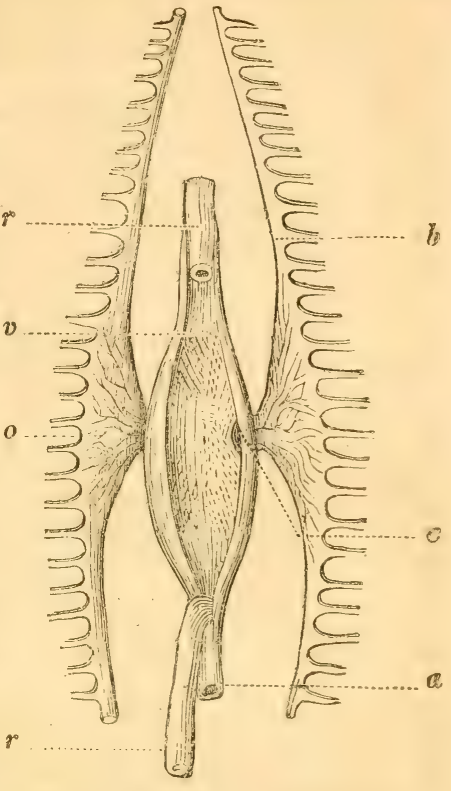

Fig. 6.-HEART OF AN ACEPHALOUS MOLLUSK.

14. Nor can we say any thing genexally of the structure of the organs of the senses, which are, however, always less com. plete than in the vertebrate animals. Certain inollusks appear to be endowed only with the sense of touch and with the sense of taste, but in a great many we find eyes which vary in structure, and in some of these animals there even exists an apparatus of hearing : but none is known to possess a particular organ of smell.

15. Mollusks are re-produced from eggs; but are sometimes hatched without, and sometimes within the body of the mother,

Explanation of Fig. 6.-Heart of an accphalons mollusk:-v. the ventricle, which in these animals has the rectum $(r)$ passing through it, and gives rise to two arteries $(a) ;-c$. one of the auriculo-ventricular openings; -0 . the two auricles receiving the blood from the branchial veins $(b)$.

In the above diagram, the ventricle $(v)$ is open, and the rectum, $(r, r)$ has been divided, and the lower part turned downwards :- a (at the lower part of the figure) represents the origin of one artery, the other artery having a similar origin above:

13. What is the character of the organs of respiration in mollusks?

14. What senses are possessed by mollusks?

15. How are mollusks re-produced? $2 *$ 
and then the young are born alive. In all cases they possess at birth nearly the form they preserve through life, and do not un. dergo metamorphosis.

We have already stated that mollusks differ very much in the general form of their body, and as these external modifications are accompanied by corresponding differences in the degree of complication of their internal organization, they enable us to divide these animals into six natural groups. The following table will give an idea of this classification:

(CLASSES.)

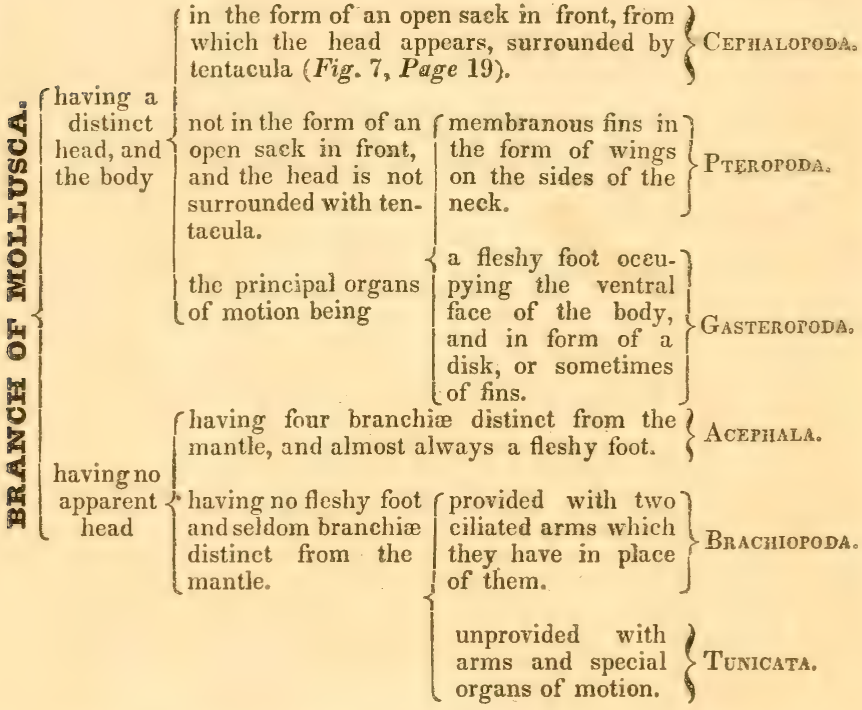

Cuvier, and many other zoologists, arrange the cirrhopoda also in the branch of mollusca; but it is now ascertained that these animals belong to the branch of articulata, the third great divi. sion of the animal kingdom.

16 Into how many classes is the branch of mollus'ca divided? 


\section{IESSON II.}

Class of Ceprialopoda.-General Form-Respiration-Circulation-Organs of Digestion-Cephalic Cartilage Organs of Locomotion -. Organs of the Senses - Nervous System-Habits-Division into two Families.

Family of Cephalopoda Dibranchiata.-Octopus vulgaris, or Poulpe-Argonaut-Calmaries-Cuttle-fishes.

Family of Cephalopoda Tétrabranchita. - Nuutilus Ammonites-Belemnites-Foraminafera.

\section{CIASS OF CHPHAIOPODS.}

1. This class is cornposed of mollusks which are of fantastical shape, for their head is placed between the trunk and feet, or tentacula, which serve them for locomotion, and when they walk, the body is uppermost, and the head down, dragging on the ground. Their feet are attached, around the mouth, to the head, which circumstance has obtained for them the name of Cephalopods (from the Greek, kephale, head, and pous, foat - pra. nounced lkef-a-lo-pod).

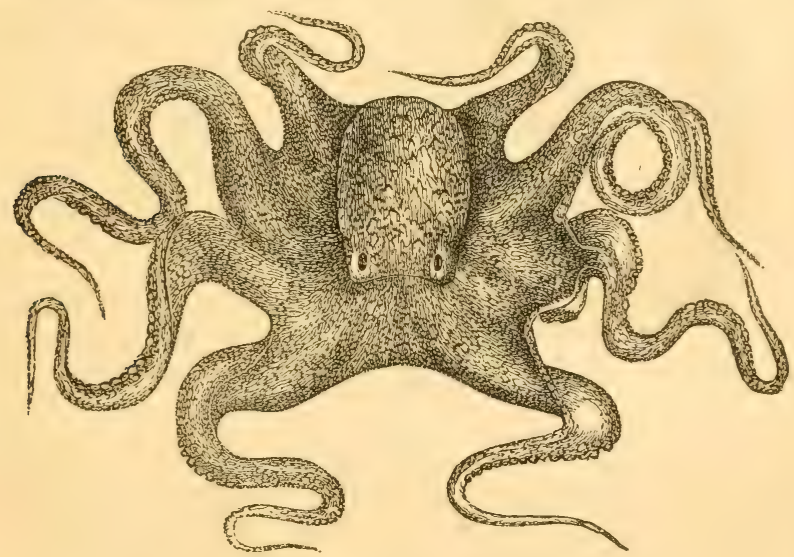

Fig. 7.-оctopus* vulgaris, - OR Conmon roulfE。

2. The trunk of these animals is covered by the mantle, which is in the form of a sack, sometimes almost spherical, and sometimes more or less elongated; it encloses all the

* From the Greek, okto, eight, and pous, foot,-eight feet.

1. What kind of animals compose the class of Cephalopods? Why are they called Cephalopods?

2. What are the general form and characters of the Cephalopods? 
viscera and is open only in front, $(f g .8, o)$. The head issues from this opening: it is round and generally provided with two round eyes, very analogous in their structure to those of vertebrate animals. The mouth occupies the centre: it is armed with two jaws; and around this opening is found a crown of flexible and fleshy appendages, which are termed, indifferently, legs or arms, because they scem to be entitled to either appellation; for they scrve both as organs of prehension and locomotion (fig. 7).

3. The cephalopods are essentially aquatic animals, and consequently they breathe by means of branchir. These organs are always perfectly symmetrical, and are found con-

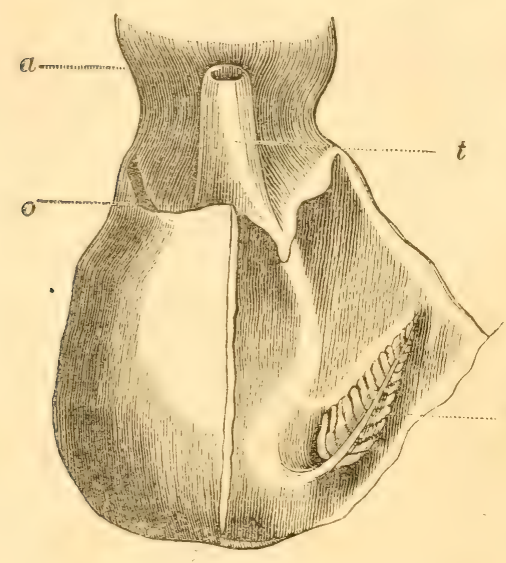

Fig. 8.-BODY OF A POULPE. cealed beneath the mantle, in a particular cavity ( $f \mathrm{~g} .8$ ), the parietes of which alternately contract and dilate, and the interior communicates externally by two openings; one $(o)$ in form of a slit, serving for the entrance of the water, and the other prolonged in the shape of

$b$ a tube or funnel ( $t$, , serving for the escape of water and excre. ment. Each branchia (b), which is in form of an elongated pyramid, the summit of which is directed forward, is composed of a great number of membranous lamellæ or leaves, placed transversely and fixed on each side of a middle stalk. Each one of these leaves is divided into lamellæ, which are in turn again subdivided, and it is in their substance that we find the capillary vessels where

Explanation of Fig. 8.-The body of a poulpe seen from beneath (the mantle is slit up on the middle line, and, on one side, raised up to show the interior of the respiratory cavity):- $a$. the base of the head; $-t$. the tube by which the water escapes from the respiratory carity; - 0 . one of the two lateral openings through which the water enters this cavity; $-b$. one of the branchiæ or gills.

3. How do cephalopods breathe? How many branchiæ have cephalopods? 
the venous is changed into arterial blood. 'The number of branchiæ varies, and this difference is characteristic of the two great natural divisions, of which this class is composed. In some there is but a single pair, while in others two pairs of branchiæ are found. For this reason the first have been called cephalapoda dilbranchiata (from the Greek dis, two, and bragchos, branchia or gills,-two-gilled), and the last, cephalopoda tetrabranchiata (from the Greek, tetras, four, and bragchos, branchia,-four-gilled).

4. The heart is situated between the branchix on the middle line of the body, and consists only of a single ventricle $(f i g .9, c)$ : the blood reaches it from the branchix by the

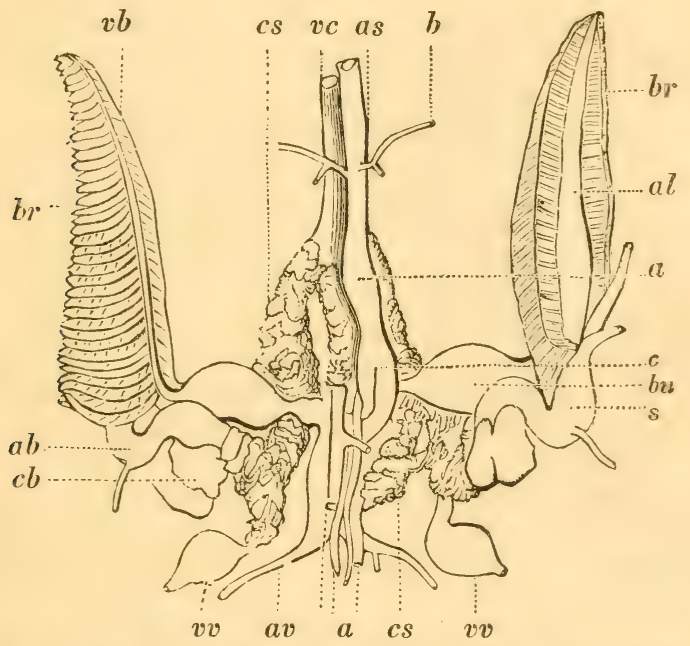

Fig. 9.-Organs of Circulation and REspiration in the CUtTle-Fish.

Explanation of Fig. 9.-The organs of circulation and respiration of the cuttle-fish; -c. the aortic heart, the upper extremity of which is continuous with the superior aorta, which distributes the hlood to the head, \&c.; - b. branches of this vessel; - $-a$. the inferior anta, which has a bulb at its origin, and soon divides into two branches $(v, v) ;-v c$. the vena cava, the parietes of which are covered by the spongy bodies $(c s) ;-a v$. veins of the viscera, going to empty into the two branches of the vena cava; $-c l$. venous sinus or branchial heart; $-s$. swelling at the base of the branchial arteries; $-l i r$. branchiæ; $-a b$. branchial artery; $-v b$. branchial vein; $-b u$. bulb of the branchial veins, situate near the termination of these vessels in the heart.

4. What is the character of the heart in cephalopods? What are the peculiarities of the circulation? 
branchial veins $(v b)$, the openings of which are furnished with valves, and then penetrates the arteries which arise from this organ. The latter vesscls are two or three in number; but one of them is always much larger than the rest, and one of them also has at its base a swelling or bulb, which is more or less muscular, and analogous to that found at the origin of the aorta in batrachians. 'The great artery to which we generally give the name of aorta, is carried forward and distributes its branches to a part of the viscera, the head and legs. The other arteries go to the viscera; and the blood, after having in this way pass $\mathrm{d}$ through all the organs, returns by the veins, and is emptied by them into a great vena cava, situate near the heart. The branchial arteries arise from the inferior extremity of this last vessel, and, in the dibranchial cephalopods, present a very remarkable arrangement; for, before penetrating the branchix, each one of them dilates so as to form a great venous sinus $(f g .9, c b)$, which most authors regard as a branchial heart, but its parietes do not appear to be really muscular.

5 . We see, therefore, that the circulation is here carried on in a mamner opposite to that of fishes; for the heart is found in the track follnwed by the arterial blond, while in fishes the venous blood passes through this organ; but in other respects, there is a great rescmblance in the general disposition of the circulatory apparatus of these two classes of animals; for, in both, the blood passes but once through the heart, and the whole of it traverses the respiratory apparatus before returning to the different organs.

6. On the vena cava and its principal branches, we remark a multitude of rery singular spongy bodies (fig. 9, cs), which, when squerzed, yield a mucosity, and which are attached to the parietes of these vessels; these appendages are enclosed in two membranous pouches, which perform the functions of a pericardium, and, at the same time, communicate by particular openings with the branchial cavity. In this way the water from without laves them, and their interior, which is hollow, communicates by other holes with the interior of the veins, so that the blood must enter them. We know nothing certain in regard to their uses; but it is probable they are the seat of some secretion, and that they serve as a reservoir to contain the superabundant blood of the veins, when the circulation is interrupted in the vessels, much in the same manner as the spleen scems to do in the superior animals.

5. How does the circulation in cephalopods differ from that of fishes?

6. What is remirkable about the vena cava? 
7. The apparatus of digestion is very complicated. The mouth is surrounded by a circular lip, and armed with two ver. tical mandibles, which closely resemble the beak of a parrot; they are set in motion by powerful muscles. A fleshy tongue, furnished with papillæ and many horny pieces, occupies the interior of this cavity, and is attached to a particular cartilage. Salivary glands, the number and arrangement of which vary a little, surround the pharynx and œesophagus, and pour into the alimentary canal the product of their secretion. 'The œesophagus contracts in general, and before terminating in the stomach, presents a large dilatation or crop ( fig. 10, $j$ ); but sometimes, this first digestive pouch is wanting. Commonly the stomach is in the form of an elongated sack ; its parietes are muscular, and its structure reminds us of the gizzard of birds. A third cavity $(s)$ succeeds this or. gan, which, in dibranchial cephalopods, is in the form of a coecum spirally folded, while in the tetrabranchial, it assumes that of a spherical sack internally lamella-

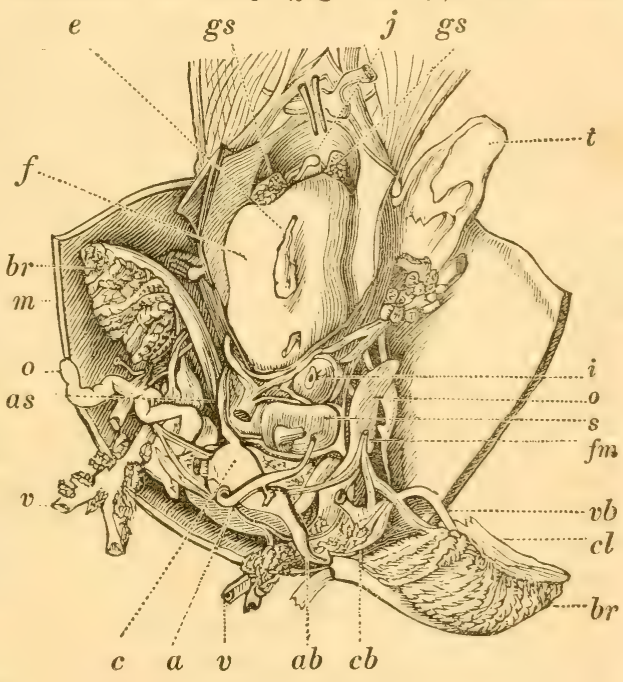

Fig. 10.--viscera of a POUlpe.

Explanation of Fig. 10.-Viscera of a poulpe:-j. the crop situated beneath the cephalic cartilage ;-gs. inferior salivary glands; $-f$. mass formed by the liver and ink-bag; $-e$. excretory duct of the ink-bag going to empty in the funnel; $-t$. this funnel or tube $;-m$. the open mantle ; $-s$. the cœcum spirally folded; $-i$. a part of the intestine, the rest being remored to show the organs situate beneath; -0 . the oviducts ; $-c$. the heart; $-a$. the inferior aorta ; - as. the superior aorta ; - vb. the branchial veins ; - br. the branchiæ; - cl. the partition by which these organs adhere to the parietes of the respiratory cavity; $-a b$. the branchial arteries; $-c b$. venous sinus or branchial hearts $;-v$. venæ cavæ; $-f m$. muscular fasciculi.

7. What organs constitute the apparatus of digestion in cephalopods? What is remarkable about the mouth? What is the character of the stomach? What is the nature of the liver? 
ted: the bile is poured into this cavity by two canals. The liver is very voluminous, sometimes simple, and sometimes divided into two or more lobes: its colour is reldish yellow, and its texture very soft. 'The intestine, which arises very near the cardiac orifice, is simple, and communicates, at a short distance from the pylorus, with a glandular pouch which seems to be ana. logous to the pancreas; and, after making several curves, this tube empties into the branchial cavity, at the base of the funnel through which the water escapes that has served the purposes of respiration.

8. In dibranchial cephalopods, there exists in the neighbourhood of the liver another very remarkable secretory organ, which produces in abundance a blackish liquid, called ink; the excretory duct of this gland ( $f \mathrm{~g} .10, e$ ) empties into the intestine near its extremity, and, when the animal is in danger, pours out, through the funncl or tube, enough of this liquid to darken the water around, and thus conceal itself from the sight of its enemies. The ink of one of these cephalopods-the cuttle-fish-is employed in painting, under the name of sepia; and many authors suppose that the Indian ink of the Chinese is an analogous substance, though it appears the material commonly used in the manufacture of Indian ink is nothing but very finely porvdered charcoal. The tetrabranchial cephalopods do not possess anything similar.

9. It has been already stated that mollusks have no solid, articulated frame within their body, similar to the skeleton of vertebrate animals. In the cephalopods, however, we find traces of something analogous; for there exists in the head a cartilage which not only protects the brain, but enlarges the head in different directions, to furnish points of insertion to the principal muscles of the animal.

10. The disposition of the organs of locomotion and prehension, which are fixed around the mouth, varies in these animals. In the dibranchial cephalopods, there is a crown of eight or ten large fleshy tentacula, the inferior surface of which is furnished with suckers, like cupping-glasses, by aid of which they fix themselves very strongly to bodies that they embrace (see fig. 7, page 19). In the tetrabranchial cephalopods, on the contrary, these appendages, though very numerous, are slender and unprovided with suckers.

11. The organs of the senses are most perfect in the dibran-

8. What is sepia? How is it formed? What is Indian ink?

9. Have cephalopods anything resembling an internal skeleton?

10. What is the disposition of the organs of locomotion? 
chial cephalopods. In these mollusks there are two very large eyes of spheroidal form, lodged in the lateral parts of the head. These organs are composed of a transparent cornea, let into the skin, and sometimes protected by a fold, like an eyelid, a crystalline lens, a vitreous body, a retina, a choroid coat, a sclerotica, \&c., nearly the same as in vertebrate animals. In the tetrabranchial cephalopods the eyes are borne on projecting peduncles, and consist of a cavity only, the black interior of which contains a retina, and receives the luminous rays through a circular opening. No auditory apparatus has yet been discovered in the first of these two families. We find in the cephalic cartilage of the latter, two small cavities, closed on all sides, except at the point through which the nerve penetrates; they lodge a membranous vesicle, and are filled with a peculiar fluid, containing a small stone. This, as we see, is a still more simple arrangement than that of fishes; for the whole apparatus is reduced to a vestibule and a nerve only.

12. The nervous system of the cephalopods is more complicated than that of the other mollusks, and the different ganglia, grouped around the œsophagus, have a greater tendency to become confounded in a single mass. The medullary collar, thus formed, is composed of three pairs of ganglia, namely: the cephalic ganglia ( $f i g .11, c)$, the tentacular ganglia $(t)$, and the thoracic ganglia $(g)$; the two first pairs are placed above the œsophagus, and, by joining the first, form a double collar around this tube; sometimes they are very distinct, but at others, they are almost entirely confounded. The cephalic ganglia give rise laterally to two large nervous cords, which, from their origin, enlarge into ganglia, and then furnish the optic nerves; from this species of brain, nerves also arise, which go to the mouth, and sometimes form around this opening a new collar, furnished with two pairs of small ganglia (fig. 5, page 13). The tentacular ganglia afford origin to the nerves of the feet or tentacula, which, before ramifying on these organs, also present ganglionic swellings. Finally, the thoracic ganglia, sometimes very distinct from the preceding, and at others confounded with thein (see fig. 6, page 17), furnish many nerves, the most important of which are, 1 st, The two nerves of the viscera ( fig. 11, v), which in their course present a pair of ganglia and distribute their branches to the branchia, the heart, stomach, \&c.; $2 d$, The nerves of the mantle, which, in the dibranchial cephalopods,

11. Where are the eyes situated in cephalopods? Are cephalopods capable of hearing?

12. What is the general character of the nervous system of cephalopods? 


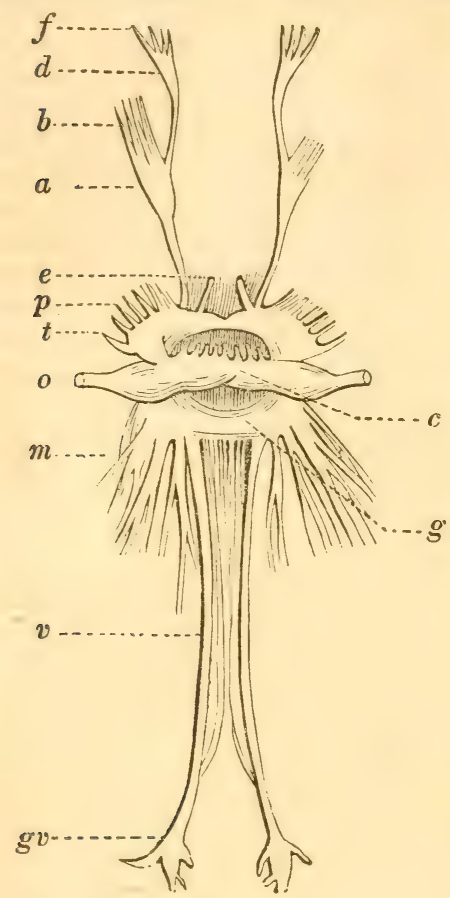

Fig. 11.-NERvous SYSTF.M OF THE NAUTILUS.

also terminate in ganglia, from which arise a great many filaments. In the tetrabranchial cephalopods, the œsophageal collar is simply protected by the cephalic cartilage; but in the dibranchial cephalopods, in which the nervous system acquires its highest degree of develop. ment, this medullary mass is lodged in a special cavity, hollowed in the cartilage through which the œesophagus passes.

13. The cephalopods are never hermaphrodite, as are most others of the mollusca. The ovary is always simple and lodged at the bottom of a sac formed by the body of the animal; sometimes there is but a single oviduct; at others, we find two, which open at the base of the fun. nel; finally, all these ani. mals are oviparous.

14. All these mollusks are marine: they are very voracious, and feed chiefly on crustacea and fishes, which they scize by the aid of their supple and vigorous arms, and easily devour by means of their sharp mandibles. Their flesh is eaten.

15. This class is divided into two families.

Explanation of Fig. 11.-Nervous system of the Nautilus :-c. the brain; - o. the optic nerves; $-g$. the sub-œsophageal or thoracic ganglix; $-t$. the tentacular ganglia; $-p$. nerves of the tentacula; - e. the nerves of the fumnel; - a. a ganglion from which arise other tentacular nerves (li); - d. a second, and similar ganglion, also giving rise to tentacular nerves $(f) ;-m$. nerves of the mantle, \&c.-v. the great visceral nerves, each of which gives rise to a ganglion $(g v)$, from which the principal nerves of the viscera take their origin.

13. Do cophalopods lay eggs?

14. Where are cephalopods found? Upon what do they feed?

15. How is the class of cepkalopods divided? 
16. The family of Cephalopoda, Dibranchiata,-or AceTABULI'FERA, - that is, cupping-glass bearers, is very numerous. In it are placed the poulpes, cuttle-fishes, calmaries, argonauts, \&c. Most of these mollusks have no external shell, and their naked skin includes a great number of contractile vesicles, filled with differently coloured fluids, which, by alternately contracting and expanding, produce and cause again to disappear, in turn, often very brilliant spots; but we find in their interior a more or less developed shell, situated on the back. This shell is largest in the cuttle-fishes; it is oval, and composed for the most part of a great number of transverse calcareous laminæ; it is very common on the sea-shore, and is generally known under the name of cuttle-fish bone. In the calmaries it is of a horny consistence, and in its form resembles a feather or lamella; and in the poulpes it is mercly represented by two horny stylets, lodged in the thickness of the mantle.

1\%. The tentacula of these cephalopods form a simple crown around the mouth, and bear on their internal face circular cups or suckers, the number of which varies from eight to ten. In the following family we shall find an entirely different arrange. ment.

18. The Poulpes-Octopus (Fig. 7, Page 19)-are easily recognised by their naked body, which is in the form of an oval sack, unprovided with fins, and their eight very large and nearly equal feet. They make use of these last organs to seize their prey as well as to swim and crawl upon the ground, and are even formidable to swimmers on account of the force with which they press those bodies they cmbrace. 'These animals are essentially carnivorous. Their size is often very great: there is one species in the Pacific Ocean which attains about six feet in length. These mollusks are objects of terror to the natives of the Polynesian Islands, who dive to the bottom of the sea for shells; but their size and strength are wonderfully exaggerated. Pliny speaks of a poulpe that had arms thirty feet long; and a modern author gravely relates the history of one of these gigantic mollusks, which, attacking a vessel, nearly upset it! The Common Poulpe-Sepia Octopodia-is about two feet long; it inhabits the coasts of Europe, and commonly keeps among rocks: it destroys a great many fishes and crustacea.

16. What are the general characters of the cephalopoda dibranchiata? What is cuttle-fish bone?

17. How are the tentacula of cephalopods arranged?

18. What are the general characters of the poulpes? What is the naturo of their food? Where are they found? 


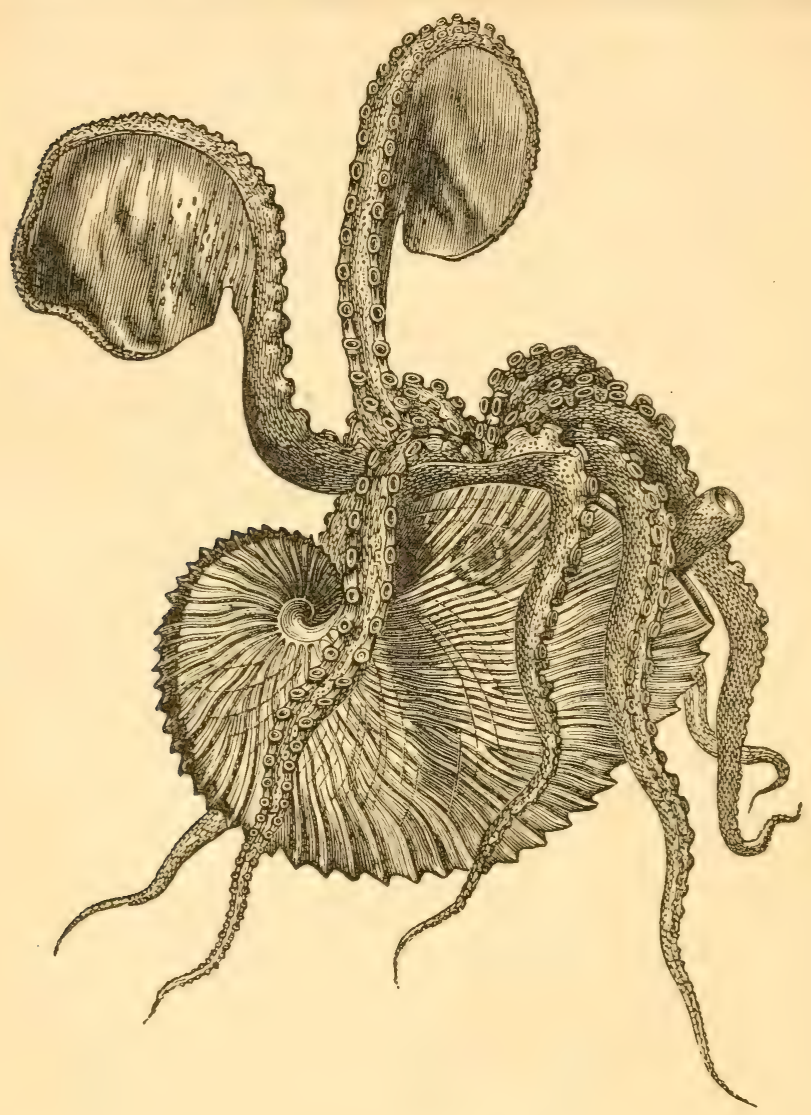

Fig. 12.-ARGONAUT.

19. The Argoxauts-Argonauta (Fig.12)-are cephalopods very closely allied to the poulpe, but the pair of feet which is nearest the back is dilated at the extremity into a broad membrane, and the body is always lodged in a very delicate and extremely beautiful shell, vulgarly called the paper nautilus. It is not certainly known, however, whether this shell really belongs to the animal that inhabits it, or whether it is derived from some other mollusk. Be this as it may, the cephalopod does not ad. here to it, but uses it as a boat to float on the surface of the water 
when the sea is calm. Six of its tentacula are then folded be. neath and act as oars, and it is pretended that the two others, the extremities of which are enlarged and raised up, are spread for sails, as represented in the figure (12); but we should not infer from their structure that these tentacula are adapted to such a purpose. 'The common species is found in the Mediterranean, the Indian Ocean, \&c.; it was known to the ancients under the name of nautilus, and pompilius.

20. 'The Calmaries - Loligo-differ from the preceding in their elongated sack, and being provided with two terminal fins, by the horny lamina, lodged in the back, which supplies the place of shell, and by their tentacula, which are ten in number, and not of the same configuration throughout (fig. 13).

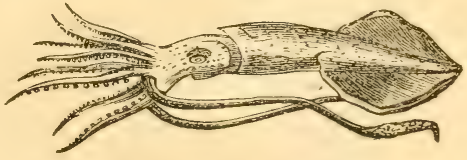

Fig. 13.-THE COMMON CALMARY. Eight of these feet are of moderate size, and are armed with little cups in their whole length, while the two other's are very much elongated and have cups only near their extremities.

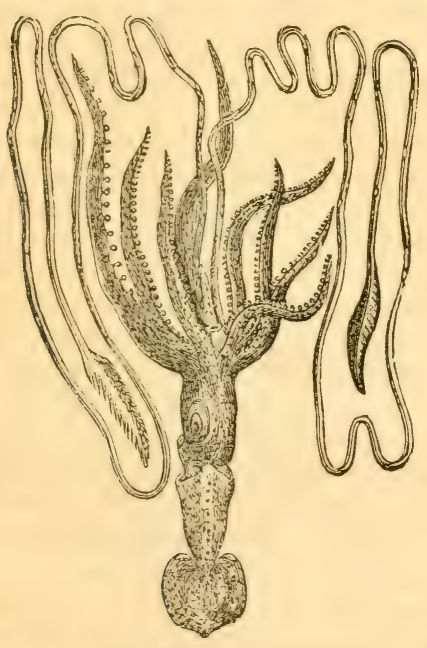

Fig. 14.-The calmaret.

21. The Calmarets-Lo. ligopsis-are remarkable for the great length of two of their arms (fig. 14), which are filiform, and widened at the end only; in other respects they differ but little from the Calmaries : they are found in the Mediterranean.

22. Certain cephalopods, which resemble the Calmaries very much, but have their long arms furnished with hooks, form the genus of Onychoteuthis from the Greek onux, in the genitive onuchos, nail, and teuthis, a calmary, that is, a calmary with nails.

'23. The Cuttue-Eishes - Sepia-have the tentacular

20. How do the Calmaries differ from the Argonauts?

21. What are Calmarets?

22. What is the ony'choteuthis? (pronounced o-ni-ko-tu-this.)

23. What are the general characters of the cuttle-fish? Of what use is cuttle-fish bone? 
appendages arranged like the calmaries; but their body, which is oval and depressed, is furnished with fleshy, lateral fins, occu. pying the whole length of the sack, and the back is sustained by a large internal shell, the structure of which has been already mentioned. The species most commonly found in the seas of Europe-Sepia officinalis-attains a foot in length or more. The cuttle-fish bone or shell, in powder, is used as a dentifrice, and is employed in the arts for several purposes, as for polishing, for forming moulds for silver castings, and as a pounce.

24. The family of Cephalopoda Tetrabranchita has for its type the Nautiuus, a very remarkable mollusk, the body of which is enclosed in the last chamber $(a)$ of a large shell, folded spirally, and divided by transverse

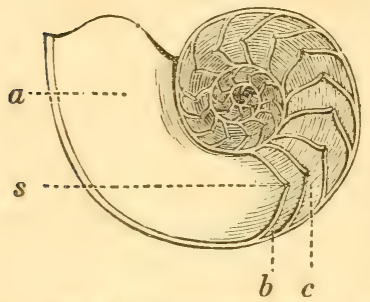

Fig. 15.-SECTION of A NAUTILUS. partitions $(b)$ into several cavities, (fig. 15). Each one of these partitions is pierced by a hole, and the canal thus formed, which is called the syphon $(s)$, extends to the posterior extremity of the shell; it is traversed by a contractile mem. branous tube, posterior to the body of the animal. This structure seems designed to facilitate the ascent or descent of the animal in the water, by increasing or diminishing the specific gravity of the shell; for the syphon communicates with an external reservoir, and can empty or distend itself with the water found in it; now, the chambers which it passes through are filled with air, and when this tube becomes inflated, it must compress this elastic fluid, and increase its density, which, at the same time, augments the specific gravity of the whole shell, and must give it a tendency to sink towards the bottom of the water in which it floats.

25. The conformation of the animal differs very much from that of the poulpes, calmaries, and other dibranchial cephalopods. The head of the nautilus is surrounded by a large fleshy disk, which bears some analogy to the foot of the gasteropods, and

Explanation of Fig. 15.-Vertical section of the nautilus shell :- $a$. the last chamber, in which the animal is lodged; $-b$. one of the partitions which divides the chambers $(c)$ from each other; $-s$. the syphon.

24. What are the peculiarities of the nautilus shell? What seems to be the object of this peculiar structure?

25. How is the animal of the nautilus characterized? 
probably serves the animal in crawling. The tentacula, which are inserted near the mouth, are not furn ished with cups as in the preceding family : they are retractile and in considerable number. eyes are pedunculate, that is, supported on a sort of foot-stalk or stem: there is no organ of hear ing, nor pouch, nor fins, and the branchiæe are four in num. ber.

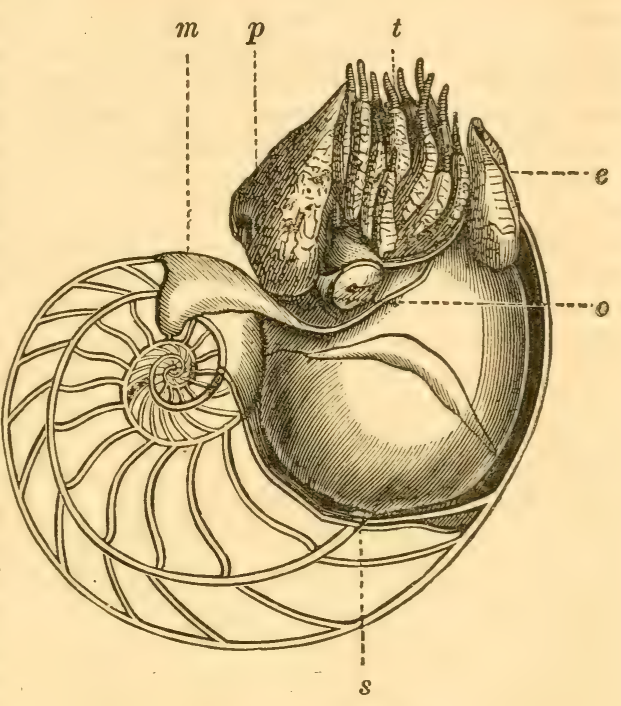

Fig. 16.-Nautilus.

26. A great number of shells are found in the fossil state which are very analogous in structure to the nautilus, and which probably belonged to cephalopods of similar conformation; they are the Amonites (fig. 17), vulgarly called Horns of Ammon,

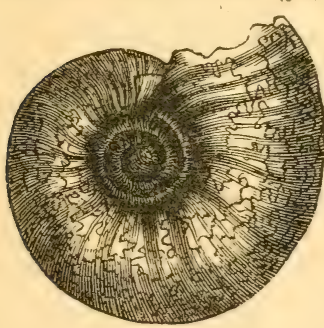

Fig. 17.-АMmonite. in consequence of the resemblance of their volutes or whorls to those of a ram's horn. These animals were among the most ancient inhabitants of the earth and lived in every sea. Their remains abound in the secondary formations (See Geologr), and are met with in all parts of the world; but they have long since disappeared from the surface of the earth, and in those layers which rest upon the chalk, not even a trace of them is found. Consequently, their destruction must have occurred at a period long

Explanation of Fig. 16.-The nautilus shell opened:- $t$. the tentacula ;$e$. the funnel or reservoir ; $-p$. the foot $;-m$. part of the mantle; -0 . the eye ; $-s$, the syphon. 
anterior to the creation of nearly all the mammals; they vary much in form, and still more in size; some are not larger than a bean, and others are more than four feet in diameter. More than three hundred species of them are known, and they are divided into several genera, according to the manner in which the shell is rolled, the position of the syphon, the form of the partitions, \&c.

27. We give the name of Belexinites (from the Greek belemnon, a dart) to other fossils, which also seem to have belonged to the cephalopods, but which, in place of being an external shell, must have been lodged in the interior of the animal, like the bone of the cuttle-fish. They are conical in form, and are chiefly composed of a series of little horns, fitting one in the other like boxes in a nest, traversed by a syphon and terminated anteriorly by a horny plate that forms a sort of chamber, in the interior of which we sometimes find the remains of an ink-bag,-similar to the sack which fulfils the same purposes in the naked cephalopods. The belemnites are not met with in strata as old as the ammonites; but they abound in the middle and upper layers of the secondary formation, and cease to exist in the upper layers of the chalk.

Until lately, a host of microscopic shells of lenticular form and without apparent opening, designated by authors under the names of Numultes (from the Latin numma, a piece of money), CAMERINES (from the Latin camera, chamber), ForAMINIFERA (from the Latin foramen, a hole, and fero, I bear), \&c., were referred to the order of cephalopods; these little bodies abound to such an extent in certain soils, that they of themselves exclusively constitute chains of hills and immense banks of building stone ; but they are also found in European seas, and, on observ. ing them when alive, we are convinced that the animals to which they belong do not resemble either the cephalopods or even the mollusks, in anything : they are beings of a very peculiar structure, and seem more to approximate the polypi.

27. What are belemnites? What are their characters? Where are they found? 


\section{LESSON III.}

Class of Gasteropoda.-General Conformation-Classification.

Order of Gasteropoda Pulmonea.-Organization-Division into two families.

Family of Terrestrial Pulmonea.-Limax-VaginulusHelix-Bulimus-Pupa-Chondrus-Clausilia-Achatina. Fanily of Aquatic Pulmonea.-Onchidium-PlanorbisLimnaus-Physa-Auricula.

Order of Gasteropoda Pectinibranchiata.-Organization -Classification.

Fanily of Trochomdes. - Trochus-Turbo-Delphinula- Turritella-Cyclostoma-Valvata-Paludina-Littorina -Monodon-Phasianella-Ampullaria-Janthina-Nerita.

\section{CTASS OF GASTEROPODA.}

1. Mollusks that are provided with a head, and crawl upon the belly, or swim by means of a fin formed of this part of the body, constitute a very numerous class, the type of which is the slug and snail. The body is elongated, and terminated anteriorly by a more or less developed head, which ordinarily has tentacula inserted above the mouth; the back is furnished with a mantle, which extends more or less, and the belly is covered by a fleshy mass, generally in form of a broad disk (fig. 18), and serves the animal for crawling on the ground, but which is sometimes very much compressed, and then constitutes a vertical fin (fig. 78). Many of these animals are entirely naked; others have an internal shell concealed in the thickness of the mantle; but most of them have an external shell, and this

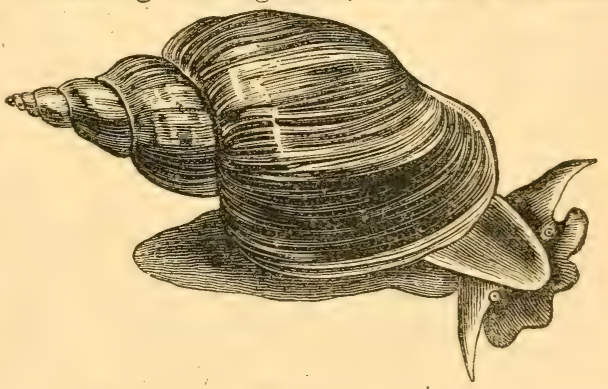

Fig. 18.-LIMNE-FRESH-IVATER SNAIL. calcareous envelope is almost always sufficiently large to contain them entirely, and afford them protection.

1. What is the general character of the class of ga'steropods? Have they. any shell? 
2. The arrangement of these shells varies much; sometimes they are composed of many pieces, at others, of a single piece, sometimes they are symmetrical, at others not symmetrical, and in this last case, in proportion as they are elongated, they are rolled or twisted upon themselves, and constitute a spirally

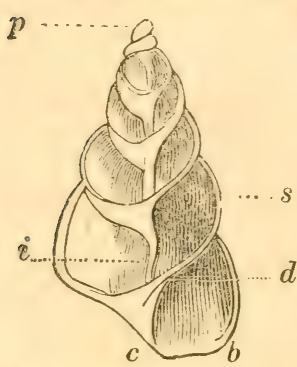

Fig. 19.-SECTION of twisted cone. This last form, which is seen in the shell of the snail, is the most common in gasteropods, and presents numerous varieties. Sometimes the part which grows less rapidly and upon which the cone rolls itself, is full (fig. 19), and sometimes empty; it is called columella or pillar $(c)$, and, when empty, we give $d$ the name of umbilicus to this opening (fig. 20,u). If the turns of the shell remain in the same plane, the spire is flat or concave, and the general form of the shell is discoid, resembling a disk, as in the planorbis (fig. 29); sometimes the height of each turn completely envelopes thepreceding involutions, so that the spire is concealed; but in most cases the turns are inclined towards the edge of the columella, and there results an oblique spire, which is more acute in proportion as the cone is less rapidly widened ( $f i g .19$ ). Those shells are called turbinated, in which the first turns are raised up above the succeeding ones ( $f$ ig. 19), forming a projecting spire, and it is remarked that the turns or whorls are almost always directed from the right side. Sometimes however the spire of these turbinated shells is turned from the left side of the animal (fig. 25), and in this case they are said to be perverse.

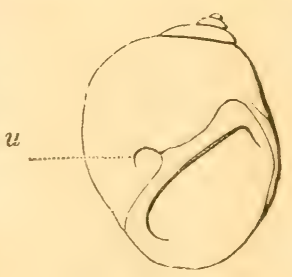

Fig. 20. N.1Tics.

Explanation of Fig. 19.- Section of a turbinated shell to show how it is spirally wound upon itself : $-b$. the mouth or aperture of the shell $;-c$. the columella; $-d$. the part of the columella included in the last turn of the spire; -s. turn of the spire next to the last; $-p$. the apex or summit of the shell; i. part of the columella.

2. Do the shells of ga'steropods consist of a single piece? What is meant by the colume'lla? What is the umbili'cus? What is meant by a turbinated shell? What is meant by a perverse shell? 
3. The mass of the viscera occupies the upper part of the cone formed by these shells, and always remains enclosed in it but the head and foot project externally when the animal extends itself to walk, and return again into the last turn of the spire, when it contracts : and the size of this latter part of the shell and the form of its opening are always in relative proportion ta the foot. In most of the aquatic gasteropod mollusks, with a spiral shell, there is a horny or calcareous disk or door, a called operculum (fig. 32, o), which is fixed to the posterior part of the foot, and which closes the entrance of the shell, when the animal retires into it.-

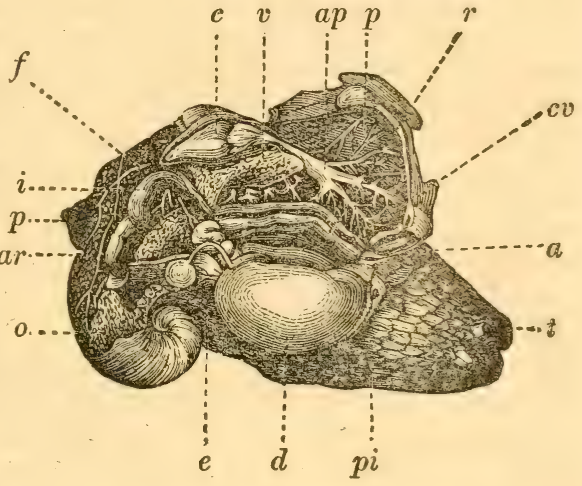

Fig. 21.-ANatoiry of a snaIL. The operculum of certain small shells constitutes what is vulgarly termed an eye-stone.

4. The organs of respiration are formed sometimes for breathing the air, and sometimes for aquatic respiration; but in mollusks with a spiral shell, they are always lodged in the last turn of the spire, and receive the ambient element beneath its edge, either by a hole pierced through the mantle, or between the body and the free edge of this cutaneous fold, which is also often prolonged into a canal, by means of which the auimal can obtain the fluid (whether air or water) necessary for its respiration, without

Explanation of Fig. 21.-Anatomy of a snail;-pi. the foot;-t the tentacles partly contracted;- $d$. a sort of diaphragm which separates the respiratory cavity from the other viscera; $-e$. a portion of the stomach; $-f$. the liver;-o. the ovary; $-i$. the intestines;-r. the rectum;-a. the anus;-c. the heart (the pericardium-the sack containing the heart-being open;ap. the pulmonary artery ramifying on the parietes of the pulmonary cavity $(p) ;-v$. the gland which secretes the viscosity;-cv. its excretory canal, going to open near the anus.

3. In what part of spiral shells are the viscera of the animal contained ? What part of the shell contains the head and foot? What is the operculuin? What are eye-stones?

4. In what part of the spiral shells are the organs of respiration placed? By what means is the air or water admitted to these organs? Where is the respiratory tube situated? 
putting its head or foot out of its shell. In this latter case, the shell has on its edge a notch or canal, destined to lodge the respiratory tube; this notch is near the termination of the columella, and on the side opposite to that towards which the spire is directed. Consequently this canal is to the left, in the common species, and to the right, in perverse shells.

5. The heart $(f i g .21, c)$ is always aortic: it is generally composed of an auricle and a ventricle, and its position, as is the case with the respiratory tube, is in relation to the direction of the spire of the shell. This organ is situate on the same side with the tube, that is, on the side opposite to that towards which the shell turns, and the procreative organs (the form of which varies much) are always placed on this latter side, and consequently on the side opposite to the heart.

6. The mouth is surrounded by contractile lips, and sometimes armed with horny teeth which occupy the palate. In many other animals of this class, the anterior part of the œsophagus is very fleshy, and possesses the faculty of projecting itself externally, in such a manner as to constitute a trunk. Sometimes the stomach is also furnished with cartilaginous or bony pieces, proper for dividing food; the intestine is folded on itself and lodged between the lobes of the liver and ovary; and the anus $(f i g .21, a)$ is almost always situate on the right side of the body.

7. In this class, the organs of the senses are less developed than in the cephalopods; the tentacles, which most gasteropods bear on their front, varying in number from two to six, serve chiefly for tact and perhaps for smell. No organ of hearing has been found, and their eyes, which are sometimes wanting, are very small, and of a very simple structure: they resemble those of the nautilus, and are sometimes adherent to the head, and sometimes borne at the base on the side, or at the end of the tentacula.

8. The class of gasteropods is divided into eight orders, the principal characteristics of which are derived from the disposition of the branchial (brank-e-al) apparatus, as may be seen in the following table :

5. What is the character of the heart in ga'steropods?

6. What are the peculiarities of the digestive organs?

7. Where are the tenta'cula placed? What is the number of tentacles in ga'steropods? Where are their eyes situated?

8. Into how many orders is the class of ga'steropods divided? Upon what are these divisions founded? 


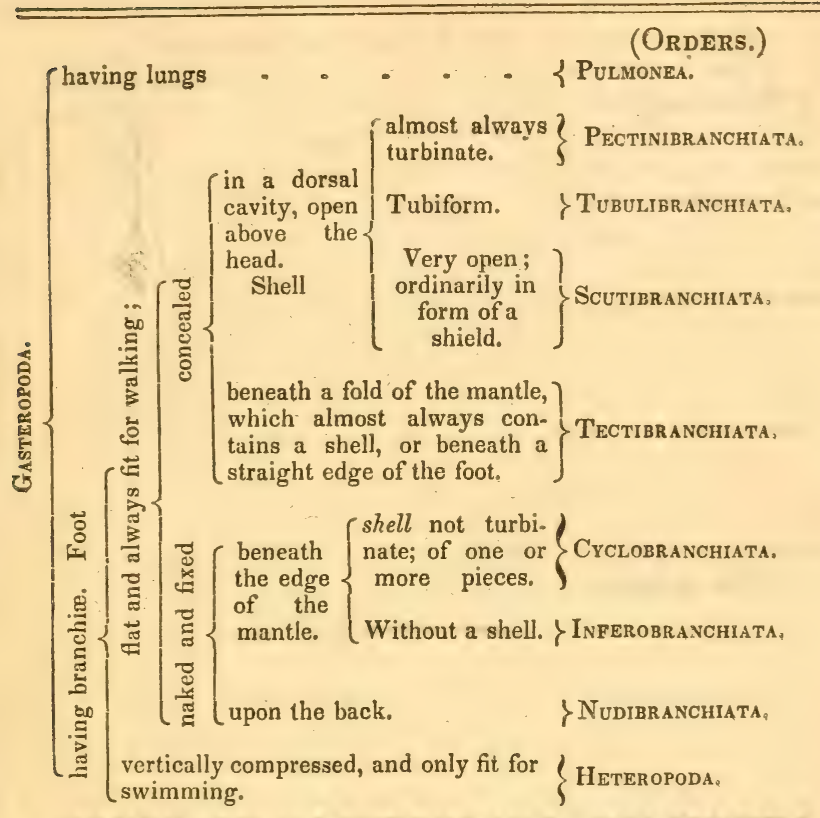

\section{ORDER OF GASTEROPODA PUIMONEA.}

9. Gasteropods formed for aerial respiration have no branchiæ, but have a cavity on the back, upon the parietes of which the pulmonary vessels form a complicated net-work (See fig. 21, page 35), and the lung receives the external air through a hole in the edge of the mantle above the right side of the nape, which is susceptible of being opened or shut at the will of the animal. All the pulmonic gasteropods are not however terrestrial mollusks. Many of them live in the water; but then they are obliged to come to the surface from time to time, to obtain air necessary for their respiration. All these animals feed on vegetable substances.

10. The order of pulmonic gasteropods is divided into two families; the terrestrial pulmonea, and the aquatic pulmonea.

11. The Family of Pulmonea Terrestria are generally recognised with ease by their four tentacles. These append. ages are retractile, and those forming the upper pair, which

9. What are the general characters of the breathing apparatus of the order of Ga'steropoda Pulmonea? Upon what do they feed?

10. How is the order of pulmonic ga'steropods divided?

11. What are the characters of the family of terrestrial pulmonea? 
are longest, have the eyes at their extremities. The mouth is armed with one palatine tooth, and a small tongue studded with microscopic teeth; and the body varies in form; some are naked or only provided with an internal shell, while others have an external shell spirally twisted, with a blunt summit, and the mouth without a notch. The small tribe formed by the first is divided into Limax, Vaginula, \&c. The tribe of terrestrial pulmonea with an external shell comprises the genera of helix, vitrina, bulimus, pupa, chondrus, succinea, clausilia, and achatina.

12. The Lruaces (slugs) form the type of the terrestrial pulmonea without apparent shell. The body, as every one knows, is elongated, and their mantle is a fleshy disk, scarcely separated from the rest of the skin $(f i g, 22, m$,$) and which only$ occupies the fore part of the back, where it covers the pulmonary cavity; it often encloses in its thickness a small, flat shell. On the right side of this species of shield, there is a notch, at the bottom of which we observe a contractile opening ( $f g .22$, ro), that leads into the pulmonary cavity; the anus is situate upon the anterior border of this respiratory orifice, and a third opening belonging to the procreative apparatus is situate on the external side of the base of the right superior tentacle. The four tentacula are cylindrical, more or less swelled at the end, and hollow; they are drawn in and pushed out, on unrolling themselves, like the inverted fingers of a glove, by the aid of muscular fibres lodged in their interior; the eyes, which are borne on the ends of the superior tentacles ( fig. 22, st), are black; the mouth is armed with a sort of palatine tooth in the form of a crescent, and a smooth tongue. The heart is lodgred in a particular cavity beneath the mantle, and is composed of an oval auricle, which receives a large pulmonary vein, and a pearshaped ventricle, from which the aorta arises. And there exists near the heart a secretory apparatus which pours out a viscid matter upon the external surface, through an excretory canal, opening near the respiratory orifice.

13. These animals are herbivorous: they feed principally upon young plants, fruits, mushrooms, and are most voracious towards evening. During the heat of the day they remain concealed in holes under stones, or some heap of half-decayed leaves, or even in the earth, and they seldom go out except in the morning and evening, when the air is bumid; they are especially abundant after rain. During the cold season they bury themselves in the ground and remain torpid.

12. What are the general characters of the Lima'ces?

13. Upon what do the Lima'ces feed? Where are they found? What Decomes of them in the cold season? 
14. Some, called Arions, have the pulmonary orifice situate near the anterior part of the dorsal shield, such as the Limax rufus, which is everywhere met with in wet weather; [a decoction of this species is sometimes used in France for pulmo. nary disorders :] the others, named Limax properly so called, or

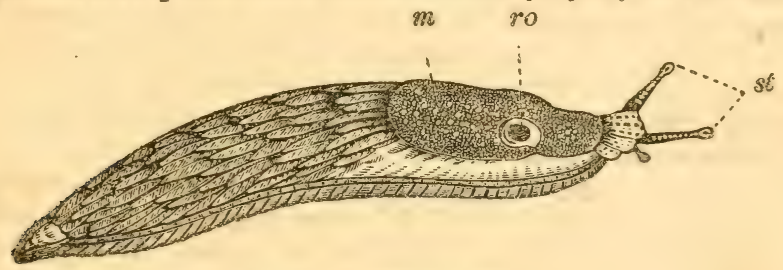

Fig. 22.- LIMAX RUFUS.

Lima, have this orifice situate more posteriorly, and frequentiy have a pretty well formed internal shell; the Limax cinereus, which inhabits caves and shady forests, belongs to this division, as well as the Limax agrestis, which abounds in some countries, and is very injurious to agriculture.

We give the names of Vaginula, Testacelia, and ParmaCELLA to other naked gasteropods, nearly resembling the limaces, but which differ from them in the position of the anus, the extent of the mantle, \&c.

15. The SNarls-Helix-form the most important tribe of terrestrial pulmonea with a complete and apparent shell.Their organization differs very little from that of the limaces; the mantle, instead of being in the form of a convex shield, constitutes a large cone twisted on itself, containing the viscera, which is covered by the shell (fig. 21, p. 35). We distinguish them by their shell, the opening of which is ordinarily raised like a pad or collar, forming a thickened lip in the adult; the shell is a little twisted by the projection of the penultimate whorl of the spire, and in this way takes somewhat of a crescent shape. In snails properly so called, this opening is at least as broad as high, and the shell is sometimes globular and sometimes depressed. The habits of these mollusks are nearly the sime as those of the limaces. In summer they are very voracious, but in the autumn they eat very little, and, on the approach of

Explanation of Fig. 2\%. - Limax rufus :-st. the eyes on the extremity of the superior tentacles; - $m$. the mantile; -ro. the notch over the pulmonary cavity.

14. What are Arions?

15. What are the general characters of snails? What are their hahits? Do their wounds heal? In what respect does the genus IHelix differ from the genus Limax? 
winter, they retire into some hole, draw themselves into their shell, shutting up the mouth with a calcareous matter, secreted by the edge of the mantle, and remain torpid until spring.Very curious, and frequently repeated experiments, have proved that not only do wounds inflicted on these animals readily heal, but that considerable portions of the body, after being removed, can be renewed. 'The eyes, the tentacles, and even the head of snails have been known to be entirely renewed in this way. A very great number of species of snails are known; they are found in all parts of the world.

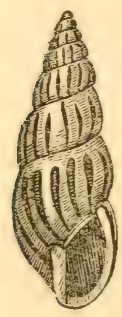

Fig. 23. BULIMUS.

16. We give the name of Vitriva to snails the shell of which is very thin, flattened and un. provided with a thickened lip, and too small to enclose the body entirety; some small species are found in Europe. The Bucrues-Bulimus ( $f$ ig. 23)-have an elongated shell, the opening higher than wide, furnished with a thickened lip, and without notches. A small species which is found in France, is remarkable for the singular habit of successively breaking the whorls of the apex of the shell. There is a large species in Brazil which is eaten as a delicacy. Other mollusks of the same tribe, the genus Pupa, have an ellipsoid, or even almost cylindrical shell, with the opening higher than wide, furnished with a thickened, notched, and generally dentate lip ( $f g .24)$ : they are of small size, and live in humid places, among moss, \&c.

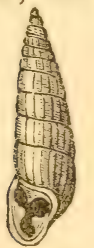

Fig. 25.

Crausilia L. AEVIS.

Shells of the genus Chondrus also have a notched and dentate lip; but their form is more ovoid.

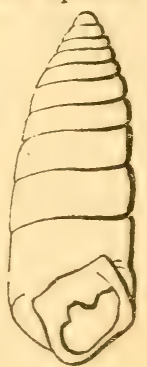

Fig. 24.

PUPA.

17. The genus of Clausilia is composed of small mollusks which live in moss, at the roots of trees, and have a shell similar to that of the Pupa, but much more slender and pointed ( fig. 25).

18. The AnвRETtes-Succinea-differ from all the preceding in the absence of a thickened lip around the opening of the shell, which is oval, and too small

16. What is the Vitrina? What are the characters of the genus Buli. mus? How is the genus Pupa distinguished?

17. Of what is the genus Clausi'lia composed?

18. What are the distinguishing marks of the Ambrettes? Where are they found? 


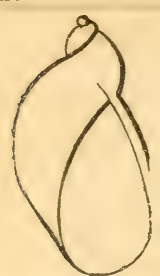

Fig. 26.

AMBRETTE. feed on shrubs; they have an oblong shell with the opening wider than it is high, without a thickened lip, and truncate at the extremity of the columella, a disposition somewhat analogous to that of the shell of most marine gasteropods.

20. The family of Pulmonea Aquatica have but two tentacles (fig. 18, page 33); their mode of respiration obliges them to come frequently to the surface of the water to breathe: they cannot keep at great depths, and they ordinarily live in fresh waters, or near coasts.

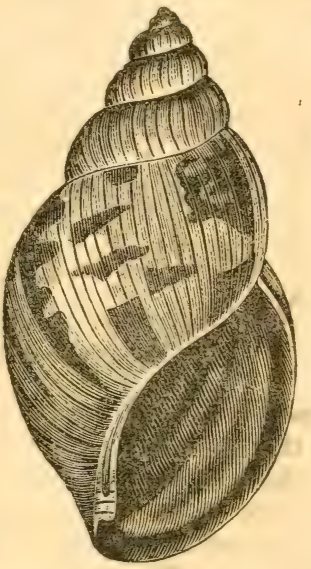

Fig. 27.-AChatina.

21. As in the preceding family, we find here mollusks without a shell, and others that are provided with one : the first form the genus of Onchidium ( $f$ g. 28), which have a very straight and very extensible elongated body; they inhabit the fresh waters of

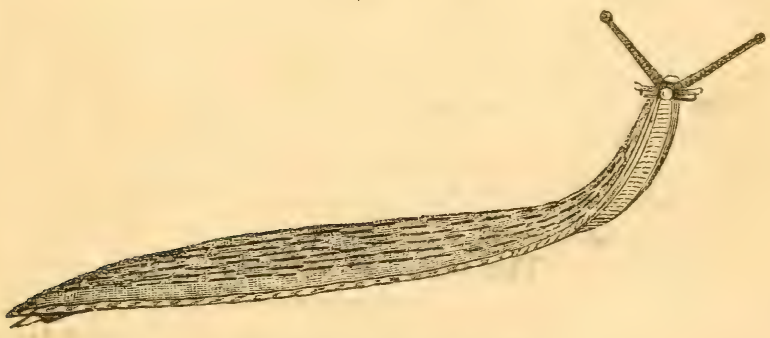

Fig. 28.-ONCHIDIUM L.æVE.

19. What shells form the genus of Achatina? (pronnunced $a$-ka-te-na).

20. What are the characters of the family of Pulmonea Aquatica.

21. What are the characters of the genus Onchidium? 
the warm parts of both continents : the second are subdivided into the genera of Planorbis, Limnea, Auricula, de.

22. The mollusks of the genus Planorers have a thin shell rolled upon the same plane, which is consequently discoid, and the whorls very gradually increase in size $(f g .29)$. Their

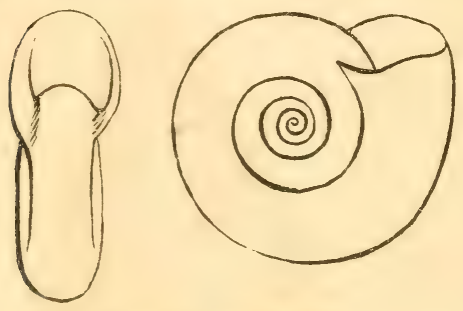

Fig. 29.-PLANORBIS. tentacles are long and filiform; and the eyes are placed at the internal side of their base. These gasteropods feed on vegetable substances, and in. habit stagnant waters; in winter they bury them. selves in the mud, and lie torpid.

23. The Limnea ( $f g$. 18 , page 33) have the same habits, and are almost always found in the same localities as the planorbis, from which they are readily distinguished by the form of their shell, the spire of which is oblong ; their tentacles are thick and triangular. In the laying season, they are often found in great numbers joined together, so as to form a sort of chaplet. They swim on the back with the ventral disk extended on the surface of the water, and in winter they become torpid like the planorbis.

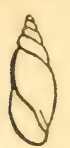

\section{We give the name of Physa} to small mollusks found in fountains, the shell of which $(f g .30)$ is similar to that of the limnæa, but very thin, without a thick lip, and

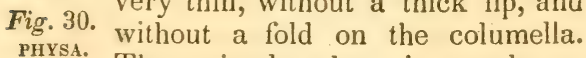
The animal, when it crawls or swims, covers its shell with the two lobes of its mantle. In other respects it closely resembles the limnæa.

25. 'The Auricule differ from the preceding by having large oblique grooves upon the columella of their shell, which is oval or oblong ( fig. 31). The name is derived

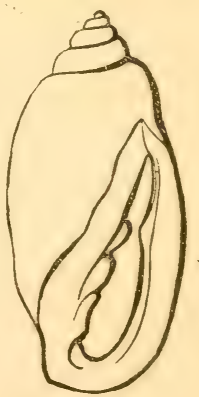

Fig. 31.

AURICULA.

22. What are the characters of the genus Planorbis? Upon what do animals of this genus feed? Where are they found?

23. How is the genus Limnæ'a distinguished from the genus Planorbis ? What are the habits of this genus?

24. What are the characters of the genus Physa?

25. How is the genus Auri'cula characterized? (Auri'cula is formed from the Latin, auris, ear, and means a little ear.) 
from the shape of the opening, resembling a human ear. Many of these gasteropods are of considerable size. One species is found on the shores of the Mediterranean.

\section{ORDIR OF PECTINIBRANGHEATA.*}

26. This division of the class of Gasteropods is the most numerous in genera and species: it comprises nearly all the mollusca, in which the shell is univalve and spirally twisted,

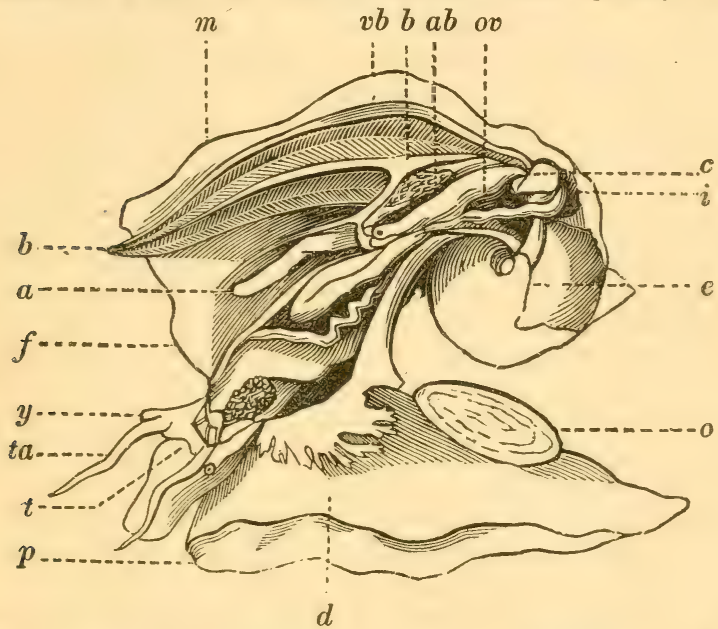

Fig. 32.-Anatomy of a pectinibrancil gasteropod. Turbo Pica (See fig. 44).

Explanation of Fig. 32.-Anatomy of a pectinibranch gasteropod (the Turbo pica), to show the arrangement of the respiratory cavity :- $p$. the foot of the animal ; - 0 . the operculum;-t. the trunk;-ta. the tentacles;-y. the eyes $;-m$. the mantle, split open longitudinally so as to expose the respiratory cavity :- $f$. the anterior edge of the mantle, which in its natural po. sition covers the back of the animal, and leaves there an opening or great slit, through which the water reaches the branchiæ; $-b$. the branchiæ :- $v b$. the branchial vein which goes to the heart $(c) ;-a b$. the branchial artery ; $a$. the anus; $-i$. the intestine;-e. the stomach and liver;-ov. the oviduct. Above the nucha or nape, we see the cephalic (nervous) ganglion, and the salivary glands; $-d$. fringed membrane, which below borders the left side of the opening of the respiratory cavity.

* Pec'tinibranchia'ta.-From the Latin, pecten, a comb, and branchia, gills; because the branchiæ or gills $(f g .32, b)$ resemble a comb in form.

26. What are the peculiarities of the pectinibranch ga'steropods? In what parts of the shell do we find the respiratory cavity? 
and many of those in which the shell is simply conical. The most remarkable feature of almost all these animals is the arrangement of the branchial apparatus; but this character is not constant; for in two genera (cyclostoma and helicina), which, in other respects, are too nearly allied to the ordinary pectinibranchiata to be separated from them, there are no branchiæ, and their respiration, which is aerial as in pulmonea, is carried on by means of a vascular net-work that lines the bottom of the respiratory cavity. This cavity occupies the last whorl of the shell and opens externally by a great slit, situate betwixt the body and the edge of the mantle; in most instances it lodges branchiæ ( fig. 32, b), which are composed of small leaves or fringes arranged parallel and attached to its superior parietes upon one, two, or three lines, according to the genus. All these mollusks have two tentacles $(t a)$ and two eves, sometimes borne on particular peduncles; the mouth is in the form of a tube or trunk $(t)$, and encloses a tongue armed with small hooks; the males have, on the right side of the neck, an appendage, sometimes very thick, which cannot, in general, be drawn into the body of the animal, but is folded into the branchial cavity ; the rectum and the oviduct (ov) are also found on the right side of this cavity, and near them we remark a particular organ, enclosing a very viscid humour, designed to form a common envelope around the eggss.

27. This order is divided into three families. In the two first (that of the Trochoides and of the Capuloides), there is no syphon by the aid of which the animal can breathe without leaving its shell (fig. 33), while in the third family (that of the Buccinoides) there is a respiratory tube, formed by a prolongation of the edige of the pulmonary cavity of the left side, which passes throurh a corresponding canal or notch in the shell (fig. 34).

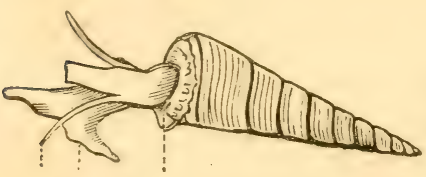

Fig. 33.-TURRITELLA.

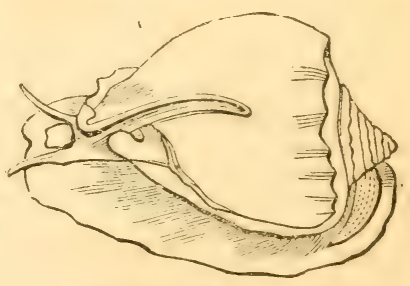

Fig. 34.-Cassis.

27. How is the order of pectinibranch ga'steropods divided? How does the family of Buccinoides differ from the other two families, the Trochoides and Capuloides? 
28. The family of Trochordes are distinguished from other pectinibranch gasteropods without a syphon, by the form of their shell, which is spiral, with an entire aperture, and by the existence of an operculum, or some organ in the place of it. 'This family is divided into three tribes, which are distinguished by the form of the opening of the shell; namely, Troclus, in which this opening, angular at its external edge, is nearly quadrangular, and, as regards the axis of the shell, lies in an oblique plane (Figs. 35 and 36); the tribe Turbo, in which the mouth of the shell is perfectly round (Figs. 43, 45 and 46), and the tribe of Hemicyclostoma, in which this opening is more or less in the form of a crescent, as in the Helices (Figs. 26 and 27).

29. The Trochus-so called from the general form of the shell, that of a top; its spire is more or less raised, and terminates in a point, and the circumference is trenchant or carinate: animals of this tribe are mollusks with a short foot, the mantle ordinarily furnished on the edge with two or three pairs of filiform appendages, the two eyes being placed on a swelling at the base of the tentacles, the mouth armed with a sort of spirally rolled tongue, and the anus opens on the right side of the respiratory cavity, which encloses two unequal branchiæ. The operculum is horny, and marked by numerous spiral turns. The tribe of Trochus is aivided into several little groups, according to the absence or presence of an umbilicus, and some other not very im. portant characters. Figure 35 gives a view of the base of the Trochus niloticus, showing the umbilicus or hole in the base of

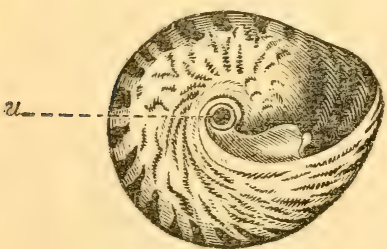

Fig. 35 .
TROCHUS NILOTICUS.

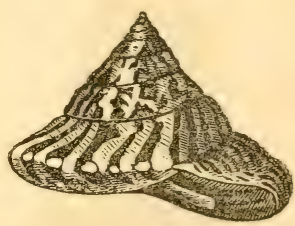

Fig. 36.

the columella $(u)$, while Figure 36 is another view of the same shell. The Solarium is a trochus in which the shell is conical in

28. What are the peculiarities of the family of Trochoides? (pronounced tro-koi-des.) Into how many tribes is this family divided?

29. What are the characters of the tribe of Trochus? (pronounced tro-kus.) 
form ( $f g .37)$, with a quadrangular aperture, and an extremely flaring umbilicus $(f g .38, u)$; the anterior edges of all the invo-

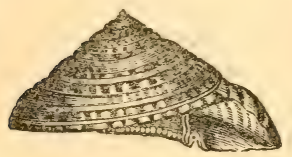

Fig. 37 .

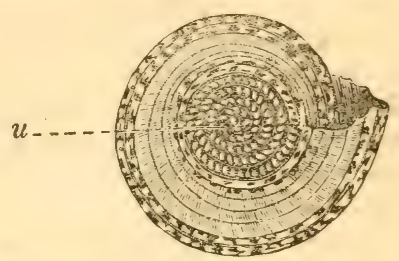

Fig. 38.

lutions or whorls of the spire are marked by a crenulated cord, that is, notched on the edge ( fig. 38).

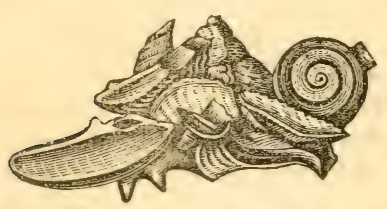

Fig. 39.-Trochus agglutinans.

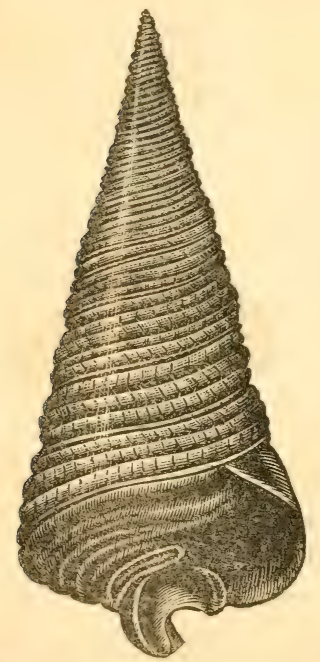

30. Among the Troch I properly so called, with an umbilicated shell, we will mention the Trochus agglutinans, which is found in the West Indies and Pacific. It has the singular faculty of glueing to itself movable bodies found on the ground on which it rests ; sometimes it glues stones and sometimes shells or pieces of shells, according to the place where it is found. From this habit of building out its habitation from materials not its own, it is sometimes called the $\mathbf{M a}$ son (Fig. 39).

There are some without an umbilicus, very conical, and very tall, that are marked by numerous whorls in the spire, with crossing striæ; the extremity of the columella is much twisted, and projects beyond the origin of the lip. A specimen of this variety is seen in the annexed figure of the telescope trochus (Fig. 40).

Fig. 40.-Trochus telescopium.

30. What are the peculiarities of the Trochus Agglutinans? 
Another variety is remarkable for a deep excavation at the base of the columella, resembling an umbilicus, and a projection of the circumference, as is seen in the figure of the con. cave trochus (fig. 41), which inhabits the Indian Seas, and is considered rare.

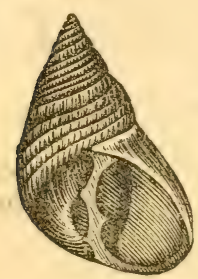

Fig. 42.

There are other species, without an umbilicus, conical with a very oblique

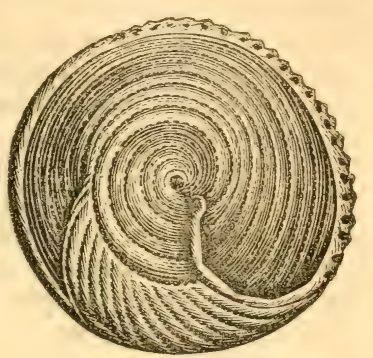

Fig. 41,-Trochus CONCAVUS. base; the aperture large, slightly angular: the columella twisted, and forming a kind of tooth at its termination. Such is the rainbow trochus ( $f \mathrm{~g} .42)$, the nacre of which is a beautiful golden green, with very brilliant reflections of red.

Trochus IRIS. 31. The tribe of Turbo comprises all the pectinibranch gasteropods which have a completely and regularly turbinated shell, terminated by an entirely round aper. ture. In it we range the turbo properly so called, delphinula, turritella, scalaria, cyclostoma, valvata, \&c. (fig. 43).

32. The Turbos properly so callerl are recognised by their round or oval thick shell, in which the aperture is completed within by the whorl of the spire next to the last. These mollusks have two long ten-

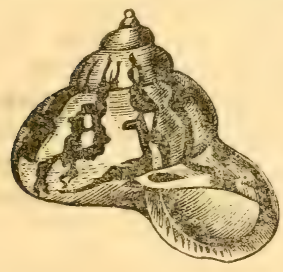

Fig. 44. 一 TURBO PICA. tacles, which, at their base, externally,

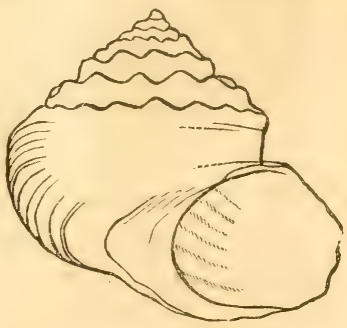

Fig. 43.-TURBo. support the pedunculated eyes; on the sides of the foot we remark membranous wings, sometimes simple, sometimes fringed or furnished with one or two filaments; and their operculum is sometimes horny, at others calcareous, or extremely thick.Among the varieties of this genus is the Turbo Pica (fig. 44), which inhabits the

31. What are the characters of the tribe of Turbo? (Turbo is a Latin word, meaning a whirling or twisting.)

32 What are the characters of the Turbo properly so called? 
equatorial regions of the Atlantic Ocean. It is a common, heavy shell; it has a horny operculum, and is remarkable for a tooth situate at the orifice of the umbilicus.

33. The Deephinula has a thick shell like the last, but rolled almost in the same plane, and the aperture is entirely formed by the last whorl of the spire ( $f \mathrm{~g} .45)$ : the most comrnon species is remarkable for its twisted and branching spines.

34. The Turritella and Scalaria have a very elongated spire : in the first (fig. 33, page 44), the mouth or aperture of the shell is formed as in the Turbo, properly socalled, and in the last,

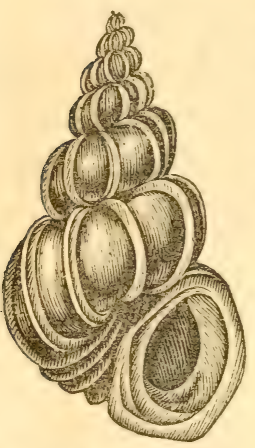

Fig. 46. - scalaria. it is similar to that

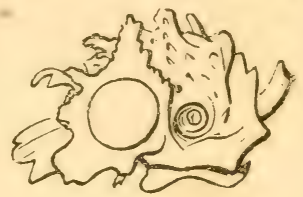

Fig. 45.-Delphinula.

of the Delphinula. The Wentletrap or Precious Scalaria ( $f i g .46)$ has the volutions connected by longitudinal ribs.

35. The Cyclostone, which are distinguished by the absence of branchiæ, and by their aerial respiration, also have a shell with a round mouth, closed by a thin circular operculum ( $f i g .47$, o) ; it is in form of an oval spire, and finely striated transversely.These animals live in woods, under moss and stones.

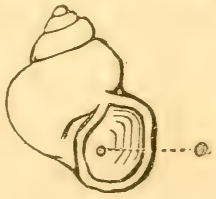

Fig. 47. eYCLOSTOMA.

36. Finally, the fresh-water mollusks, named Valvata,-in which the shell somewhat resembles that of the Planorbis, but has a circular aperture, furnished with an

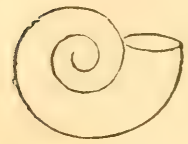

Fig. 48.

VALVATA. operculum,-also take their place here. One species, which inhabits stagnant waters in France, has been called the feather bearer, from the manner in which the branchia, which is in form of a feather, is protruded and floats on the surface of the water when the animal wishes to breathe.

33. What are the characters of the Delphinu'la?

34. What are the characters of the Turrite'lla and Scala'ria?

35. What are the characters of the Cyclo'stomæ? (Cyclostoma : from the Greek, kuklos, round, and stoma, mouth,-round-mouth.)

36. What animals belong to the genus Valva'ta? (Valvata, Latin, formed from valva, folding doors). 
37. The tribe of Hemícyclo'stoma is composed of pectinibranch gasteropods, which resemble snails in the form of their shell, of which the whorl next to the last presents a sunken arch, which gives its aperture more or less resemblance to a crescent. They form many genera, among which we will mention the Paludina, Littorina, Monodonta, Janthina, and Nerita.

38. The Paludine were, for a long time, confounded with the cyclostomæ, but the aperture of their shell is without the rolled lip, and they are provided with branchiæ for breathing in

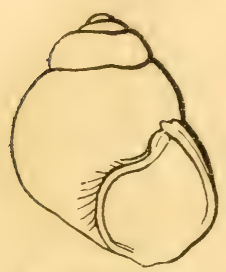

Fig. 49.-PALudina.

water ; they show the first vestiges of the syphon which always exists in the following family; we observe on each side of the body a sort of membranous wing, and on the right side this prolongation curves into a small canal, through which water is introduced into the branchial cavity. Many species are found in fresh waters in the United States. A common species, the Paludina vivi'para, so called because its young are born alive, is marked by purplish longitudinal bands, and the shell is greenish; it abounds in the standing waters of France.

39. The Litrorine do not differ much from the Paludinæ, except that they have a thicker shell, and inhabit the sea. The Vigneau, or Turbo littoreus, the shell of which is round, of a brown colour, streaked with black, belongs to this genus; it abounds on the coast of France, where it is eaten by the natives.

40. The Monodons are distinguished from the littorinæ by the presence of a blunt, slightly projecting tooth at the base of the columella. The animal generally bears on each side three or four filaments, as long as the tentacles, and has the eyes supported on peculiar pedicles. A small species, the Trochus tesselatus, with a brown shell, spotted whitish, abounds on the coasts of France.

37. What is the characteristic of the Hemi'cyclo'stoma?

38. What are the characters of the genus Paludi'na? (Paludina, formed from the Latin palus, a marsh.)

39. What are the characters of the genus Littorina?

40. What are the characters of the genus Monodon? 


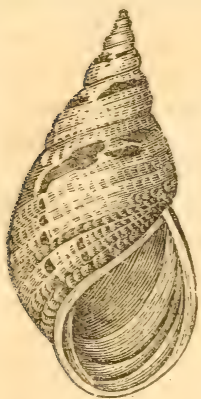

Fig. 51 .

PHASIANELLA PICTA

41. The Phasiatella ( $f g .51$ ) have an oblong or pointed shell; the aperture is higher than it is wide, and furnished with a strong operculum; the base of the columella is flatten. ed, but there is no umbilicus. These animals inhabit the Indian Ocean, and their shells are much sought after by collectors, on account of the beauty of their colours.

42. $\mathrm{T} \mathrm{h} \&$ shell of the Ampullaria ( $f i g .52)$ is round, ventricose, with a short spire, as in most of the Helices; the aperture is higher than it is wide, and provided with an operculum; the columella is umbilicated. The Ampullariæe inhabit the fresh or brackish waters of hot countries. Many species are found in the United States.
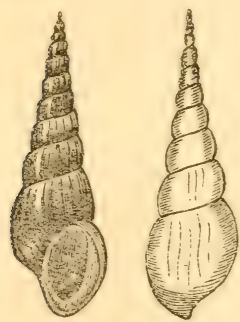

Fig. 53.-Melania.

43. The shell of the Melana (fig. 53) has the aperture higher than wide, and it enlarges opposite to the spire; the colu. mella has neither plicæ (folds) nor umbilicus; the length of the spire is very various. The animal has long tentacles, the eyes being at about one-third of their length, on the external side. The Melaniæ inhabit fresh-water rivers; a number of species is met with in the United States.

44. The Jantrive ( fig. 54) resemble snails in the general form of their shell, but differ considerably from the different mollusks we have described

41. How is the genus Phasiane'lla characterized? (Phasianella, from the Greek, Phrsianos, a pheasant, because this shell bears some resem. bl ince to the pheasant in its colours.)

42. How is the genus Ampulla'ria recognised?

43. What are the characters of the genus Meld'nia? (Melania, from the Greels, melns, black.)

44. What are the characters of the genus Janthi'na? (Janthina, from the Greopk ianthon, violet colour.) 
in the form of the animal. It has no operculum, but carries on its foot a substantia! vesicular organ, which resembles froth bubbles, which hinders it from crawling, but enables it to float on the surface of the water. Its head is in the form of a trunk, and has a forked tentacle on each side. The common

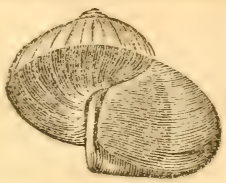

Fig. 54.- dANTHINA. species-Janthina fragilis - with a very thin violet-coloured shell, is very common in the Mediterranean, and the seas of all warm regions. Great numbers of them are frequently met with in perfectly calm weather floating on the surface of the ncean. When the animal is touched, it ejects a deep violet-coloured liquor, which dyes the water all round it. The vesicular or froth-like buoy is about three times the size of the animal; it is in the form of a cone, projecting from one side.

45. The NERTre are distinguished by the columella being a straight line, which makes the aperture of the shell either semi-circular or semi-elliptical. They are divided into Natica, in which the shell is umbilicate (fig. 20, page 34 ) and the operculum horny; into Nerita, properly so called, in which the shell is not umbili. cate, thick ( $f i g .55)$, and the operculum stony, and into Neritina, in which the shell is also without an umbilicus, very

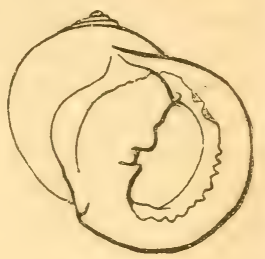

Fig. 55.

NERITA PELORONTA。

Bleeding Tooth. thin, and the operculum is horny. The last live in fresh waters.

45. How is the genus Neri'ta distinguished? 
LESSON IV.

Family of Buccivoldes,-Buccinum-Buccinum properly so called-Harpa-Purpura-Cassis-Cerithium-MurexStrombus-Voluta-Ovula-Cypraa-Conus.

Family of Pectinibranchiata Capuloida. - Pileopsis Hypponyx - Crepidula - Calyptraa - Siphonaria - Sigaretus.

Order of Gasteropoda Tubulibranchita.

Order of Gasteropoda Scutibranchiata.-Haliotis-Fissurella-Emarginula.

Order of Gasteropoda Cyclobranchiata. - PatellaChiton.

Order of Gasteropoda Inferobranchiata.

Order of Gasteropoda Tectibranchiata.-Pleurobran. chus-Aplysiu-Dolabella-Bullea-Bulla.

Order of Gasteropoda Nudibranchiata. - Eolidia Glaucus.

Order of Gasteropoda Heteropoda.-Carinatia. Class of Mollusca Pteropoda. - Clio borealis.

1. In the Family of Buccivordes, the shell is spiral, and in its aperture, near the extremity of the columella, there is a canat or notch, serving for the passage of the syphon or respiratory tube (fig. 56), which is formed by a fold of the mantle, ana destined to afford the animal the power of breathing, withour going out of its shell. This family is divided into three tribes, namely: Buccinum, Murex, and Angiostoma.

2. The Tribe of Buccinur comprises all the Buccinoides in

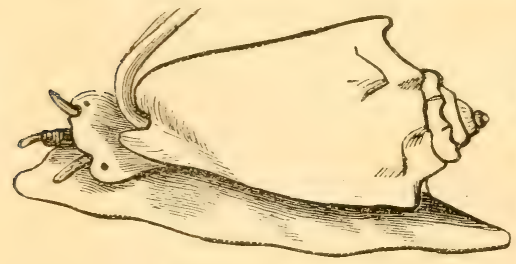

Fig. 56.-voluta. which the shell is without a plica (fold) in its columella, but is fur. nished with a notch or short canal inflected towards the left, and its aperture is very large. The foot of these mollusks is generally of moderate length, and rounded in front ( $\mathrm{fggs} 33$ and 34.) The mantle is unprovided with fringe, and is prolonged anteriorly into a long canal, which

1. What are the characters of the shell in the family of Buccinoides? Into how many tribes is this family divided?

2. How is the tribe of Buc'cinum characterized? (Buccinum, Latin, a trumpet.) 
is always uncovered. The mouth is armed with a trunk, and there is generally a small horny operculum.

3. 'The Buccinum PROPERLY SO CALled (fig. 5i), has an oval, elongated shell, the aperture of which is oval, nolched, and without a canal. The operculum is complete, and these animals have no veil on the head like the Cerita. A great many species are known. Lamarck describes fifty-eight species.

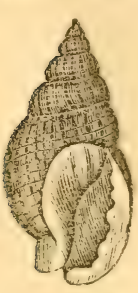

Fig. 58 .

NASSA.

4. We give the name of NAssa to mollusks that differ very little from the preceding, but in which the columella of the shell, in place of being convex and naked, is covered by a plate of greater or less thicliness ( $f$ ig. 58). Dolium also belongs to this tribe, and is remarkable for the length of its trunk and the size of its foot. It is without operculum, and the shell is recognised by being almost globose, very ventricose and fur. nished with projecting ribs, which follow the direction of the whorls of the spire, and make the margin of the aperture un. dulated ( $f i g .59$ ). A very large species is found in the Mediterranean.

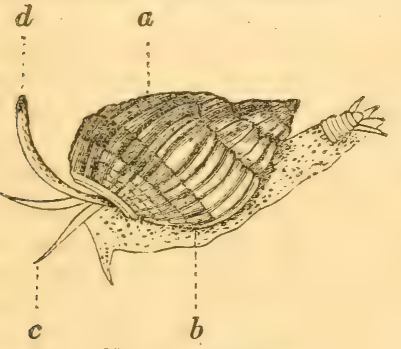

Fig. 60.-HARPA.

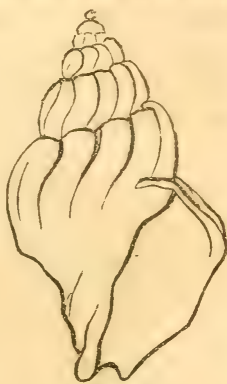

Fig. $5 \%$.

BUCCINUM UNDATUM.

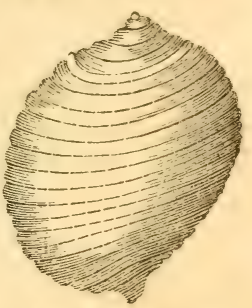

Fig. 59.-DOLIUM GALEA.

5. The HARPS-Harpahave a more oval shell, furnished with projecting ribs parallel with the margin of the aperture, and differ from the preceding in the form of their foot (fig. 60).

6. The Purpura is fur. nished with an operculum, like the Buccinum properly so

Explanation of Fig. 60.-Harp:-a. the shell; -b. the foot of the animal; $-c$. the tentacles; $-d$. the syphon.

3. What are the characters of the Buccinum properly so called?

4. What are the characters of the genus Nassa? (Nassa, Latin, a net). What are the charac'ers of Do'lium? (Dolium, Latin, tub, a tun).

5. How is the Harp characterized ?

6. What are the characters of the genus Pur'pura? (Purpura, Latin, purple.) 
called, which it very much resembles. The shell is ovate, thick, most frequently tuberculated, and characterized by its flattened columella, which is trenchant towards the end opposite to the spire, and forming, at that point with the external margin of the aperture, an unprojecting canal.

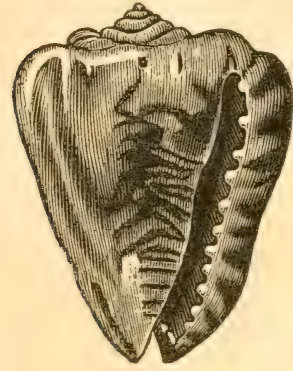

Fig. 61 .

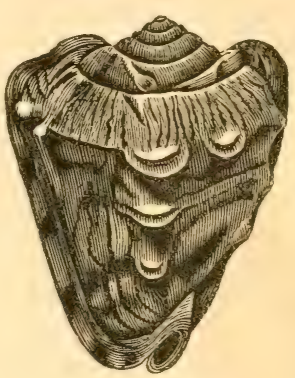

Fig. 62 .

7. The Henmet - Cassis (figs. 34, 61, 62) - also very much resembles the ordinary Buccinum; but their shell, which. is ovate, with a short, slightly projecting spire, is furnished with

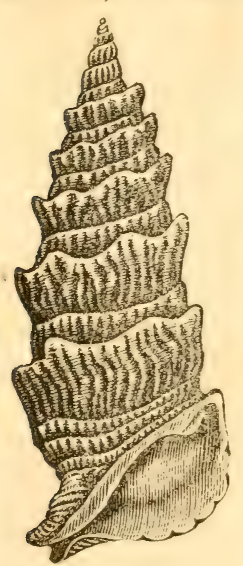

Fig. 63.

CERITHIUM ALUCO. a transversely wrinkled plate, covering the columella, like the Nassa. The aperture, sometimes oblong, sometimes straight, is also wrinkled externally, and its notch terminates in a little short canal which is curved backwards.

6. The Terebra differs still less from the Buccinum properly so called: it is distin. guished from it only by the elongation of its spire.

9. The Cerithium (fig. 63), the shell of which is turreted, like that of the Terebra, but furnished with a short canal curved to the left or backwards, also differs from other Buccina by having a veil above the head: this animal has but a single branchia. Some of the mollusks of this genus inhabit the sea, and others fresh water. A great many living species are known; but they were formerly more abun-

7. What are the characters of the genus Cassis? (Cassis, Latin, a helmet.)

8. How is Terebra distinguished from Buc'cinum? (Buccinum, Latin, a trumpet, a shell-fish.)

9. What are the characters of Cerithium ? 
dant than in our day; for, in certain formations, such as the calcareous tertiary of the environs of Paris, an immense number is found in the fossil state.

10. In the Tribe of Murex, the aperture of the shell is always prolonged into a canal, either straight or inflected (fig. 64). The animals themselves very closely resemble those of the tribe of Buccinum; they have a trunk, no veil. on the head, the right edge of the mantle furnished with lobes or filaments, and a horny operculum. They are all carnivorous and inhabit the sea. They are subdivided, according to the form of the shell, into Murex properly so called, Fusus, Strombus, \&c.

11. The Murices properly so called are distinguished by their shell, the canal of which is projecting and straight, and the whorls are furnished with transverse elevations, in form of varices or ridges, which often present spines, or ramified and slashed plates, or lamellæ.

12. The Fusus has a canal formed like the common Murex; but the shell is without varices, that is, longitudinal ribs.

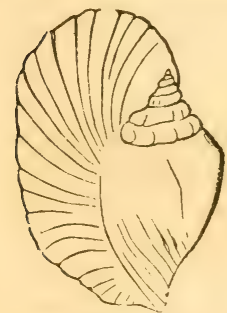

Fig. 65.

STROMBUS.

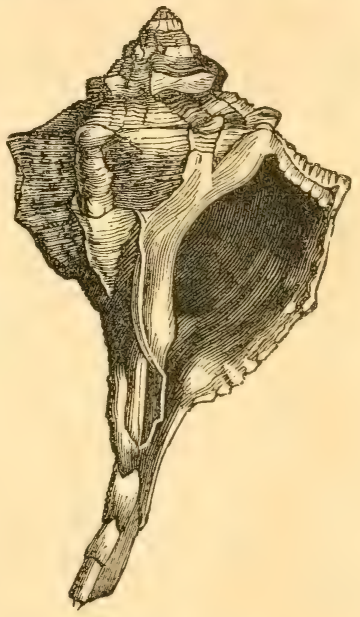

Fig. 64.-MUREX.

13. The Strombus has a shell in which the canal is straight or curved to the right, and its external edge expands with age, and this canal presents a sinus (hollow) behind, in which the head lodges, when the animal extends itself. In the Strombus ProperLy so CALLED, the sort of wing formed by this prolongation of the margin of the shell is entire ( $f g$. 65), while, in the Prerocera, it is divided, in the adult, into long and slender digitations.

10. How is the tribe of Mu'rex characterised? (Murex, Latin, a shellfish.)

11. How are Mu'rices properly so called distinguished?

12. What are the characters of Fusus? (Fusus, Latin, a spindle.)

13. What are the distinguishing characters of Strom'bus? (Strombus, Latin, name of a shellfish.) 
All have the aperture of the shell very narrow ( $f g$. 66), a disposition approaching to the characteristic of the following tribe.

14. In the Tribe of Angiostoma, the aperture is cenerally so narrow that, to enter it, the foot of the animal is obliged to be doubled.

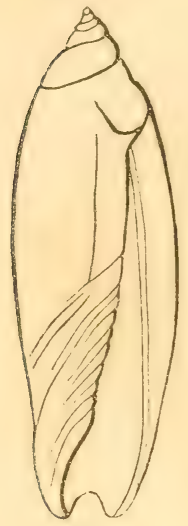

Fig. 67.

OLIVA.

In some, designated under the com. mon name of Volutes-Voluta - the aperture, which is of various forms, is terminated by a notch without a canal, and the columella is marked by oblique,

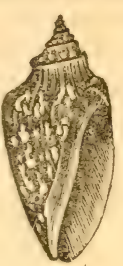

Fig. 66. STROMBUS TRICOR NIS. projecting plicæ (folds), (fig. 67): they are subdivided into Volutes proper ( $f g .56$, page 52), in which the aperture is wide, and the columella is marked by some large plicæ, and the last whorl of the spire is sometimes ventricose, sometimes conical; in the Mitra the spire is in general pointed and elongated, and in OLIva, so called from the oblong or ellipsoid form of the shell, the aperture is long, narrow, and notched opposite to the spire, and the coltumella is marked by numerous plicæ ( fig. 67).

16. In others the shell is oval, the spire is concealed, and the aperture, which is long and narrow, has no plicæ on the side of the columella, but presents a notch or canal at its two extremities; these are the Ovulæ $(f g .68)$.

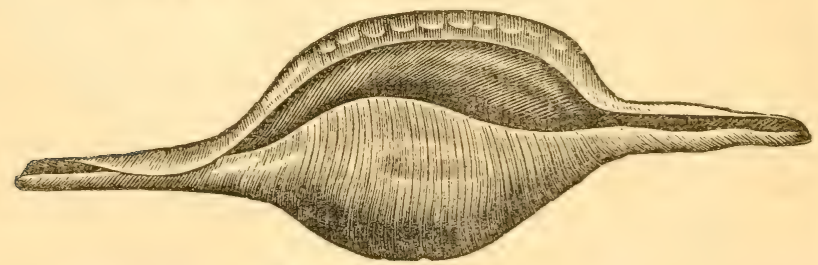

Fig. 68. -ovíla volva.

17. In others again, the Crprize (Porcelaxa), the shell, which is protuberant in the middle, and almost as much con-

14. What is the peculiarity of the tribe of Angio'stoma? (Angiostoma, Greek, aggeion, a vessel, and stoma, mouth.)

15. What are the characters of Volu'ta? (Voluta, Latin, a wreath.) What is the character of Oli'va? (Oliva, Latin, an olive.)

16. What are the eharacters of the genus O'vula? (Ovula, from the Latin, ovum, an egg.)

17. What are the characters of the genus C'ypræ'a ? (Cypræa, Latin, a cowry. 
tracted at the two extremities, has a very narrow aperture, transversely wrinkled on both sides; when the animal expands itself, the mantle extends over the shell and envelopes it entirely

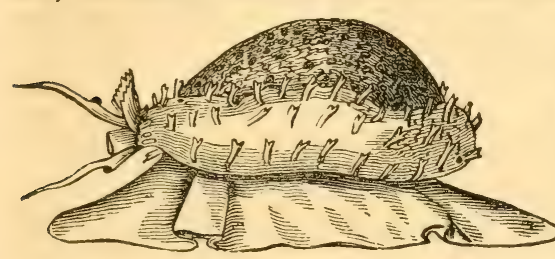

Fig. 69.-CYPREA.

(fig. 69), which, in the progress of time, produces considerable modification in the colours of the latter; for, at a certain period, it deposits new layers of calcareous matter, not only around the aperture, but also upon the whole external surface of this solid envelope.

18. Also to this tribe of mollusks belongs the genus Conus ( $f g .70$ ), which differs from all the preceding in the conical form of the shell, which gives the genus its name; a slightly, or not at all projecting spire, forms the base of this cone, and the aperture, which is nearly straight, extends from one end of the shell to the other.

19. A great number of the shells, the principal characters of which we have briefly noted, are remarkable for the elegance of their form and the beauty of their colours; the Cones, the porcelain shells (Cypræa), the Volutes, and the Olives especial$l y$, are much admired for the brilliance of their mark-

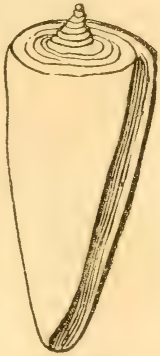

Fig. 70.

conus. ings. Many other mollusks of the family of Buccinoides are also worthy of attention on account of the viscid liquid, secreted by the gland placed, as we have already seen in the snails, betwixt the heart and rectum. And in a considerable number of these animals, this humour has the property of changing colour when exposed to the action of air and light, and thus passes from greenish yellow to purple; spread upon stuffs, it imparts to them this rich shade, and appears to be the material employed by the ancients for producing their beautiful purple dyes. Pliny relates that on the shores of Tyre, and many other points along the coasts of the Mediterranean, there are found two genera of shells, called Buccinum and Purpura, both of which furnished dye for the colours termed purple and conchilian. The first of these mollusks appears to be the Buccinum lapillus, and the second the Murex branduris (fig. 64); but the quantity of colouring

18. What are the characters of the genus Co'nus? (Conus, Latin, a cone.)

19. What animals are supposed to yield the purple dye which was cele. brated among the ancients? 
matter these animals yield is so small, it is difficult to explain how they could furnish so active a trade; and it must have been that the ancients used for the same purposes the purple liquid secreted by larger and more common mollusks, such as the aplysia, which we have yet to mention.

20. The Fammy of Pectinieraxch Capuloides is recog: nised by the shell being widely open, slightly turbinated, and without either notch, syphon, or operculum. The conformation of the animal differs but little from that of other mollusks of the same order; there is only a single branchia, often with very long filaments, attached transversely to the arch of the respiratory cavity.

In this division are arranged the genera of Pileopsis, Hippo. nyx, Crepidula, Calyptraa, Sigaretus, \&c.

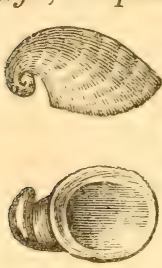

21. Animals of the genus Pileopsis, or Capulus (fig. 71), have their branchire on the anterior edge of the respiratory cavily; the shell is conical, and presents at its summit the commencement of a spire; their neck is covered by a membranous plaited veil, and they have two conical tentacles, and a tolerably long trunk or proboscis. They inhabit the sea. shores of warm countries.

Fig. 71.

CAPULUS

INTORTA.

22. The genus of Hipponyx (fig. 72) consists of fossil shells, which closely resemble the preceding, but are very remarkable for a support formed by calcareous layers, upon which they rest, and which seem to have been secreted by the foot of the animal.

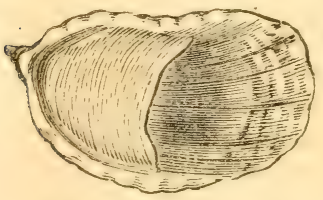

23. The Crepidula have an oval shell, the whole base of which is half closed by a horizontal plate, which supports the abdominal sac above it, and is covered beneath by the foot (fig. 73).

Fig. 73.- CREPIDULA.

20. How is the family of Pectinibranch Capuloi'des distinguished? (Capuloides, from the Latin, capulus, a hilt or handle, and the Greek, eidos, resemblance.)

21. What are the characters of the genus $\mathrm{Ca}^{\prime}$ pulus? (Capulus, Latin, a hilt.)

22. What are the characters of the genus Hippony'x ? (Hipponyx, from the Greek, ippos, a horse, and onux, nail; horse nail, or hoof.)

23. What are the characters of the genus Crepi'dula? (Crepidula, Latin, (alipper.) 
24. The Calyptrae have in the interior of the shell, in form of a hollow cone, a small plate projecting downwards, which seems to be the commencement of a columella, and is embraced in a fold of the abdominal sac; their branchiæ are composed of longy slender filaments like hairs.In some of them the plate or lamina adheres to the bottom of the cone, being itself bent into a portion of a cone or of a tube, and descending vertically.

25. The Siphonaria deserve notice, because

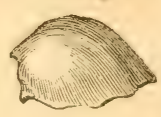

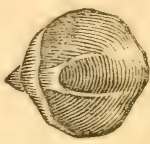

Fig. 74.

CALYPTRAA. they show how much the organization of mollusks may vary without any very striking difference in the form of their shell. Until recently these animals have been ranged with the patellæ, to be described in the sequel, which they resemble in their shell, but differ from them very much in the structure of their most important organs; their branchia is composed of a few leaflets transversely attached to the bottom of a respiratory cavity,

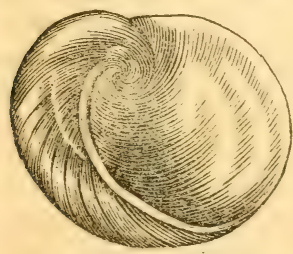

Fig. 75.-SIGARETUS. which is on the back, and communicating externally by a lateral hole in the mantle; they do not appear to possess tentacles, but have a narrow veil on the head.

26. The genus Sigaretus ( $f i g .75)$ has a flattened shell, with a slight spire, and a very large aperture, which is concealed in the mantle.

\section{ORDER OF GASTFROPODA TUBUIIBRANCHIATA.}

27. Tubulibranch gasteropods are very analogous to the pectinibranch gasteropods, but are distinguished from them by very important differences in the organization of some of their organs, and in the structure of their shell, which is fixed to submarine bodies, and is in the form of a more or less irregular tube, the commencement of which only is spiral. It is divided into the genera Vermetus, Magilus, and Siliquaria.

24. What are the characters of the genus Calyptræ'a? (Calyptræ'a, from the Greek, kaluptra, a hood.)

25. What are the characters of the genus Siphona'ria?

26. What are the characters of the genus Sigare'tus?

27. How are the tubu'libranch distinguished from the pecti'nibranch gasteropods? (Tubu'libranch, from the Latin, tubulus, a little tube, and branchia, gills). 


\section{ORDER OF GASTEROPODA SCUTIBRANCHIATA.}

28. In the general form of their body and the position of their branchiæ, the scutibranch resemble the pectinibranch gasteropods; but they differ from the latter in their anatomical and physiological characters. Their shell is very open, slightly or not at all turbinated, and, like a shield, it covers the branchiæ or even the whole body. A peculiarity of their internal organization approximates them to the acephalous mollusks; their heart is traversed by the rectum and receives the blood by two auricles. They are not numerous, and are divided into Haliotis, Fissurella, \&c.

29. The Haliotides (fig. 76) have a slightly turbinated shell, with a spire so small that it is only seen from the inside: it is flattened and the aperture is very large. In the Haliotides properly so called, there is along the columella a series of holes,

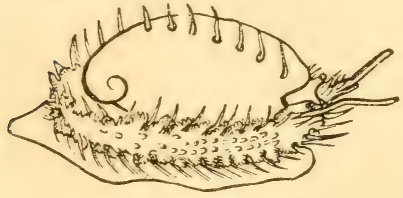

Fig. 76.-HALIOTIS. through which the water reaches a slit on the right side of the mantle, and penetrates to the branchial cavity ; the filiform appendages of the edge of the mantle can be protruded through these holes, and all around the foot there is a double membrane cut in fringes and furnished with long filaments. On the outside of the tentacles we find two cylindrical pedicles, bearing the eyes; and the mouth is armed with a trunk or proboscis. The external surface of the shells of these mollusks are not remarkable; but internally they are covered by a layer of nacre, of the richest and most beautifully iridescent colours. They are found in great numbers on the rocky shores of California.

30. The Fissurella, (fig. 77) are recognised by their conical shell placed upon the $m$ middle of the back, and $p$ pierced at its summit by a small opening, which serves to give

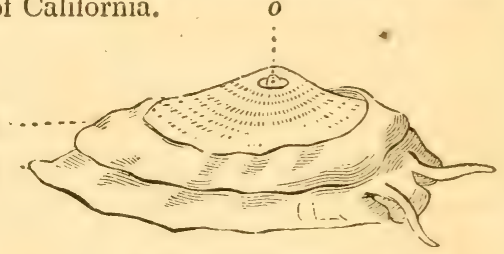

Fig. 77.-Fissurella.

Explanution of Fig. 77.-p the foot of the animal;-m. the mantle;-0. the opening at the apex of the shell, and the anus.

28. What are the characters of the scuti'branch ga'steropods? (Scutibranch, from the Latin, scutum, a shield, and branchic, gills.)

29. What are the characters of the Halio'tides? (Haliotides, from the Greek, als, the sea, and ous, ear ; sea-ear, or haliotis, and eidos, resemblance.)

30. How is the genus Fissure'lla recognised? (Fissurella, Latin, Fis. sura, a slit.) 
passage to the air necessary for respiration, and also for the ex. pulsion of the excrements.

31. We give the name of Emarginula to mollusks very much like the Fissurellæ, but their shelı, in place of being open at the top, presents a slit or notch in front, communicating with the branchial cavity.

\section{ORDIR OF GASTEROPODA CYCLOBRAITCHIATA.}

32. The cyclobranch gasteropods closely approximate the preceding, either in their general form, or in the disposition of their internal organs; but they are distinguished by their branchiæ being fixed around the edges of the mantle (fig. 78).

38. Some, the Patella (fig. 78), for example, are provided with a broad-based, conical shell, which covers the whole body; they very much resemble the Fissurel. læ and Emarginulæ, but the shell is not perforated at the apex, nor is there a notch in front as in the latter. The head is furnished with two pointed tentacles, having the eyes at their base, and a stout trunk; the anus is situate to the right, and a little above the head, and the branchiæ are composed of

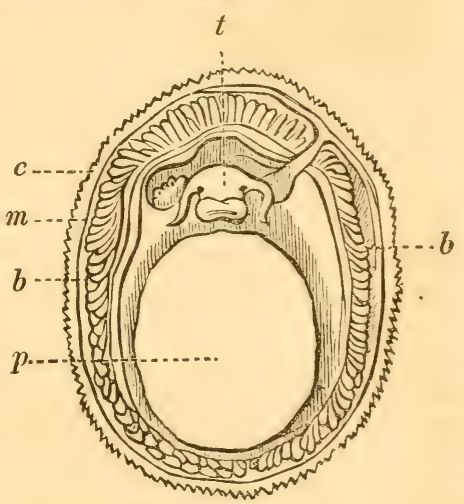

Fig. 78.--PATELLA. leaflets or fringes, arranged in a row around the body, under the edges of the mantle. Patellæ are found in almost all parts of the world; they are found on rocks to which they adhere, and lie completely concealed beneath their shell, even after they are left by the ebbing sea.

Explanation of $\boldsymbol{F}$ ig. 78. - The animal of the patella scen from below ; $-c$. the edge of the shell $;-p$. the foot; $-m$. the mantle; $-b$. the branchiæ; $-t$. the head.

31. How does the genus Emargi'nula differ from Fissure'lla? (Emarginula, from the Latin, $e$, from, and margo, marginis, the margin-from the margin-notched.)

32. How are cy'clobranch ga'steropods distinguished? (Cyclobranch, from the Greek, kuklos, a wheel, and bragchia, gills.) knee-pan. 


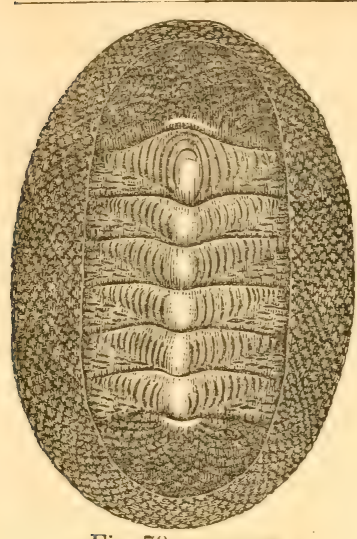

Fig. 79.-chiтos.

34. Other cyclobranch gastero. pods, called Clition ( fig. 79), differ from all mollusks, in the nature of their shell, which, instead of a turbinated or shield-like piece, is composed of a row of testaceous and symmetrical scales, generally eight in number, let into the mantle, and occupying the middle line of the back. The edges of this mantle, thus protected, are also very leathery, and often furnished with little scales, spines, or hairs. A membranous veil placed over the mouth, takes the place of tentacles; the branchiæ are composed of lamellar pyramids, arranged on each side, beneath the edge of the mantle; the anus is at the posterior extremity of the body. Chitons most abound on the shores of tropical seas.

\section{ORDER OF GASTEROPODA INFEROBRANCIIATA.}

35. The order of Inferobranch gasteropods is composed of a very small number of naked mollusks, characterized by their branchiæ, consisting of a long series of leaflets, placed on each side of the body, between the foot, and the advanced edge of the mantle. Like the preceding, they are marine, and differ from them, not only in the absence of every vestige of shell, but also in some points of their internal anatomy, which approximate them to the gasteropods. They are divided into Prrulidia (from the Greek, phullon, a leaf), in which the anus is posterior to the mantle, and the head is furnished with four tentacles; and into Dipuxulidia (from the Greek, dis, two, and phullon, leaf), in which the anus is on the right side, and the head has a pointed tentacle, and small tubercle on each side. In all of them, the body is oval, or more or less tuberculous.

\section{ORDER OF GASTEROPODA TECTIBRAFCKIATA.}

36. The Tectibranch gasteropods are, like the preceding, marine molluslis, but their branchiæ are not symmetrical; they

34. What are the characters of the genus Chi'ton? (pronounced ky-ton.) (Chiton; Greek, a garment.)

35. How are the In'ferobranch ga'steropods characterized? (Inferobranch; from the Latin, inferus, below, and branchice, gills.)

36. What are the characters of the tectibranch gasteropods? (Tectibranch; from the Latin tego, I cover, and branchia, gills.) 
are composed of leaflets, more or less divided, attached along the right side ( $f \mathrm{~g} .80, \mathrm{br}$ ), or on the back (fig. 81), and more or less covered by the mantle, which almost always encloses a small shell in its thickness. -

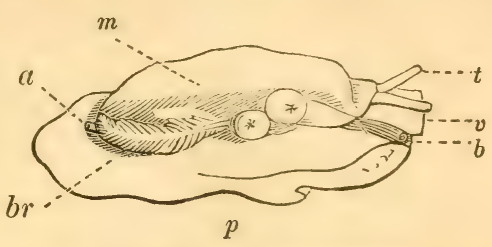

Fig. 80.-PLeUrobranchus.

Their form is very variable. They are divided into Pleurobranchus, Pleurobranchides, Aplysia, Dolabella, Akera, \&c.

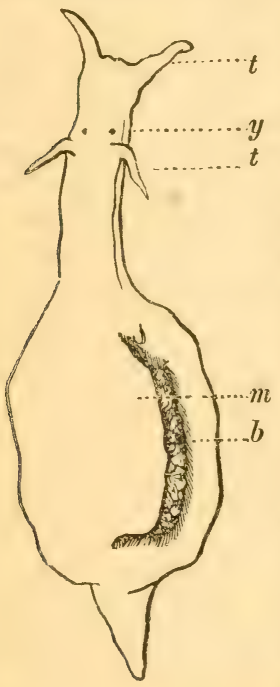

Fig. 81.-APLisia.

37. The Pleurobranchi are mollusks of an oval form; in which the branchix are fixed on the right side, between the mantle and foot ( $f i g .80)$. The mouth is in the form of a proboscis or trunk, and is surmounted by a small triangular veil, and two tentacles; they have four stomachs, the second one of which is sometimes armed with bony pieces, and the anus opens behind the branchiæ. One species, of a lemon yellow colour, is found on the coasts of France.

38. The Aplysiæe, which the ancients called sea-hares, have a very singular form; the body resembles that of a sort of Limax; but the edges of the foot, erected in flexible crests, surround the back and may be even reflected over it. Their head is supported by a neck of greater or less length, and furnished with four tentacles ( $f g .81, t)$, the two upper ones being hollowed like the ears of a quadruped, and placed above the eyes $(y)$. The branchiæ, in the form of very complicated

Explanation of Fig. 80.-m. the mantle, raised up to show the branchiæ, br $;-a$. the anus $;-b$. the mouth and trunk; $-v$. the veil $;-t$. the tentacles; $-p$. the foot.

Explanation of Fig. 81.-t,t. the tentacles; $-y$. the cyes; $-m$. the mantle; -b. the branchiæ.

37. What are the characters of the genus Pleu'rohranchus? (Pleuro. branchus, from the Greek, pleura, side, and bragchia, gills.)

38. What are the characters of the genus Arly'sia? (Aplysia, from the Greek, aplusia, uncleanness.) 


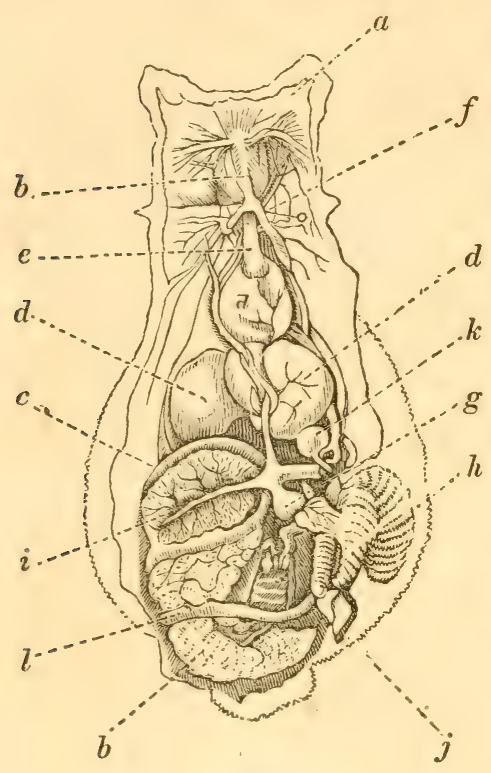

Fig. 82.-ATLYSTA.

leaflets, are fixed upon the back, by means of a broad membranous pedicle, and covered by a small mantle $(m)$, in the thickness of which we find a small horny shell. And the anus is situate behind the bran. chiæ. These mollusks live on fucus, and are provided with an enormous crop, and three other stomachs (fig. 82, d), the second and third of which are arm. ed internally with sharp hooks, and cartilaginous plates. A particular gland secretes an acrid liquor, and pours it out through an opening situate on the right side. A purple coloured liquid exudes sweats from the edge of the mantle, when the animal contracts, and is sufficient in quantity to dye the

water to a considerable distance around it. Several species of Aplysiæ, which vary in colour, are found on the coasts of France.

39. The Dolabella do not differ much from the Aplysix, except in the position of their branchiæ, and their mantle at the posterior extremity of the body. They are found in the Mediterranean as well as in the Indian seas.

40. The Akerce (fig. 83) also resemble the Aplysiæ in the complication and armature of the stomach, as well as in the position of their branchix, and several other important points of their organization; but they are distinguished by their tentacles, which are short, very thick, and so arranged as to form together a

Explanation of Fig. 82.-Anatomy of the Aplysia:- $-a$, the head; $-b$. the pharynx; $-e$. osophagus; $-d$. the three stomachs; $-c$. the intestines; $-f$. the nervous collar surrounding the œsophagus; $-g$. the heart; $-h$. the branchia ; $-i$, the liver $;-j$. the anus $;-k$. the bladder : $-l$. the orary.

39. What is Dolabe'lla? (Dolabella, Latin, a little axe or hatchet.)

40. How are Ake'ræ distinguished from the Aplysiæ? (Akera, from the Greek, $a$, without, and keras, horn.) 
large fleshy shield above the eyes (fig. 83, v). Many of these animals effuse a purple liquid. Some are entirely unprovided with shell, or have only the vestige of a shell: these are the Akera properly so called; others have a shell somewhat rolled upon itself, and without a projecting spire or notch, which is concealed in the thick-

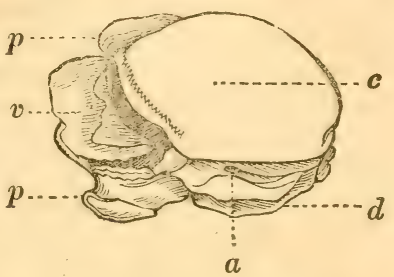

Fig. 83.-BULLA HYDATIS. ness of the mantle; these form the genus Bullaa; and there are still others in which the shell, only covered by a slight epidermis, is more convoluted and sufficiently large to afford a retreat for the animal: these constitute the division of Bulla.

\section{ORDTR OF GASTEROPODA NUDIRRANCHIATA.}

41. The mollusks composing this group are without a shell and carry their branchiæ on some part of the back ( $f g .84$ ). The structure of some of their internal organs approximates them to the Pulmonea, the Inferobranchiata, and the Tectibranchiata; they all inhabit the sea.

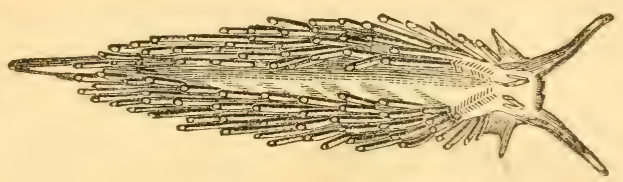

Fig. 84.-EOLIDIA.

42. Among the genera possessing this kind of organization, we will cite the Doris, the general form of which is nearly the same as that of the Pleurobranchus (fig. 83), and in which the branchiæ are inserted in a circle around the anus, at the posterior part of the back; the Tritovia, in which the branchiæ, in form of miniature trees, are attached along the two sides of

Explanation of Fig. 83.-Animal of the Bulla hydatis:-c. the shell;$p, p$. the two lobes of the foot; - $d$. posterior part of the foot:- $v$. the sort of veil formed by the union of the tentacles; $-a$. the anus.

41. What are the characters of the Nudi'branch gasteropods? (Nudibranch; from the Latin, nudus, naked, and branchie, gills.)

42. What are the characters of the genus Glau'cus? (Glaucus; from the Greek, glaukos, blue.) What are the characters of the Eolidia? 
the back, and in which the mouth is armed with lateral horny jaws, similar to shears; the Glaucus, remarkable for its blue colour (fig. 85), in which the branchiæ, three pairs in number, are situated in the same manner, but each one is composed of several long fringes, spread like a fan; and the Eolidia ( fig. 84), which resemble small Limaces in form, in which the branchiæ are composed of laminæ, or leaflets, arranged like scales, more or less crowded together on each side of the back. They are found in every sea.

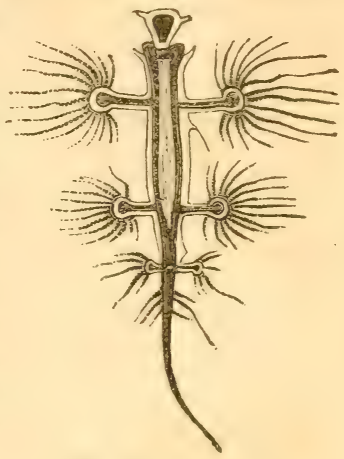

Fig. 85.-Glaucus.

\section{ORDER OF GASTEROPODA IETEROPODA.}

43. These gasteropods are not organized, like all the preceding, for crawling on the belly, but for swimming only. In fact, their foot, in place of forming a horizontal fleshy disk, is compressed into a vertical membranous plate, which is used as a fin. Their body is formed of a transparent, gelatinous substance, and their branchiæ are placed on the posterior part of the back.

The principal genera of this group are the CARINARIA and Fiorola.

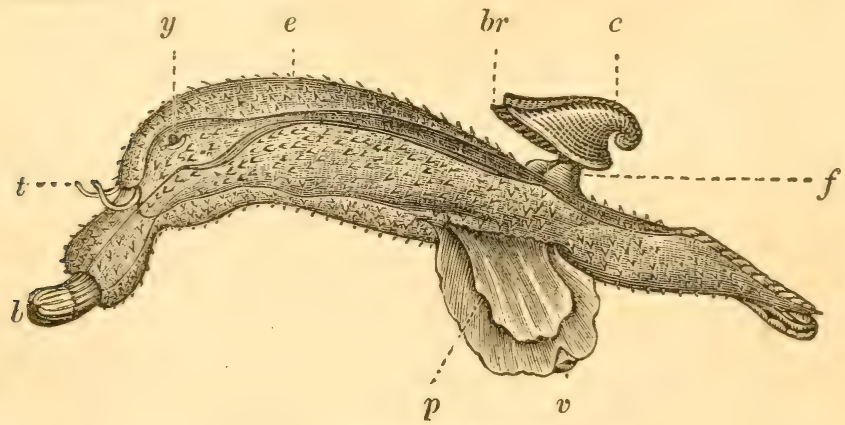

Fig. 86.-Carinaria Mediterranea.

Explanation of Fig. 86.- b. the month; - t. the tentacles; - y. the eyes;e. the stomach; $-f$. the liver $;-c$. the shell $;-b r$. the branchiæ $;-p$. the foot; $-v$. a small sucker situate on the side of the foot. 
44. The Carinarie have the abdomen (that is to say, a kind of sac enclosing the heart, the liver and some other organs) covered by a symmetrica! and conical shell, the apex of which is curved backwards, and the anterior edge covers the base of the branchiæ $(f i g .86, b r)$. There is one species in the Mediterranean, but three have been discovered.

The Frorous have no shell, but, in other respects, very much resemble the Carinariæ.

\section{CLASS OF IMOLIUSCA PTEROPODA.}

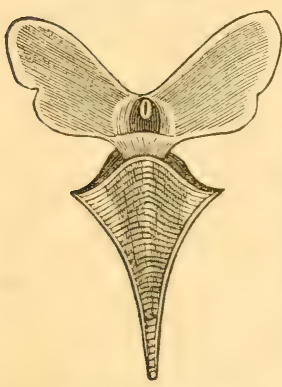

Fig. 87-HYALEA.

45. The mollusks composing this group are organized for swimming only: they possess no organ by means of which they can crawl, or even attach themselves to submarine bodies, but continually float in the sea, and move by the assistance of fins, placed like wings on each side of the mouth ( fig. 87). They are all of small size, and most of them inhabit the seas of warm countries; but they are also found in the neighbourhood of the poles. The Clio borealis, for example, abounds so extensively in the arctic regions, that, in spite of their very small size (scarcely an inch long), they become, in certain seasons, the ordinary food of whales. Their form varies much : some of them are naked; others are provided with a shell. They constitute several genera, the principal of which are the Clio, Hyalea, Cleodora, Cymbulia, \&c.

44. What are the characters of the genus Carina'ria? (Carinaria; from the Latin, cari'na, a keel.)

45. How are the Pte'ropoda characterized? (Pteropoda; from the Greek, pteron, wing, and pous, foot.) 


\section{LESSON V.}

Class of Mollusca Acephala, or, Lamellibranchiata.Organization-Classification.

Family of Ostracea.-Classification-Oysters-GryphaaPecten - Lima - Malleus - Anomia - Spondylus - Perna Etheria-Avicula-Pearls-Pearl fishery-Pinna-ArcaPectunculus-Trigonia.

Family of Mxtilacea.-Mussels (Mytilus)-Modiolus-Anodonta-Unio.

Family of Chamacea.-Tridacna-Chama-Isocardia.

\section{CIASS OF MOLIUSCA IAIMEIIIBRAFCEIATA.}

1. All the mollusks we have heretofore considered have a dis. tinct head; those we have yet to mention are without this part, and their whole organization is of the simplest kind. The mouth is always concealed at the bottom of the mantle, or between its folds: they have neither teeth nor eyes. The nervous system is very simple, and the organs of locomotion are very incomplete or lamellibranch.

2. In animals which form the class of acephalous mollusks (called by Lamarck Mollusca conchifera), the mantle is very large and folded in two, so as to enclose the body, as the leaves of a book are enclosed by its covers. Sometimes these two leaves are free at their inferior edge, sometimes united so as to constitute a tube ( $f g .88, t s, t i)$. A shell, composed of two pieces, called valves, covers this mantle entirely or in part, and at its superior part there is a hinge furnished with an elastic ligament. the play of which causes the valves to gape whenever the muscles $(m a, m p)$, which extend from one valve to the other, do not contract so as to keep them shut. The branchix $(b r)$ are in form of great leaves, transversely and regularly striated; they are always four in number, and placed between the internal face of the mantle (or pallial membrane) and the body of the animal. The mouth is at one of the extremities of the body, and has on each side of it two small triangular bodies $(t)$, which are formed by the extremities of the lips and serve as tentacula; the stomach, liver, and other viscera, are lodged between the mouth and anus, and beneath the heart (co), which is situate on the back; and the lower part of the body

1. What is the distinguishing feature of the lamellibra'nch mollusks? (Lamellibranch; from the Latin, lamella, a thin plate, and branchice, gills.)

2. What are the general characters of acephalous mollusks? (pronounced a.kef'-alus; from the Greek, $a$, without, and kephale, head. 


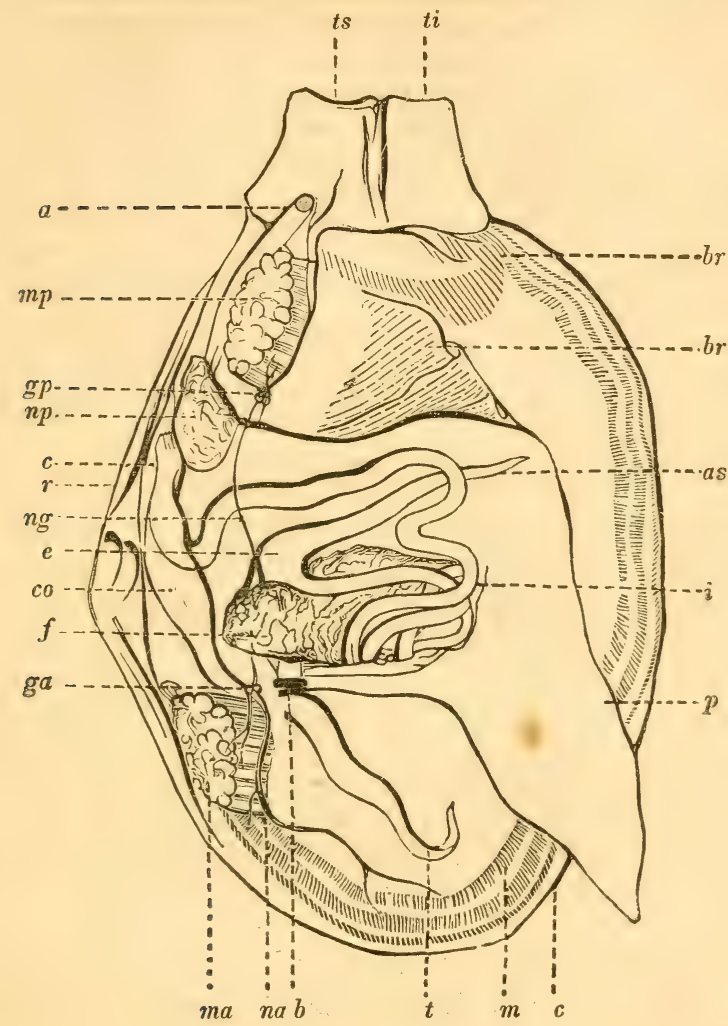

Fig. 88.-ANATOMY OF a MaCtra.

Explanation of Fig. 88.-Anatomy of a mactra; one valve of the shell, the corresponding half of the mantle and the branchix have been removed on the left side $:-c$. the shell; $-m$. the mantle; $-m a$. the anterior muscle; -mp. the posterior muscle; $-b$. the mouth; $-t$. the tentacle; $-e$. the stomach;-as. appendix of the stomach; $-i$. the intestines; $-f$. the liver; $-p$. the foot; $-c o$. the heart traversed by the rectum $(r) ;-t s$. the superior tube into which the anus $(a)$ opens; $-t i$. the inferior or respiratory tube; $-b r$. the branchiæ of the right side;-ga. the anterior ganglia;-na. nerves arising from them; - ng. inter-ganglionic nerves; $-g p$. posterior ganglia;-np. nerves arising from them and distributed to the mantle. 
is almost always prolonged into a fleshy mass $(p)$, called the foot, which serves for motion, and sometimes has at its base a bundle of horny threads, called byssus, by means of which the animal fixes itself to submarine bodies.

3. This class is divided into five great families, which may be recognised by the following characters:

Shaving the mantle open, and without tubes or particular ? apertures.

(FAMILIES.)

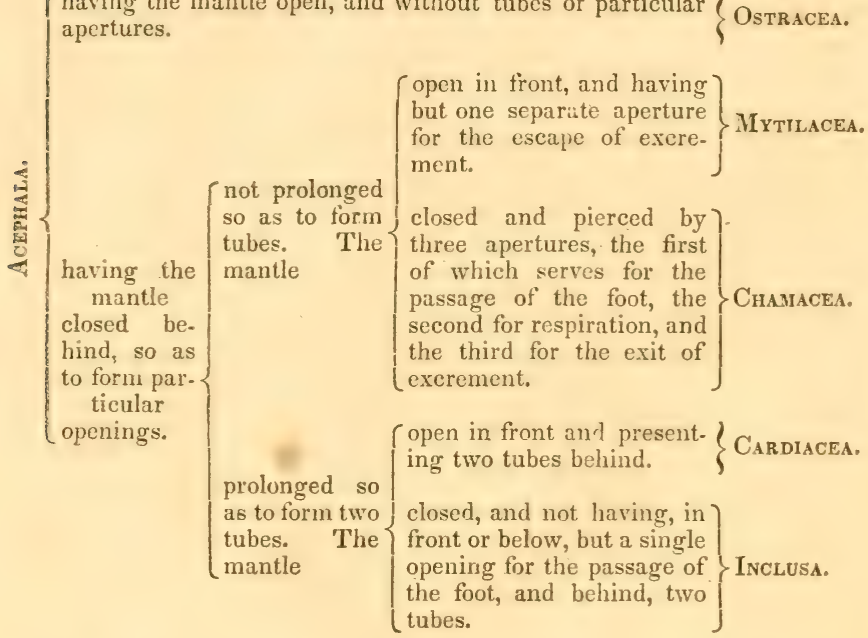

4. The Family of Ostracea has the oyster for its type, and is composed of a great number of mollusks, that are entirely without a foot, or having a very small one only, and which, for the most part, live attached to submarine bodies, either by their shell or by their byssus. 'The mantle is open behind as well as in front, and its two lobes are nowhere united to form particular openings, as we have remarked in all other acephala.

5. This group is divided into two tribes, according as there is a single muscle, going from one valve to the other, or two

3. Into how many families is the class of lamellibranch mollusks divided?

4. What are the characters of the fumily of Ostra'ct:a? (From the Iatin, ostrea, an oyster.)

5. What is the distinguishing character of the tribe of Mono'mya'ria? (Mono'mya'ria. From the Greek, monos, single, and muôn, muscle.) How is the tribe of Di'mya'ria distinguished? (Di'mya'ria. From the Greek, dis, two, and muôn, muscle.) 
of these organs, one placed near the anus and the other in front of the mouth, an arrangement which exists in nearly all other acephala. 'The first tribe, in which there is but one muscle, is called Monomyaria, and the second Dimyaria.

6. To the first of these divisions belong the Orstens, Ostrea. The shell of these mollusks is irregular, laminated, and composed of two unequal valves, united by a short ligament lodyed at either extremity in a pit, and the hinge is without teeth or projecting laminie. The structure of the animal itself is

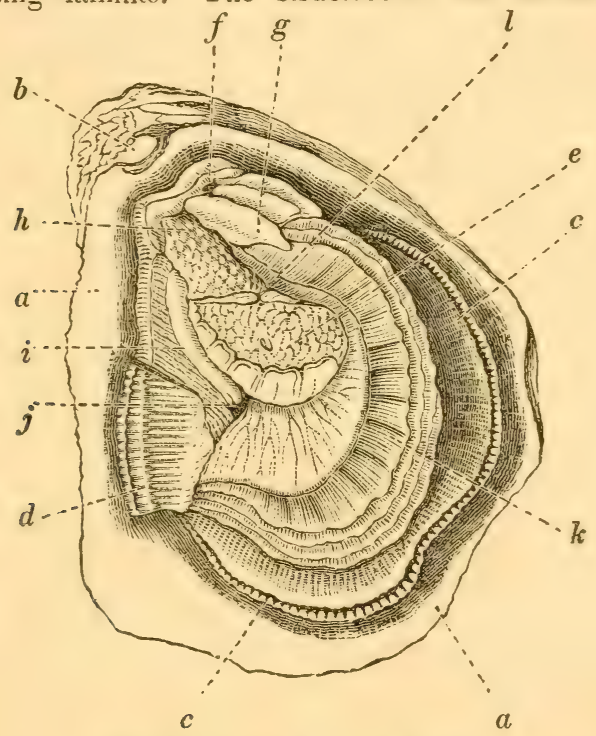

Fig. 89.- anatomy OF AN OYster.

very simple. Its mantle, the lobes of which are united abovo near the hinge $(b)$, has a double fringed border: there is no appearance of foot. The adductor muscle $(e)$ of the valves (commonly called the heart), is situate near the centre of the body, and the heart (l), instead of being placed as usual on the back,

Explanation of Fig. 89.-Anatomy of an oyster;-a. one of the valves of the shell; $-b$. the hinge $;-c$. mantle of the left side $;-d$. portion of the right lobe of the mantle; $-e$, the muscle; $-f$. the mouth; $-g$. the labial tentacula $;-h$. the liver $;-i$. the intestine $:-j$. the anus; $-k$. the branchiæ; $-l$. the heart.

6. What are the characters of the family of Ostracea? Where are oysters found? 
is found between this muscle and the mass of the viscera, where it is readily distinguished by the brown colour of its auricle; the mouth is concealed under a sort of hood, formed by the union of the upper portion of the two lobes of the mantle; the tentacles, which surround this opening, closely resemble the branchiæ, which are large and cover the whole abdomen; and the anus is seen above the muscle. All these mollusks have an ovary and produce eggs, which, at the time of laying, are extremely small and suspended in a whitish liquid, the appearance of which is analogous to that of minute drops of tallow. This spawn floats on the water and soon adheres to neighbouring shells or some other submarine body: and the young oysters are always adherent, either to each other or to an adult oyster or to the rocks on which they live; but, in the first case, they generally detach themselves as they advance in age, and form extensive masses which are called beds or banks. Their growth is very rapid. We are assured that at the end of three months after being spawned, they are of the size of a quarter of a dollar, and at the end of the first year, they are about two inches in diameter; and in three years they attain to about three inches in length. Nothing is precisely known of the duration of their existence.

7. Many species of oysters are described : the most interesting and most extensively diffused is the Ostrea edulis-the edible oyster ; it affords us a wholesome and agreeable article of diet, and its consumption has been immense since the remotest antiquity. These mollusks are ordinarily found in great numbers together, forming beds of considerable extent, situate near sea coasts, in bays or estuaries, or in localities where the sea is not very deep. They are objects of active pursuit, and are caught by means of a kind of rake with a net attached, called a drag, or dredge, which is drawn over the oysterbed; or where the water is shallow, they are taken up by long tongs of a suitable formation : in France, after being caught they are not immediately consumed, but are placed (planted out) in particular basins, where they are kept for a time, and where they fatten and acquire a more delicate flavour. The largest are usually taken from the shell and pickled; but the others are eaten without preparation, and are esteemed by many only while alive. In fact their preservation for any length of time is prevented by the habit these animals have of closing the shell as soon as they are taken out of the water. When dead their shell remains open. 
8. European oysters possess a much more decided flavour, a stronger taste, than those of the United States; Americans, on first eating oysters in London or Paris, commonly complain of their strong coppery taste, and it is not until after several trials they learn to prefer them to our own. The locality of oyster beds exercises a great influence over the taste of the oyster; within the tropies they are rarely found good, and they are almost un. known in the Pacific Ocean. Oysters taken near the entrance of the Chesapeake and Delaware Bays have a high reputation, and are consumed in great quantities. Norfolk oysters are pro. verbially excellent.

The markets of Paris and the north of France are chiefly supplied from the bay of Cancale; from which the boats of Houlle, near Cancale, and Granville, carry away more than eighty millions of these mollusks every year, the major part of which are sent to Courseulles and other parts of Normandy, where there are considerable establishments for the parkage (planting out) of oysters, whence they are sent post to Paris. About the beginning of summer these mollusks cast their spawn: at this season it is customary not to eat them, and it is generally believed they are then unwholesome, but this opinion does not appear to be well founded.

9. We give the name of Gryphas to shells, which for the most part are fossil, and which are very analogous to oysters, but the convex valve is more projecting at the apex or beak, and at that point bends into a hook ( fig. 90). They are found in very ancient for: mations. There is ${ }^{\circ}$ but one living species known.

10. The Scallors-Pecten (also called the pilgrim's shell, from being worn as an ornament by pilgrims) -

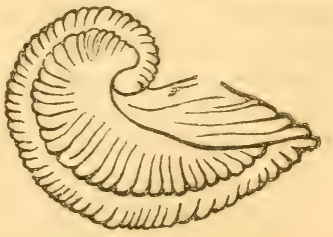

Fig. 90.-GRYPH.A. resemble the oysters in the disposition of the hinge, and may be easily recognised by their inequivalve, semicircular shell, almost always marked by ribs, radiating from the apex of each valve towards their margin, and having on each side of the hinge an angular enlargement called the ear $(f i g .91, e)$. In some species of Pecten there is a byssus; but most of these mol.

8. How do European oysters differ from those of the United States?

9. What is the character of the Gryphæ'a ? (Gryphæa; from the Greek, grupos, incurved.)

10. What are the characters of the genus Pecten? (Pecten, Latin, a comb.) What is meant by the ear of a shell ? 


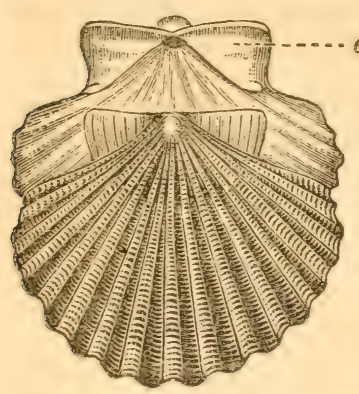

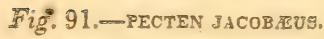

and Pedum, the shells of what resembling the shell of the Scallop in their gene. ral form:

11. The Hammer Oysfers-Malleus (fig. 92)which have a notch near the hinge for the passage of a byssus: the shell is irregular and the ears are prolonged, making its shape slightly resemble a harnmer: the Anomrs, in which the interior valve is deeply notched (fig. 93)

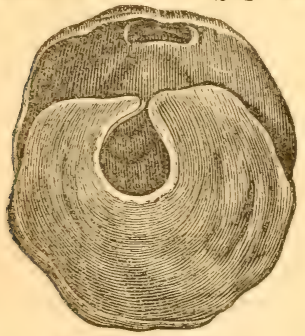

Fig. 93.-A.romi.

lusks are not adherent, and can even swim with considerable rapidity by suddenly closing their valves. The mouth is furnished with many branched tentacula, which lake the place of labial lamellie, and between the branchiæ there is a small oval foot. St. James' Pecten is found on the coast of France. The species of this genus are very nu. merous and are very generally difo fused.

The following genera are also placed among the oysters; Lime which are oval or oblong and somes

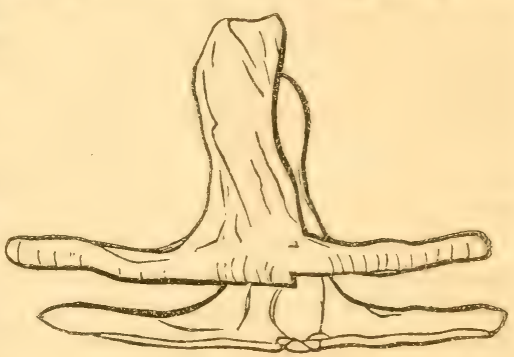

Fig. 92,- Mazleus.

alongside of the ligament, permitting the central part of the muscle to pass through it to be inserted into a plate, sometimes horny, sometimes stony, by aid of which the animal attaches itself :

12. Spondyus, in which the shell is foliated or even spiny, and on each valve at the hinge there are two teeth which are received into pits in the opposite valve:

11. What are the characters of the genus Ma'llous? (Malleus, Latin, a hammer.) What are the characters of the genus Ano'mia? (Anomia; from the Greek, $a$, without, and nomos, law; because not easly placed accor. ding to the laws of classification.)

12. How is the genus Spo'ndylus known? (Spondylus, Latin, a spindle, or shellfish.) 
13. Perna (fig. 94), in which the hinge is composed of several ligaments inserted into particular pits; besides a great many other shells, either recent or fossil.

Among the Ostracea provided with two distinct muscles, and the shells con. sequently marked, on the internal surface of each valve, by two irregular sur. faces (muscular depressions) corresponding with the in.

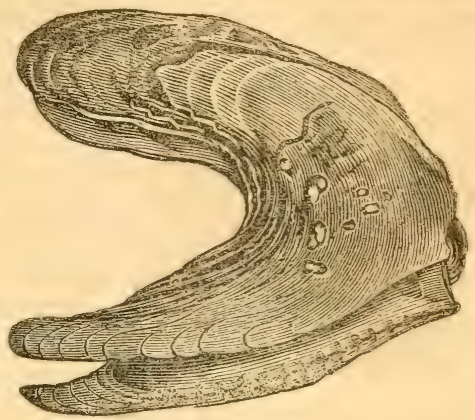

Fig. 94.-PERNA。 sertion of these organs, we will mention Etheria, Avicula, Pinna, Arca, and Trigonia.

14. The Etheria are very analogous to oysters : their shell is farge, inequivalve, very irregular, without teeth at the hinge and provided with a ligament, which is partly internal and partly external. They are very rare shells, and have been overlooked by travellers from being attached to rocks at considerable depths. They inhabit the East Indian seas.

15. The Avicule are recognised by their inequivalve shell, with a rectilinear hinge furnished with a narrow ligament, and

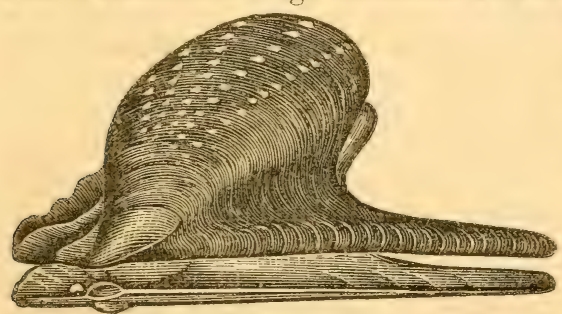

Fig. 95.-Aviculs. frequently elongated into wings at its two extremities ( $f i g \cdot 95)$. The body of these mollusks is very small and prolonged into a vermiform and coni. cal foot, and furnished with a byssus, for the passage of which there is a notch in the side of the shell. The anterior adductor muscle is extremely small and the labial appendages very large. 'These mollusks have

13. What is the genus Per'na? (Perna, Latin, a gammon of bacon, : shell-fish.)

14. What are the characters of the genus Ethe'ria? (Etheria, from the Greek, aithô, I shine.)

15. How is the Avi'cula recognised? (Avicula, from the Latin, avis, a bird; because, when the shell is widely open, it bears a remote resemblance to a bird with spread wings.) How does the genus Meleagri'na differ from Avicula? (Meleagri'na; from the Greek, meleng'ris, a guinea-hen.) 
been divided, perhaps without sufficient reison, into two genera, Avictla and Meleagriva, according as the shell is with

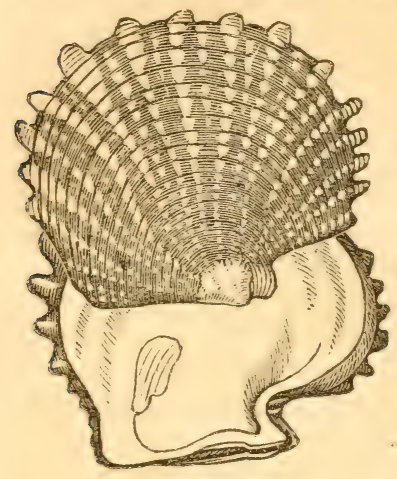

Fig. 96.-MELEAGRIN MARGARITIFERA. or without the wing-like prolongations, and the hinge is armed with a tooth or unprovided with a similar protuberance: the shell of the latter is nearly equivalve, and the passage of the byssus produces in each valve a notch. The Meleagrince are more scaly externally than the Aviculæ. Their nacre is sometimes very thick and very brilliant; and the extravasa. tion of the liquid destined for the periodical augmentation of the interior of the shell, frequently gives rise to isolated deposits of this beautiful nacre, forming pearls. The shell of the Pearl Oyster is nearly semicircular, scaly and greenish brown externally; it grows to considerable size, and is to be found on the coast of Ceylon, in the Persian Gulf, the Gulf of Mexico, and in many other localities, where it occurs in extensive beds, aitached by its byssus to submarine racks: it is the object of an active fishery.

16. Pearls, as stated above, are bodies of the same nature as the brilliant nacre lining the shell: they are composed of concentric layers of nacre very closely applied one over the other, like the coats of an onion, and are produced whenever this matter, instead of being spread out in thin layers over those already deposited, constitutes small isolated masses like little drops, or adhering to the shell by a mere pedicle. Their formation depends upon a kind of disease, or, at least, upon an anomalous activity of the secretory process which gives rise to nacre: hence every circumstance that stimulates this secretion, such as the presence of a grain of sand or other foreign body betwixt the shell and the mantle of the animal, tends to bring about this formation. Pearl Oysters are not the only mollusks that produce rearls. All shells that are internally nacreous may contain them. Patellæ, Haliotides, and our common mus. sels sometimes contain them, and it is not uncommon to find them in a sort of large mussel (Unio) which inhabits the great rivers of northern Europe and the United States; but the 
Meleagrinæ furnish the greatest quantity and yield the most beautiful pearls.

17. The chicf pearl fisheries are in the Gulf of Mamaar on the coast of Ceylon, in the Persian Gulf, the Gulf of Panama, and on the coast of California; but there are banks of Mcleagrinæ (pearl oysters) in many other localities, such as the coasts of Japan, Cumana, \&c. To obtain these precious mollusks, men accustomed to the exercise dive to the bottom of the sea and collect them at depths of from twenty to fifty feet. To accelerate his descent the diver seizes a stone (weighing from 15 to 25 pounds) with his toes, and on reaching the bottom he abandons the diving stone (which is drawn up by attendants in the boat, to be prepared to take him down again), clings to the ground, and begins to fill a net which he carries down with him for the purpose. When, from the necessity of breathing or fear of sharks, he wishes to ascend, he checks the cord of the net, which is insiantly feli by the attendants, who commence pulling up as fast as they are able; the diver remains with the net until it is so far clear of the bottom as to be in no danger of upsetting, and then cominences hauling himself up by the cord (hand over hand), which his attendants are likewise pulling; when by these measures his body has acquired an impetus upwards, he forsakes the cord and rapidly ascends to the surface, swims to his diving stone, and by the time the contents of his net have been emptied into the boat, he is ready to go down again. One diver will take up in a day from one to four thousand nysters. The diver seldom exceeds a minute under water; the more common time is from 53 to 57 seconds. In order that the banks may not be devastated, they are under regulation, and it is sup. posed that seven years are required for the oyster to attain its full size. At Ceylon the fishing season lasts from the middle of February to the end of March.

"During this period, the shores of Arippo are enlivened by crowds of people from all parts of the country; divers, boat-owners, speculators, and the curious, assemble to behold

'Pale glistening pearls, and rainbow-colour'd shells,'

while the lapidary attends with his wooden stand and bow, to drill the pearls and fit them to be strung, so soon as they are got out of the oyster, which, according to all accounts, is a tedious and rather disgusting operation. The oysters are put into pens, and there left until the animal matter becomes softened by putrefaction, when it is subjected to frequent washings, and the pearls shine forth, emblems of purity in the loathsome mass. Some are of a bluish, some of a yellowish, and some of a whitish lustre; each class finds a ready market among its admirers; in the East, the bluish and yellowish varieties are most prized, but in the eyes of the Christian fair the pure white shines brightest."-Ruschenberger's Voyage round the World. 
The annual revenue from the pearl fishery of Ceylon is estimated at about $\$ 80,000$.

18. The Prixe have two equal valves in form of a half-open fan, gaping and united by a ligament along one of their sides. A very large species is found in the Mediterranean, which lives half-buried in the sand, and anchored by its byssus, the fila* ments of which, being very strong, fine, and brilliant as silk, are employed by the inhabitants of some parts of Calabria and Sicily in the manufacture of precious stuffs.

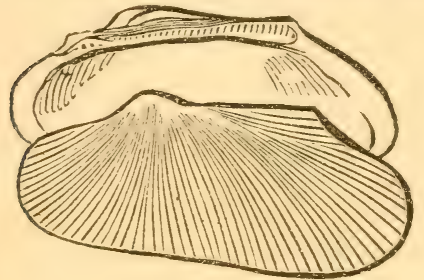

Fig. 97.-ARCA.

19. The ARce are dis. tinguished from all the preceding by their equi. valve shell. The hinge which extends along the side of the valves is studded with a great many little teeth, which fit into the intervals of those of the opposite side recipro= cally; in some, the Arca PROPERLY so CALLED ( $f i g .97$ ), the hinge is rectilinear, and the shell is longer in a direction parallel to this junction; in others, named Pecturculus (fig. 98), the hinge is curved, and the shell is lenticular in form. The first are met with near the shore in rocky situations, and are ordinarily covered by a hairy epidermis; the latter live in the mud.

20. Finally, the 'Trigonie, most of the species of which are fossil, are remarkable for their peculiar hinge; the right valve is furnished with two projecting plates, crenulate

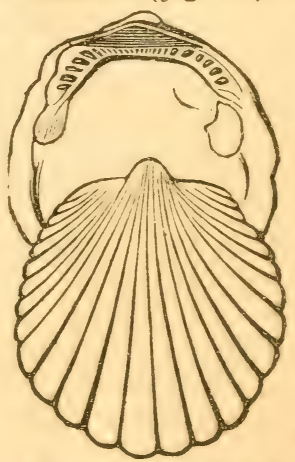

Fig. 98.-PECtunculus,

18. What are the characters of the genus Pi'nna? (Pinna, Latin, a fin.)

19. What are the characters of the genus Arca? What are the characters of the genus Pectu'nculus? (Pectunculus, Latin, the diminutive of pecten, a comb.)

20. What is Trigo'nia? (From the Greek, trigonos, having three corners.) 
on each face ( $f i g .99)$, and entering between four plates of the left (opposite) valve, likewise crenulated upon their internal face only. There is but one living species known, - Trigonia pectinata, - which in. habits the seas of New Holland; exter-

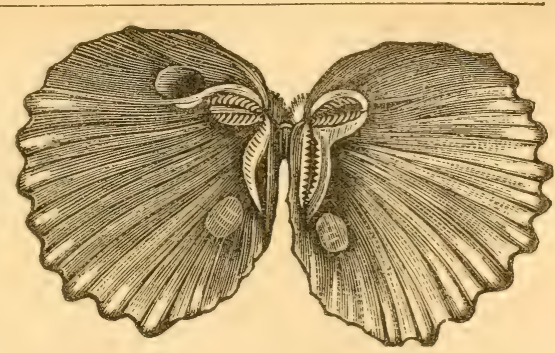

Fig. 99.-TRIGonia PECTINATA. nally, it has the aspect of Pecten without ears.

21. In the Family of Mrtrlacea, the mantle is widely open in front, as in the Ostracea, but there is a particular opening for the escape of excrement ; this orifice, however, is not prolonged into a tube, as in the families that follow, and there is no special aperture for the passage of water for the purpose of respiration. There is always a distinct foot, and the valves are approximated by the action of two adductor muscles.

The Mytilaceæ resemble each other sufficiently to be commonly known under the single name of Mussels, but they require, nevertheless, to be separated into several genera, the most important of which are, Mussels properly so called,-Mytilus,-Anodonta, and Unio.

22. Mussels properly so called-Mytilus-abound on the rocks of the coast of France and of other countries, where they live fixed by the byssus, and generally closely united to each other. Their shell is shut, and its valves, triangular in form, are equal, arched and united by a narrow ligament on the side of their acute angle. The mouth of the animal is situate near the summit of the shell, the opposite extremity of which gives passage to the byssus; the anus also is placed near the hinge; and opposite to this orifice there is a particular opening or small tube formed by the mantle; towards the round angle of the shell, where the water necessary for respiration passes, the edge of the mantle is fringed; and the foot is slender, cylindrical, and furnished behind with a silky byssus. Mussels are generally eaten as food, but they sometimes occasion a kind of poisoning, accompanied by very violent symptoms, occasionally followed by death.

21. What are the characters of the family of Mytila'cea?

22. What are the characters of the genus My'tilus? (From the Greek, mutilos, a mussel.) 
23. We distinguish those Mussels which have the hinge placed Iower, under the name of Moniouss, and another is called Lituopory, which has the shell almost equally rounded at both ends, aud excavates holes in stones, to which it was at first only suspended.

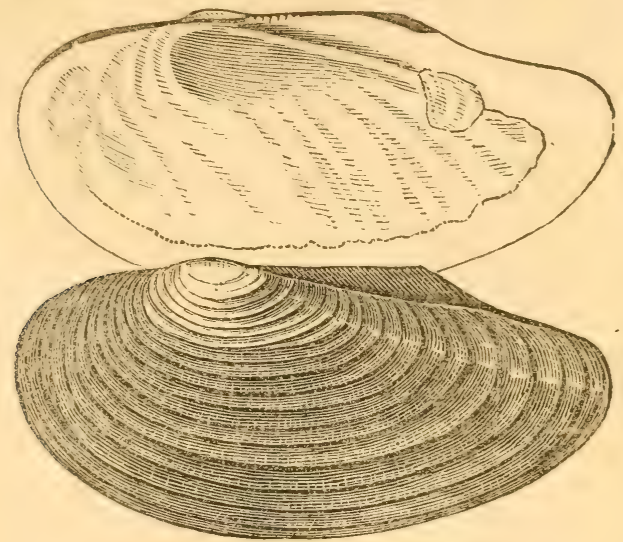

Fig. 100.-ANODONTA.

24. The Axodoxte live in fresh waters, and are recog: nised by theij thin shell, moderately inflated, oval, close, and without teeth in the hinge ( fig. 100); they want the byssus, and are provided with a very large foot, compressed and almost. quadrangular in form, by means of which they crawl on the sand or mud. A great many species are found in the great rivers of the United States.

2j. The Uxiones closely resemble the Anodontæx, but have a more complicated hinge, the right valve having a pit (fossette) into which a tooth of the left valve penetrates, presenting behind a long lamina, which, in its turn, is received between two laminæ of the opposite side. These mollusks also inhabit fresh waters, but prefer those which are rumning. A very great number of species are found in our IVestern waters, for the description of most of which we are indebted to the labours of Mfr. I. Lea, of Philadelphia.

23. What is the genus Litho'domus? (From the Greek, lithos, a stone, and the Latin, domus, a house.)

24. How is the genus Anodo'nta recognised? (Anodonta, from the Greek, $a$, without, and odous, in the genitive case, odontos, a tooth.)

25. What are the characters of the genus U'nio? (Unio, Latin, a pearl.) 


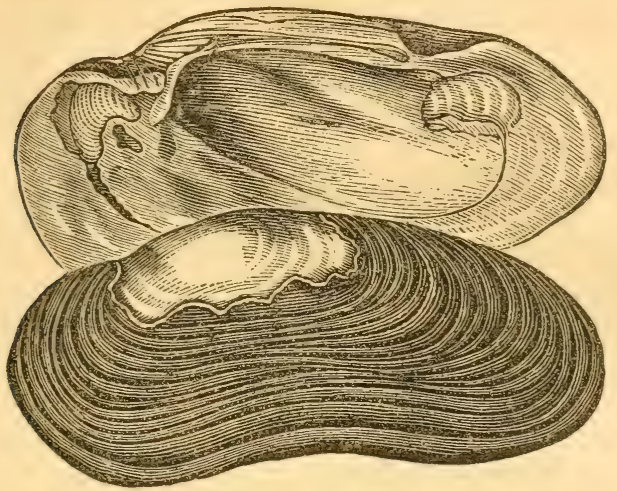

Fig. 101.-Unio.

We also place in this same group certain marine mollusks, which resemble the Unios in their organization and the general disposition of the hinge, but in which the beaks (summits) of the shell are more arched, and from which projecting ribs radiate towards the circumference; such are the genus $C_{A R}$ DiTA, the form of which is more or less oblong or cordiform (heart-shape); the Cypricardia, in which the tooth beneath the summit of the shell is divided into two or three; the CoRALLIOPHAGA, in which the shell is thin and the lateral plate much effaced, \&c.

26. In the Family of Ciramacea the mantle is closed and perforated by three openings only; through the anterior one passes the foot (fig. 102, $p)$; the next $(\boldsymbol{r})$ gives passage to the water necessary for respiration, and the third $(e)$ is for the expulsion of effete matters. As we have already stated, the last two openings are not prolonged into tubes, as in the next two families. And the hinge is very analo. gous to that of the Unios; for the left valve has a tooth near

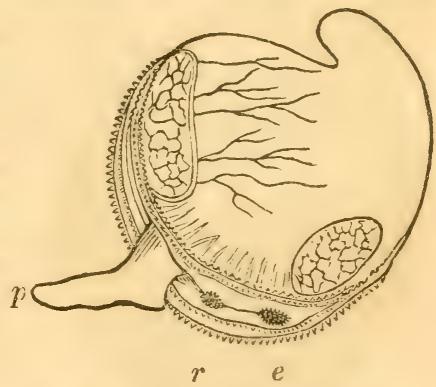

Fig. 102.-CHauA, without ITS SHELL. the summit, and further back, a projecting plate, which are re. ceived into fossæ (pits) in the opposite valve.

Explanation of Fig. 102.-A Chama divested of its shell to show the dis. position of its mantle: $-p$. the foot; $-r$. opening for respiration; $-e$. the opening for the passage of excrement. 
This family is divided into Tridacna, Chama, Isocardia, \&c.

27. The TrIDACN have an equivalve shell, which is elongate and gaping in front, or its edges are dentate (fig. 103).

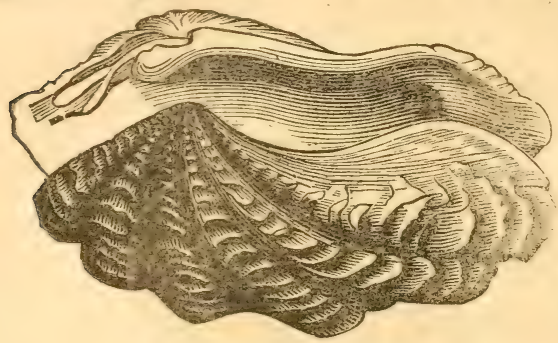

Fig. 103.-TRIDACNA.

Their internal orga. nization is remarkable in several particulars. The valves have only a single adductor muscle. The mantle is widely open in front, to give passage to the byssus, and a little beneath the an. terior angle presents another opening, by which water is conveyed to the branchiæ; and the third open. ing, which corresponds to the anus, is situate near the middle of the inferior border. To this genus belongs an cnormous

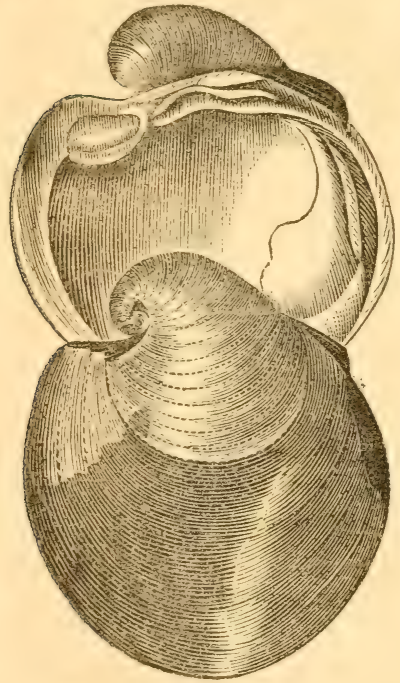

Fig. 104.-isocardia. shell of the Indian Ocean, known under the vulgar name of the Holy-water Pot; it adheres to the rocks by its byssus, which is so large sometimes that an axe is required to cut it, and the shell itself occasionally weighs over three hundred pouuds.

28. The Chara have an ir. regular, equivalve shell, which is usually lamellar and rough; they live attached to rocks, coral, \&c., like oysters, and they have a small foot bent like that of man (fig. 102).

29. The Isocardix (fig.104), on the contrary, have a free, regular, convex shell with spirally curved summits, divided anterior. ly. A large, smooth, red species, the Chama cor, inhabits the Mediterranean.

27. What are the characters of the genus Trida'cna?

28. How is the genus Chama distinguished? (Chama,-pronounced la'ma,-fiom the Greek, cha $\hat{o}$, I gape.)

29. What are the characters of the genus Isoca'rdia? (Isocardia, from the Greek, ine.. ithe, and kardia, a heart,-heart-shape.) 


\section{LESSON VI.}

Family of Cardiacea.-Cardium-Donax-Cyclas-Corbis -Tellina -Venus-Petricola-Venerupis-MIactra. Family of Inclusa.-Lutraria-Mya-Byssomia-Hiatella - Solen-Sanguinolaria-Pholas-Teredo-FistulanaGastrochana-Clavagella-Aspergillum.

Class of Mollusca Brachiopoda.-General CharactersLingulo-Terebratula-Orbicula.

Class of Mollusca Tunicata, or Acephala Nuda.-Biphora -Ascidia-Botryllus-Pyrosoma.

\section{CEASS OT ACEPHAIA, CONTMUTED.}

1. The Family of Cardiacea is characterized by having the mantle open in front, and prolonged posteriorly into two tubes, which are sometimes distinct, and at others united in a single mass; one of them ( fig. 105, r) serves for respiration, and the other $(e)$ for the passage of excrement.This mode of conformation is $p$ recognised in the shell by the impression made by the attachment of the edge of the

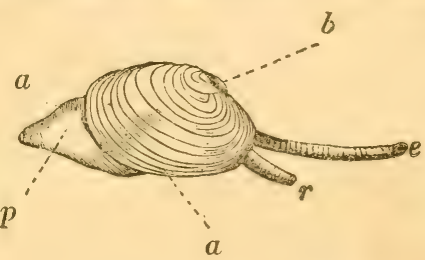

Fig. 105.-TELLINA. mantle, called the pallial line ( $f g .106, l$ ), which before

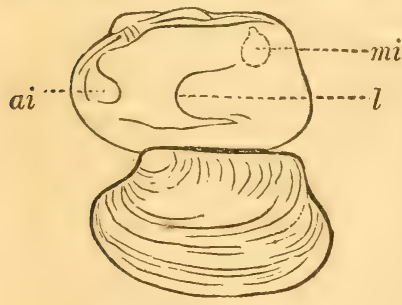

Fig. 106.-VENERUPIS. joining the posterior muscular impression or cicatrix (mi), curves more or less deeply inwards. In all these mollusks, there is a transverse muscle and a foot (fig. 105, p), which generally enables the animal to crawl. The species of Cardiaceæ that have long tubes, ordinarily live buried in the sand or mud.

Explanation of Fig. 105.-Tellina :- $a$. the shell ; - b, the hinge; $-r$, tube for respiration;- $e$. tube for excrement; $-p$. the foot.

Explanation of Fig. 106--Veneru'pis:-l. pallial line;-ai. anterior muscular impression; - mi. posterior muscular impression or cicatrix.

1. How is the family of Cardia'cea characterized? (Cardiacea, from the Latin, cardium, heart.) 
2. In this family we place Cardium, Donax, Cyclas, Corbis, Tellina, Lucina, Venus, Petricola, Mactra, \&c., genera which, for the most part, are very numerous in species.

3. The Cardia-Cardium-are chiefly characterized by the hintge, which consists of two small teeth in each valve, situate in the centre, and a projecting plate or tooth placed at some distance in front and behind. The shell is equivalve, convex, and furnished with ribs radiating from the summit towards the circumference. And when looked at from one side, its general form reminds us of that of a heart, from the manner in which the summits (beaks) of the valves rise up, and curve inwards towards each other.

4. The Donaces-Donax-have a hinge formed nearly like that of the Cardia; but their shell is flattened, nearly triangular, inequilateral, and the summits are nearly vertical. Several small species are found on the coasts of France, the shells of which are very pretty.

5. The Crclades-Cyclas-have the same hinge and are distinguished from the preceding by the rounded form of the shell, which is equilateral (that is, the two halves of the valve, situate on each side of a vertical line drawn through its summit, are alike), and striated transversely. One species, Tellina cornea, is common on the coast of France. The genera Cyrena and Cyprina belong to this group.

6. The Corbis are transversely oblong marine shells, which resemble the preceding in the hinge; their external surface is very regularly marked by iransverse ribs, crossed by diverging rays.

7. The Tellixe (fig. 105)-Tellina-closely resemble the Donaces; but they have the middle of the hinge armed with one tooth to the left, and two to the right. The shell is slightly gaping. Like the Donaces, they have two long tubes ( $f g .105$ ), which can be entirely concealed within the shell when the animal contracts. Both live buried in the sand and are found on the coast of France.

2. What are the principal genera belonging to the family of Cardiacea ?

3. What are the characters of the genus Cardium?

4. What are the characters of the genus Donax ?

5. How is the genus Cy'clas characterized? (Cyclas, from the Greek, aklos, $a$ circle.)

6. What are the characters of the genus Corbis?

7. How is the genus Telli'na characterized? 


\section{The Venus} $(f \mathrm{~g} .107)$ is re. cognised by the hinge, the anterior and posterior plates of which, instead of being separated from the middle tooth, as in the Cardia, $\& c$., are approximated in a single group beneath the summit. The shell

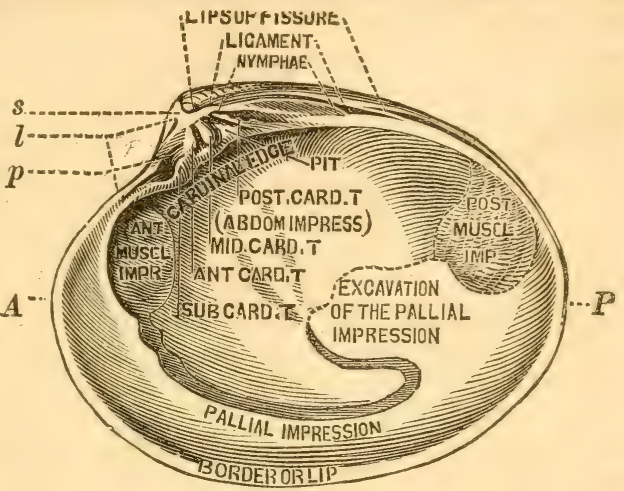

Fig. 107.-venus. is generally thick, moderately convex, and a little elongated The species of this genus are very numerous.

9. The genera Petricola and Venerupis (fig. 106) resemble the Venus very much, and have obtained their names from living in the interior of stones which they perforate.

10. The Mactre differ from other cardiaceæ in having an internal ligament, lodged in two pits in the hinge, corresponding

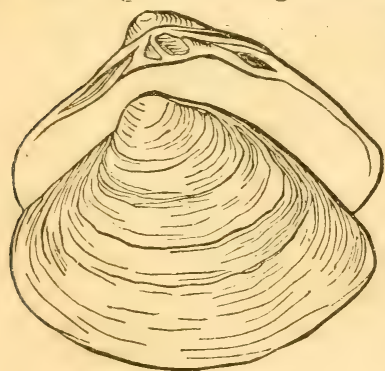

Fig. 108.-MACTRA.

with each other (fig. 108). There are some large species on our own coast.

11. The fifth and last family of testaceous acephalæ or INCLUsA, is composed of mollusks in which the mantle is only open at its anterior extremity, or near the middle, for the passage of the foot, and is prolonged posteriorly in a double tube; in other parts it is completely closed (fig. 109). The shell is always gaping at the

Explanation of Fig. 107.-Cytherea, or Venus ;-s. the summit or beak ;$l$. the lunule $;-p$. pit; $-A$. anterior, and $P$. posterior extremity of the shell.

8. What are the characters of the genus Venus ?

9. From what circumstance do the genera Petrico'la and Venerupis ob. tain their names? (Petricola, from the Latin, petra, a stone, and colo, I inhabit.-Venerupis, Latin, Venus, and rupes, a rock.)

10. How is the genus Mac'tra characterized? (Mactra, Latin, a trough.)

11. What are the general characters of the family of Inclusa? (Inclusa, Latin, enclosed.) 
extremities, and most of these animals live buried in the sand or mud; sometimes they excavate holes in stones or wood. They are divided into Mya, Lutraria, Anatina, Glycymera, Solemya, Byssomia, Hyatella, Solen, Psammobia, Pholas, Teredo, Fistulana, \&c.

12. The Lutrarie closely resemble the Mactræ; but their hinge is unprovided with lateral lamina, and their valves are very gaping, particularly behind, through which passes the thick fleshy cylinder formed by their double tube. A large species is found in the sand, at the mouths of several rivers in France.

13. In the Myæ there is a projecting plate in one of the valves and a pit in the other, joined by a ligament; the Anatrex have a small plate in each valve, giving attachment to a ligament; and the Solenre and Guycymere differ from the Mra in their external ligament.

14. The Brssoms, in place of living in the sand like the preceding, penetrate stones and corals, and attach themselves to them by the aid of a byssus. Their shell is oblong, without a distinct tooth, and gaping about the middle of the inferior edge, for the passage of the foot.

15. The Hxatelle have nearly the same general form; but the tooth of the hinge is more marked.

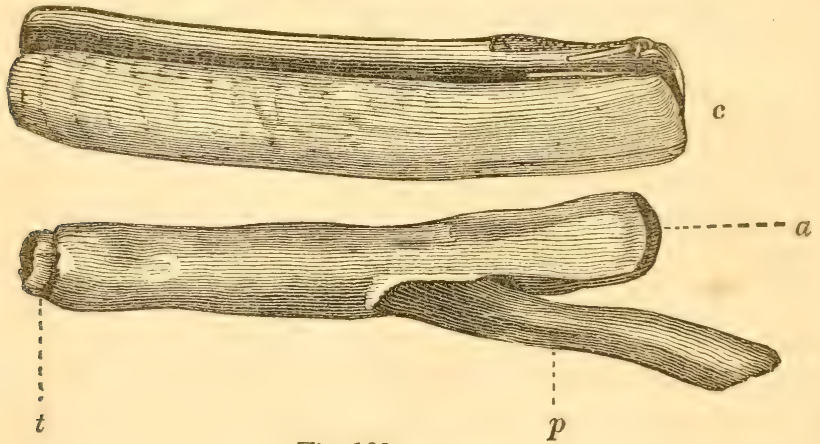

Fig. 109.- -soLen.

16. The Solexs, commonly called razor shells, lifnife handles (fig. 109), from the cylindrical and elongated form of their

Explanation of Fig. 109.-c. the shell;-a. the anterior extremity of the mantle $;-p$. the foot ; $-t$. the tentacles.

12. How is the genus Lutra'ria characterized?

13. What are the characters of the genus Mya ?

14. What are the characters of the genus Bysso'mia?

15. How is the genus Hyate'lla characterized?

16. What are the characters of the genus Solen? 
shell, have the hinge furnished with an external ligament, and armed on each side with two or three projecting and very decided teeth. Their foot is conical and is pushed out at the anterior extremity of the shell. They live in the sand, and bury themselves with great rapidity by the motions of their foot.

17. The Phozades are distinguishable from all the preceding by one or more calcareous pieces, situate between the two valves of the sholl, near the hinge. The valves, which are broad and convex anteriorly, are elongated on the opposite side, and leave betwixt them a great oblique opening at each end ; their hinge resembles that of the Myæ; their dnuble tube is not retractile and may be very much elongated. These animals inhabit tubes or long cells, which they excavate, either in the mud, or stones or wood. There are large species on the coast of France, in the West Indies, and on the coast of Peru.

18. The Teredrnes, or ship worms, are celebrated for the ravages they commit by boring into ships' bottoms, piles of dikes, bridges, \&c. These are mollusks with a very elongated and almost vermiform body, which is enveloped in a tubular mantle, open at the anterior and inferior part for the passage of the foot; it is provided posteriorly with two very short, distinct tubes, and its base is furnished on each side with a movable stony plate; the shell is composed of two rhomboidal valves, but is very small, and covers only a very small portion of the mantle. It seems that the animal, by moving the extremity of its shell like an auger, excavates, in submerged wood, the hole which serves as its abode, and, as it advances or buries itself deeper, it lines the excavation with a calcareous matter, so that in a short time it finds itself lodged in a stony tube, which at first might be mistaken for a second shell. It begins its attack upon wood when very young; hence the external opening of its gallery is very small, but it digs on until the termination of its growth, and progressively augments the size of its dwelling; the two tubes which occupy the posterior extremity of the mantle always remain near the

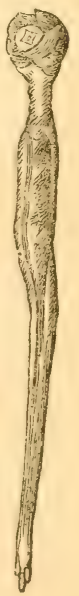

Fig. 110. TEREDO. opening of the gallery, and through one of them it causes the water necessary for respiration and nutrition to enter, for it

17 How is the genus Pholas characterized? (Pholas, from the Greek, pholeos, a lurking-place.)

18. What are the characters of the gdnus Teredo? (Teredo, Latin, a ehip-worm.) 
always remains in its hole, with the mouth down and the anus above. The common Teredo, which is about six inches long, it is said was brought from the torrid zone, but it is widely spread in the seas of France, and intests the dikes of Holland to such an exteut that its unperceived ravages have, more than once, been near producing terrible inundations. Tessels have

' been sunk by the holes bored through their bottoms by these animals. To guard against such accidents, is one among the rcasons why ships' bottoms are covered under water by thin sheets of copper.

19. The Fistudax also live buried in submerged wood or other analogrous substances, and also line the interior of their hole with a calcareous mortar which constitutes a tube, completely closed at the large end, having more or less resemblance to a bottle. Like the Teredines, they have externally a small bivalve shell and two plates, which may be regarded as analo. gous to the operculum pieces of the gasteropods. They inhabit the Indian Seas.

20. The Gastrocm.ex.e difler very little from the preceding; their shell, which is umprovided with teeth, is rery gaping in front, and their double tube, which can be retracted entirely within the shell, is susceptible of great elongation; they excavate holes in stones or masses of madrepore, and often line these holes with calcareous matter which, on becoming hard, constitutes a tube similar to that formed by the Teredo and Fistulana.

21. We also place in this division the Chavigetud and Aspergillix, which also construct a calcareous tube; in the first, one of the valves is clasped by the tube, while the other remains firee in its interior; and in the last, the tube has, at its closed extremity, a disk perforated by a great many little tubelike holes, an arrangement which has obtained for it the name of "watering-pot shell."

\section{CIASE OF BRACKIOPOD MIOIIUSIS.}

22. These mollusks are very analogous to the common acephalic; they are also provided with a two-lobed mantle,

19. What are the characters of the genus Fistulana? (Fistulana, from the Latin, fistula, a pipe.)

20. What are the cliaracters of the genus Gastrochæna? (Gastrochæna, from the Greek, gaster, belly, and chainô, I gape.)

21. What are the characters of Clarigella? (Clarigella, from the Latin, clavis, a nail or spike.) How is the genus Aspergillum distinguished? (Aspergillum, Latin, a watering-pot.)

22. What are the characters of Brachiopod mollusks? (Brachiopod, pronounced brak-e-opod, from the Greek, brachion, an arm, and pous, foot.) 
and a bivalve shell; they have no foot, but in place of it, two fleshy arms furnished with filaments, and susceptible of being unfolded externally, or drawn within the shell by folding spirally ( $f i g .111, a)$; their branchiæ are not distinct from the mantle, and the mass formed by their viscera is very small. They are unprovided with organs of locomotion, and live attached to submarine bodies.

The principal genera composing this group, are the Lingula, Terebratula, and Orbicula.

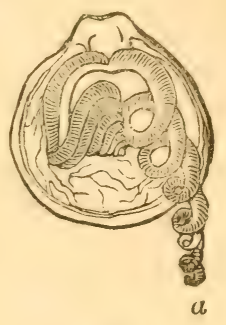

Fig. 111.

TEREBIATULA.

23. The Lingula are provided with a long fleshy peduncle, one extremity of which is generally attached to the rocks these animals ordinarily inhabit, and the other is furnished with two oblong, flattened valves. Their arms, which are inserted in the sides of the mouth, are very long; and the branchial vessels are distributed on the internal face of the mantle, and there form on each side a series of small parallel folds. They are found in the Asiatic Seas.

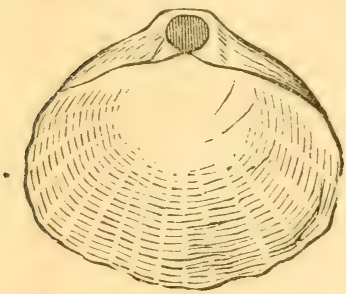

Fig. 112.-TEREBRATULA.

24. The Terebratule have two unequal valves joined by a hinge, and one of them (fig. 112) has a hole through its summit for the passage of a fleshy peduncle, by means of which the animal attaches itself. Their branchiæ are less distinct than in the Lingulæ, and consist simply of a vascular net-work spread over the internal face of the mantle; but their muscular system is more developed, and there is found in the interior of the shell a small solid frame (fig. 113), the structure of which is sometimes very complicated; its chief uses are to afford attachment to muscles, and to assist in separating the valves. Some living Terebratulæ are found in the South Seas; but they abound most in the fossil state; and are

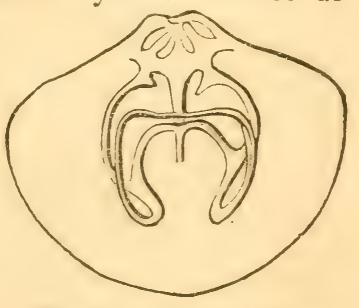

Fig. 113.-TEREBRatula.

23. What are the characters of the genus Lin'gula? (Lingula, Latin, a atchet, or tongue of a shoe.)

24. What are the characters of the Terebra'tula? ('Terebratula, from the Latin terebro, I bore.) 
found in the most ancient fossiliferous strata or layers of the earth's crust.

25. The OnBicule have one round, conical valve, like the shell of the Patellæ (fig. 78, p), while the other is flat and perforated for the passage of a very small peduncle; the conformation of their arms, and the arrangement of their branchial vessels, very closely resemble those of the Terebratulie.

\section{CIASS OF IEOIIUSCA TUNICATA, OR ACIPFAIA. WITITOUT SEIEIS.}

26. The acephalous mollusks without shells, which have also been called Tunicata, differ much from all the preceding in their general form, as well as in many important particulars of their organization. Their mantle consists sometimes of a simple tube open at both ends, and sometimes of a sack; their branchire present different forms, but always very little developed, and ar: never divided into four leaflets or laminæ, as in the ordinary acephalæ, or lamellibranch testacea, among which they are placed by many authors; they have neither foot nor arm; and they evidently form the connecting link between the mollusks we have just described and inferior animals which are ranged among the Polypi in the branch of Zoophytes.

27. The Brphoræ of all the Tunicata possess the most complicated organization. Their mantle is tubular, furnished with transverse muscular bands, and enclosed in a transparent, car-

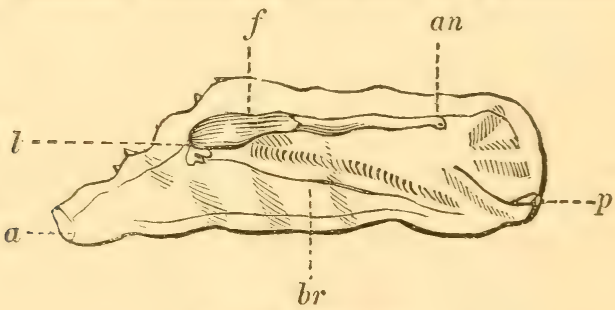

Fig. 114. - BIPHORA.

tilaginous envelope; both extremities are open, and the posterior orifice $(p)$ is supplied with a little valve, so arranged as to admit the water, but not to allow its escape; the mouth

Explanation of Fig. 114.--a. the anterior opening of the mantle;-b. the mouth; $-f$. the liver, \&c.;-an. the anus ; $-b r$. the branchiæ ; $-p$. posterior opening of the mantle.

25. What are the characters of the genus Orbicula?

26. What are the general characters of the class of Tunicata?

27. What are the characters of the genus Biphora? 
is placed in the tube formed by the mantle towards its anterior extremity; and the heart, liver, and other viscera, are united into a small mass near this opening; the anus is situate far behind, and the only branchia, which is formed of a membrane transversely plaited, extends obliquely from the superior to the inferior parietes of the pallial cavity; the water which traverses this tube, consequently laves the respiratory apparatus, and the animal moves by forcibly expelling it from the side of the mouth: hence, we see it must necessarily swim backwards. When full grown, these mollusks are free; but at birth they are fre. quently united to each other, forming a long chain, and swim in this manner for a long time; it seems that the individuals thus united, after becoming free or separated, produce young, which are not joined together in a chain as just described, and differ from them in form, and that the young arising from the last are united and similar to the first; so that in these singular animals there is the most remarkable alternation, the same form and the same mode of existence not being transmitted from one generation to the other, but constantly returning to the second generation.

The Biphoræ are found in the Mediterranean, and in the warmer-regions of the ocean; they frequently emit a phosphoric light.

28. The simple Ascidiz cannot move like the Biphoræ, but live attached to rocks; their mantle is in the form of a sack, with two orifices, and the interior of this cavity is lined with a net-work composed of the branchial vessels; the mouth and the little bag or sack containing the viscera, are attached to the bottom of the great branchial cavity, and the anus is found near one of its openings.

29. Other Tunicata, closely resembling the preceding in their organization, live united in a common mass, and for this reason they are designated under the name of Ascidia composita or Aggregata. A gelatinous or cartilaginous tissue encloses a great number of these little beings, the surface of which presents a multitude of six-pointed stars formed by their openings; their propagation seems to be effected in two ways; sometimes the mass grows by the development of reproductive buds in this common tissue, sometimes the young formed in an ovary are expelled externally, and sivim about free or separately for some time, until they become attached to some submarine body, where they establish a new colony.

28. What are the characters of the genus Ascidia? (Ascidia, from the Greek, askos, a bottle or pouch.)

29. What is meant by the Aggregata? (Aggregata; Latin, gathered together.) 
30. We give the name of Botrulus to sinall aggregated Tunicata of an oval form, which differ little from the preceding, except their branchial sack is open at both extremities, and the anal orifice tcrminates in a central cavity, around which ten or twelve of these mollusks are grouped like the rays of a star.

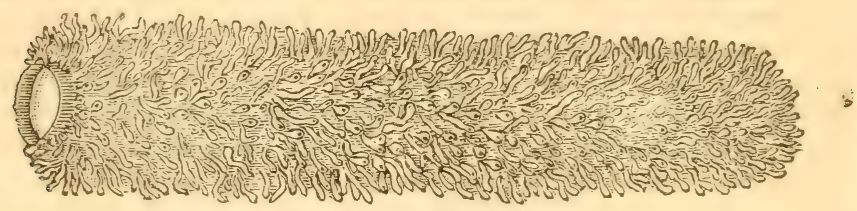

Fig. 115.-PYROSOM.

31. The Pyrosore unite in greai numbers, forming a large hollow cylinder, open at one end and closed at the other, which swims in the ocean by the alternate contraction and dilatation of the animals that compose it. In their individual organization they are similar to the preceding.

\section{OF THE PARTS OF SHELLS.}

We have now brought our history of the Mollusca to a close; but with the view of imparting clearer notions on the subject of Conchology, or History of Shells, we shall add here a few words in rolation to the parts of shells. It is absolutely necessary to understand these parts, before we can comprehend the descriptions given by conchologists, or be able to describe shells in such a way as conchologists can recognise them.

The most simple form of a shell is the cone ( $f g$. 70 , page 57). The apex of the cone is oblique and excentric. In the Limpets (Patella), Argonaut, and Nautilus, the apex is directed Eowards the head, but in most other mollusks, towards the opposite extremity of the body.

A shell may consist of one piece, as in the inopercular univalves-that is, univalves without an operculum or door.

A shell may consist of two pieces, as in the opercular uniralves (univalves with an operculum), and in most biralves.

A shell may consist of three pieces, as in the Terebratula (figs. 112 and 113, page 89).

A shell may consist of four or more pieces, as in some of the Pholades.

A shell may consist of many pieces, in which case it constitutes a multivalve, as the Chiton (fig. 79).

30. What are the characters of the Botryllus. (Botryllus, from the Greek, botrus, a bunch of grapes.)

31. What are the characters of the genus Pyrosoma? (Pyrosoma, from the Greek, pur, fire, and soma, body-fire-bodies ; so called from possessing the faculty of emitting light.) 
The univalve shells are much more numerous than any others, both in genera and species; and it requires a considerable de. gree of attention to discriminate many of the species, as they run into each other so much.

In the examination of univalve shells, the general outline or contour of the whole shell is the first particular to be attended to, as this leads to those distinctions necessary in the definition of simple, spiral, or turbinated shells, or more strictly, according to the Linnean method of discrimination, univalves with a regular spire, and those without a regular spire. Univalve shells are classified principally from the shape of the aperture, taken in conjunction with the general shape of the shell; from the spire being lengthened or depressed, being with or without a canal, the length of the beak and its direction, together with the particular form of the outer or external lip: the colour of shells only serves as a specific distinction, and, even in this respect, cannot in all cases be depended upon, although, in others, it is an unvarying test. The particular manner in which the spots are disposed, frequently characterizes species.

Apex, is the summit, tip, or highest part of a shell $(f i g .116)$.

Base, is the opposite extremity from the apex $(f i g .116)$. In shells with a beak or rostrum (as the Murex, fig. 64), it implies the tip of such beak; in shells without a beak it is understood to be the lower part, as before mentioned, opposite the apex. In the Patella, and some others, the base of the shell is that part on which it rests when it is laid on its mouth; in the Teredo, and similar shells, it is the wider end.

Body of the shell, is the first or lower whorl of the spire, in which the aperture is situated; this whorl is generally longes than the others ( fig. 18).

Front of the shell, is that side where the apcrture is situated.

Back of the shell, is the opposite side to that in which the aper ture is placed.

The venter or belly, is the most prominent part of the lower whorl or body, generally situated in the vicinity of the lip over the aperture, and formed by the convexity of the aperture. In general this term is only made use of in describing shells whose body is large in proportion to the size of the spire (figs. 52 and 59).

Sides of a shell, are the extreme edges of the sholl, when viewed either in front or from the back. The right side is the one next the observer's left hand, when the shell is viewed in front; and the side with the aperture in it, is the left side.

The conical univalve shell is generally spirally convoluted; sometimes, as in the nautilus (figs. 15 and 16), in the same 
plane, but more usually in an oblique direction. As a general rule, the spiral univalve, if viewed in

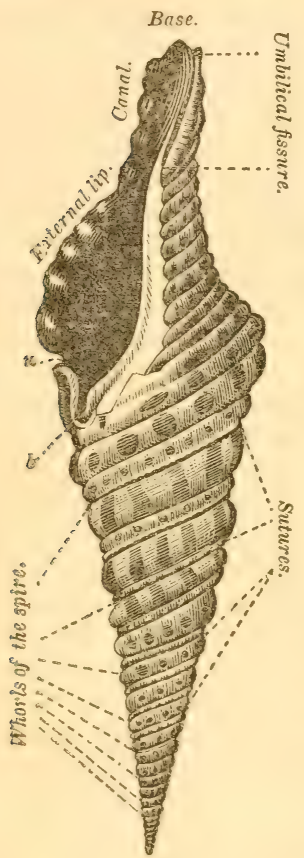

Apex. the position in which its inhabitant would carry it, if moving forwards from the observer, is twisted, from the apex downwards, from left to right, the spire being directed obliquely towards the right. The annexed figure (fig. 116) shows the involutions or whorls of the spire of the Pleurotoma. In some genera, for example, Clausilia (from the Latin, clausus, shut, fig. 25, page 40) and Physa (from the Greek, phusa, a bubble, fig. 30 , page 42 ), the shell is twisted in an opposite direction: such shells are called "perverse," or "sinistral."

The aperture or mouth, is that part of the lower whorl or body through which the animal protrudes itself. This is one of the principal means of distinguishing the genera of univalve shells, and it varies much in its form; some apertures are rounded (figs. 43 and 46); others semilunar (fig. 55); others angular (fig. 37), \&c. Some apertures have a canal at their base (figs. 63 and 116), and others are without it (fig. 51). In various genera, the aperture extends the whole length

Fig. 116.-PLeURotoma. of the shell, as in Ovula ( $f g .68$ ), Cypræa, and some of the Cones wit? depressed spires ( $f g .70)$. In several individuals, the aperture is either entirely open, or closed by an nperculum or door, which is usually affixed to the foot of the animal.

When without a notch or canal, the aperture is said to be entire (fig. 51). The aperture has two lips or borders; the intcrial lip, or border, is on the side of the aperture, formed by the columella, and the externul, or outer lip, or border, is opposite, as in the Pleurotoma (fig. 116); the letter $b$. indicates the pallial notch; $n$. notch of the syphon.

Canal, or gutter ( $f g .116$ ), is the space or hollow, formed by the prolongation of the two lips of the aperture. Some shells have two canals, one situated at the point where the outer lip and body join. 
Beal: or rostrum, is that lengthened process in which the canal is situate. This process is not so conspicuous in some of the species of Voluta, but is more marked in the genera Murex, Fusus, \&c.

The columella or pillar, is that process which runs through the centre of the shell in the inside, from the base to the apex, and around which the whorls or wreaths of the spire are wound (fig. 19, page 34). When the columella is marked by ridges or folds, as in Auricula ( fig. 31) and Oliva ( fig. 6 $\overline{7}$ ), it is said to be plicated or plaited, but when it is smooth, as in $f \mathrm{~g} .116$, it is simple.

Pillar lip, is a continuation of the glassy process with which the aperture is lined, and expanded on the columella ( figs. 58 and 66). It is also called the inner or internal lip ( $f i g .116)$.

The outer lip, or external border, is the expansion or continuation of the body of the shell, on the left margin of the aperture, and is also lined with the glossy process of the aperture (fig. 116).

Spire consists of all the whorls of the shell except the lower one, which, as before observed, is termed the body of the shell. This spire is a prominent feature of the univalve; and upon its being elevated, depressed, \&c., depends much of the generic and specific definition of these shells.

It is a remarkable circumstance, that many of the young shells have not the same number of wreaths as the adults; from which it would appear, that the part of the animal nearest the apex never increases in size. The number of wreaths cannot, at all times, be depended upon. A full-grown shell may, however, be known from the outer lip, which has generally an unfinished appearance in young shells. Indced, in all the land and fresh-water shells, it is a distinct criterion, as they are never complete in the form of the outer lip, till full-grown. 116).

Whorl is one of the wreaths or volutions of the shell ( $f g$.

Depressed spire is when the spire is very flat, as in the shells of the genus Planorbis (fig. 29, page 42).

Involuted spire, is where the spire is concealed in the inside of the first whorl or body, as in some of the Nautili, Cyprææ, Ovulæ, \&c. (fig. 68).

Suture of the spire, or whorls, is a fine spiral line or seam, formed by the joining together of the whorls; it is sometimes crenulated, undulated (waved), or sulcated (grooved), and not unfrequently elevated or projecting ( $f \mathrm{ig}$. 116).

Reversed, or heterostrophe spire, is when the volutions of the spire revolve in the same manner as the common corlsscrew, or 
when the aperture is placed downwards, the nature of the spire runs upwards from the right hand to the left ( $f i g .25)$.

Chambers are the cavities, divided by partitions at regular or irregular intervals, as in the Nautilus (fig. 15, page 30 ).

Umbilicus is a circular perforation in the base of the lower whorl or body. (See page 38).

Sub-umbilicated shells, are those which have the umbilicus covcred, in a greater or less degree, by a thin process; which, in some, almost entirely closes the aperture or mouth. This character is most commonly to be met with among species of Buccinum and Murex.

Umbilical fissure, is a groove extending from the umbilicus (fig. 116).

Shells which have no umbilicus are termed imperforate.

Siphunculus (little syphon) is that small round perforation which forms a communication between the chambers in the Nautilus, and penetrates through the whole spire of the shell (figs. 15 and 16).

Varices are transverse ribs which cross the whorls of shells in some species of Buccinum, Murex, \&c. Varices are formed by the periodical growth of the shells, these being the margin of the outer lip, to which the animal has attached its periodical enlargements ( $f g .46)$. In some species they have more the form of sutures than ribs; this is owing to the margin of the outer lip being but slightly developed.

Ribs are those longitudinal and transverse protuberances which are in many of the univalve shells (fig. 46).

Tceth of univalves, according to Colonel Montagu, are not properly tooth-shaped protuberances, but are fine white laminæe or ridges, running spirally backwards, in a direction parallel to each other; those on the exterior lip may, in most instances, be traced through the outside of the shell, and are nearly alike in length (figs. 24, 25 and 42).

Epidermis is a skin, or cuticle, covering the exterior surface of many shells, destined by nature to protect their surface from being injured.

True bivalve shells are peculiar to the acephalous mollusca; and their presence is constant, although they are in a few instances too small to cover the whole body, and in the shipborers (Teredo) exist only as small instruments, limited to the function of excavating the burrows inhabited by these mollusks. But all the species, in which the bivalve shell is inadequate to the protection of the whole body, derive extrinsic defence by burrowing in sand, or stone, or wood; and they also commonly line their burrows with a layer of smooth and compact cal. 
careous matter, forming a tube. This calcareous tube, in some cases, is of considerable size and thickness. In the Clavigella one valve, and in the Aspergillum both valves, are soldered to this tube, which, in the latter, presents a peculiar modification of its exposed extremity, which resembles the end of the spout of a watering-pot. No two shells can present a greater contrast than do those of the Placuna and Aspergillum; yet the organization of their respective constructors is essentially the same. In a classification of shells, the calcareous tubes of the Dentalium, Serpula, Aspergillum, Vermetus, \&c., would be associated in the same general group: but it needs only to observe how these products of animals, belonging not only to different classes, but to distinct primary divisions of the animal kingdom, are arranged in the cabinets of collectors, to be convinced that Conchology as a classificatory science, apart from Malacology (the science of mollusks), no longer exists.

With regard to the structure and physiological relations of bivalve shells, it may be observed, first, that in all acephalous mollusks which breathe by distinct lamellated gills (branchiæ), - Lamellibranchiata,-one valve corresponds to the left, the other to the right side of the animal; but in the brachiopodous bivalves, one valve is applied to the ventral, and the other to the dorsal aspect of the animal.

In all the lamellibranch bivalves which are free, the two valves are symmetrical, and the shell is termed equivalve; in all those which adhere by one of their valves to foreign bodies, this valve is deeper and larger than the unattached valve; such shells are termed inequivalve. Of those acephalans which are attached to foreign bodies by means of a byssus, some, as the Tridacna (fig. 10:3), are equivalve, and both valves are notched, to form the hole for the passage of the byssus; while others, as the Pecten (fig. 91), and Avicula (fig. 95), are inequivalve, the byssus passing through a groove in the right valve.

If the shell of the common cockle be examined, cach valve will be seen to be produced into a conical prominence bent towards, and nearly meeting at, that part by which the valves are joined together. These prominences are termed the umbones, or sometimes beaks. The apex of the umbo corresponds to the apex of the univalve shell, and is the point at which the development of the bivalve commences. When the apex is directed in the transverse plane of the shell, and so placed, that a division of the shell in that plane through the apices shall divide the valve into two equal parts, the shell is termed equilateral ; of this form the Pecten (fig. 91) is an example, 
When upon a similar division, a slight difference is observed in the two valves, the shell is termed subequilateral; but where the difference is well marked, it is an inequilateral bivalve (fig. 117). When the apex is bent, as is commonly the case, out of the transverse plane, it is always directed more or less towards the anterior part of the shell; if such a bivalve shell as the Cytherea, or Isocardia, be held before the observer, with the umbones directed forward, and the hinge above,-in the position, in fact, in which the living animal would place itself if it were creeping forwards from the observer, - the right valve will of course correspond with the right hand of the observer, and the left with the left.

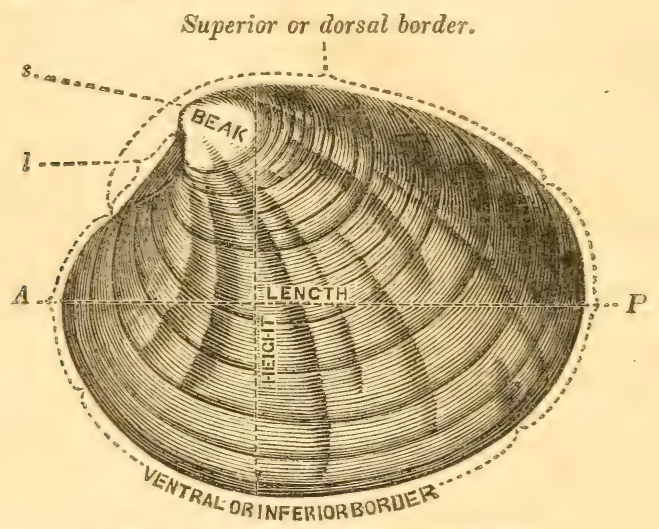

Fig. 117.-LEFT VALVE OF A CYTHEREA.

The annexed figure (117) represents the left valve of : Cytherea,-the common clam belongs to this group, and would answer our purpose as well. You see that the superior or dorsal margin is on the side where the hinge is placed, and the ventral or inferior border opposite to it; $\boldsymbol{A}$, is the anterior margin or slope; $P$, the posterior margin or slope; the umbo is marked "BEAK," and $s$, points to the summit or apex of the beak; l, shows the situation of the lunule. Now, if a bivalve in which the apices have a spiral twist, as in the Isocardia ( fig. 104), be placed in the above position, and compared with the urivalve shell of the Purpura, it will be seen that the left valve corresponds with the ordinary or dextral spiral univalve, and the right valye to the perverse or sinistral univalve.

When the circumference or margin of one valve fits exactly, at every part, that of its fellow, it is said to be "regular" or "entire;" but if it be notched at any part, so as not to come 
in contact with the corresponding part of the opposite valve, it is "irregular," or emarginate.

Besides the parts mentioned, we shall find in most cases, anterior to the apices of the beaks, a depression of variable extent and depth. 'This is the lunule (fig. $118, l$ ): it may be cordiform, of crescentic, lanceolate (oblong, and gradually tapering towards each extremity), oval, deep, superficial, \&c. Behind the beaks is another depression, longer and narrower than the lunule, and which is called the fissure $(f)$, and its margins are named lips of the fissure (lf). Behind the fissure there is sometimes a small depression called the suture: $(s)$. The general more or less convex surface of each valve is called the "venter," or belly, which terminates in the limb, circum.

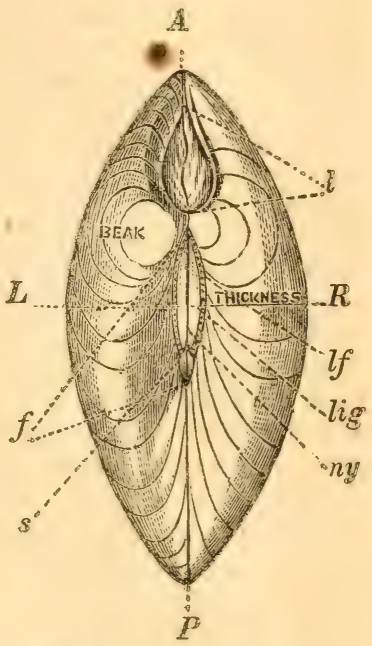

Fig. 118.-CYTHKRE. ference or margin. In the figure (118), the letters designate parts, as follows: $\boldsymbol{A}$, anterior slope; $\boldsymbol{P}$, posterior slope; $\boldsymbol{L}$, left valve; $\boldsymbol{R}$, right valve; $l$, lunule; $f$. fissure; $l f$, lips of the fis. sure; $s$, suture; $l i g$, ligament ; $n y$, the nymphæ.

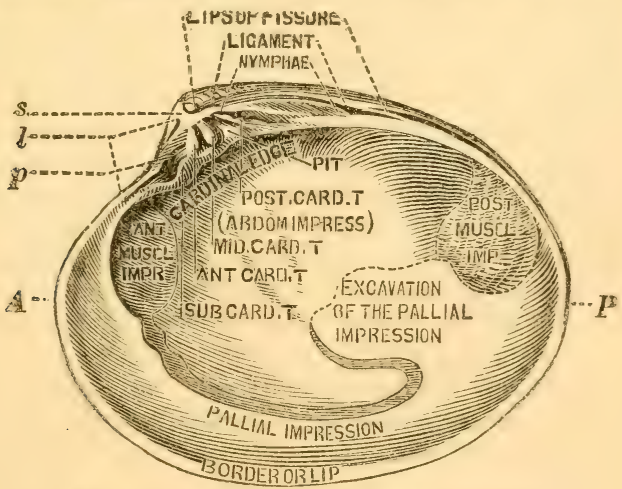

Fig. 119.-Right valve of a Cytherea.

The most important part of the margin is that which is 
modified to form the joint or hinge upon which the two valves open and shut. This part is called the "cardinal edge" ( $f i g$. 119), and generally presents certain prominences and depressions; the projections of one valve interlocking with the depressions of the other. "The projections, or " teeth," together with the cavities, or "cardinal pits" $(p)$, are very regular in their formation in each genus and species of bivalve, but what is of more importance is, that every modification in the structure of the hinge is generally found to coincide with some recognisable and more or less important difference in the organization of the soft parts; so that conchologists have justly attached great value to the characters derivable from the hinge, especially for the purpose of generic distinctions. When the teeth are situate beneath the apex $(s)$ or centre of the hinge, they are called cardinal, or primary; when they are removed froin the centre of the hinge, they are named lateral teeth; when two only are present, one is called anterior, the other posterior; when there are three, they are dis. tinguished respectively as anterior, median or middle, and posterior teeth; but when the hinge is composed of a great number of tecth, it is said to be "serial," as in Arca (fig. 97); some hinges have no visible teeth, and are termed inarticulate.

The direct medium of union of the two valves is a dense fasciculus (bundle) of elastic fibres, generally of a brown colour, called ligament, or elastic ligament. The fibres of this part are attached by their extremities to the two valves, which, in most cases, present a particular depression for their reception. The ligament is always so long as to prevent the actual closing of the valves, except when its elasticity is overcome by a certain force, as by that of the contraction of the adductor muscle or muscles: thus, the inorganic power of elasticity is made the direct antagonist of a vital and muscular contraction; and as the open or expanded condition of the bivalve shell is that which the exigences of the animal most constantly require, it is assigned to a force which can act without ever causing fatigue, while the occasional or protective action of forcibly closing the valves, is due to an ac. tion under the immediate control of the will or instinctive sensa. tion. The modifications of the internal surface of a bivalve shell are caused by the structure of the animal inhabiting it: hence, they afford the characters by which the habits of an ex. tinct genus may be to a great extent determined.

These modifications are marked on the last figure.

The pallial impression shows the development of the muscr. lar margin of the mantle. 


\section{GLOSSARY.}

\section{CON CHOLOGY.}

ABDO'MEN. - The belly; the cavity which contains the stomach, liver, \&c.

ABDo'MINAL_-Belonging or relating to the belly.

ACE'PHALA (a-ke'f-ala.) - From the Greek, $a$, without, and kephale, head,-without a head. The Latin word animalia, animals, is understood; therefore, acephala means animals without a head.

ACE' Phale (a-ke'f-alay),-Latin. Plural of acephala.

ACe'phalous (a-ke'f-alous). - Head. less; belonging or relating to acephalæ.

ACETA'bulife'ra. - From the Latin, aceta'bulum, a little cup, and fero, I carry. Applied to those cephalopods that have cups or suckers on their arms or tentacles.

Achatr'na (akaténa). - From the Greek, achates, agate. Name of a genus of terrestrial gasteropods, sometimes known as the agate snails. All the species of this genus are ovi'parous, and one, the Achatina zebra, figured on page 41, lays eggs with a hard, white shell and as large as those of a sparrow.

ADdu'ctor (muscle).-From the Latin, addu'co, I draw towards. The muscle which draws the valves of a bivalve shell towards each other, is so called.

$\mathrm{AD}^{\prime}$ NATE.-Adhering or growing together.

Agglu'tinans, - Latin. Glueing; a gasteropod which has the faculty of causing other species, or parts of shells, to adhere to it, is so named.

Aggrega'ta. - Latin. Gathered together.

AgGrE'stis.-Latin. Rural, wild.

AKE'RA,-From the Greek, $a$, with. 9 * out, and keras, horn,-hornless Name of certain mollusks that have very short tentacles, or none at all (page 64).

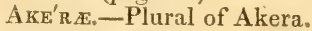

Ala'TED.-Winged.

Alimen'tary (canal).-The intestinal tube is so called because it is the medium through which food is conveyed into the body.

Alu'co. - Specific name of a shell (page 54).

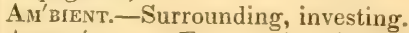

Ambre'tre. - From the French, ambre, amber; name of a shell supposed to resemble amber (page 41 ).

An'mon.-From the Greek, ammos, sand. Name of a heathen divinity whose temple was in the sands of the desert.

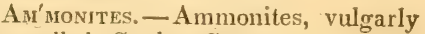
called Snake Stones, are fossil shells found in the stratia of the secondary formation, varying from the size of a bean to the dimen. sions of a coach-wheel. Their name is derived from their resem. blance to the horns on the statue of Jupiter Ammon (page 31).

Anpulia'ria,-From the Latin, am pulla, a bottle or jug; any thing puffed or swelled out.

Ampulla'Ris.-Plural of ampullaria. Ans'tifa.-From the Latin, anas, in the genitive case, anatis, a duck, and fero, I bear; a genus of bra. chiopod mollusks. It was for a long time believed that certain ducks were derived from the metamorphosis of these animals; and for this reason they were called anatifa.

Anati'na.-Name of bivalves which resemble the Solens (page 86). 
geion, a vessel, and stoma, mouth (page 56).

Anodo'nta. - From the Greek, $a$, without, odos, in the genitive, odontos, tooth - without teeth. Systematic name of a kind of musscl, the shell of which is without teeth.

Anodo'nte.-Plural of Anodonta.

stNo'sin.-Greek, $a$, without, and nomos, law. Systematic name of certain mollusks (page 74).

Anome.-Plural of Anomia.

A'Nus.-Latin. The inferior opening of the rectum for the passage of excrement.

Aor'ta.-The principal artery of the body is so called.

Aor'sic:-Belonging or relating to the aorta.

APERTURE.-The mouth or opening of the shell.

APEx.-The tip or point of the spire of a shell.

Aply'sia.-From the Greek, aplusia, uncleanness; that which cannot clean itself. Systematic name of Sea-hares, to which the ancients attributed many fabulous properties.

Aply'sre.-Plural of Aplysia.

Apparatus,-Latin ; formed from ad, for, and parare, to prepare. A collection of organs or instruments for any operation whatever.

Aqun'tica. - Latin. Aquatic; beionging or relating to the water.

AR'CA.-Latin. A chest, an ark or coffer. Systematic name of certain mollusks.

Ar'CE $(a r-k a y)$.-Plural of Area.

Are'ola. - A small area or circle.

Ar'gonaut.-From the Greek, Argo, name of a vessel, and Nautes, a navigator. The Grecian princes who attempted the conquest of the Golden Fleece, in the ship Argo, under the command of Jason, were called Argonauts. Systematic name of a cephalopod (page 28).

Argonau'ta.-Latin. Argonaut.

Artery.-A blood-vessel that conveys blood from the heart to the various organs of the body.

Articula'TA.-Latin. Having joints. The word animalia, animals, being understood, articulata means ani. mals with joints, and is applied to insects, \&c.

Artículate (animals). - Having joints.

Artículated.-Haring joints.

Asci'Dia.-From the Greek, askos, a bottle or pouch. Systematic name of certain mollusks.

Ascídie.-Plural of Ascidia.

Aspérgillum,-latin. A watering. pot.

Aúditory. - Belonging or relating to the sense of hearing.

Au'ricLe.-Name of one of the cavi. ties of the heart.

Auri'cula.-From the Latin, auris, an ear. Name of a shell, from its resemblance to the human ear.

AUri'culo-ventri'cular' (opening).The aperture betwixt the auricle and ventricle of the heart is so called.

Avícula.-From the Latin, avis, a bird. Name of a shell (fig. 95).

Batrácuian (Ba-tra'-ke-an).-From the Greek, batrachos, a frog. Belonging to that order of reptiles which includes frogs and toads.

BEAK. - The continuation of the body of univalves in which the canal is situate.

Belen'Nites.-From the Greek be. lemnon, a dart. A genus of fos. sil dibranchiate cephalopods, the shells of which are chambered and perforated by a syphon, but internal. They are long, straight, and conical, and commonly called " thunder-stones." They are often found in chalk.

Birho'RA. - From the Greek bis, double, and phorế, I bear. (See page 90, fig. 114.)

Bipho'r.e.-Plural of Biphora.

Br'valve. - From the Latin bis, two, and valve, doors. Shells composed of two pieces united by a hinge are termed bivalves, as, for exam. ple, clams, oysters, mussels, \&c.

BoreA'LIs. - Latin. Northern; belonging or relating to the north.

Botry'Llus.-From the Greek, bo. trus, a bunch of grapes. (See page 88.)

Bra'chIopod (Bra'-ke-o-pod). - From 
the Greek, brachion, an arm, and pous, foot (page 92).

BRA'CHIopo'dA.-See Brachiopod.

BránChia (Bran'k-ea). - Latin. gill.

BRA'NCHIE (bran'k-eay).-Plural of branchia.

Branchial (bran'k-eal). - Belonging or relating to the branchiæ, or gills.

Buc'CaL.-From the Latin bucce, the cheeks. Belonging to the cheeks.

Buc'cinum. - Latin. A trumpet or horn; a shell.

Buc'cins. - Latin. Plural of Buccinum.

Buccinoi'des.-From buccinum, and the Greek, eidos, resemblance. Systematic name of a family of shells, the characters of which resemble those of the Buccinum.

Bx'ssus.-From the Greek, bussos, fine flax. A bundile of silky filaments, secreted by a gland at the foot of certain bivalves, and serv. ing as an organ of adhesion to submarine rocks and other foreign bodies.

Calca'reous.-From the Latin, calx, lime. Partaking of the nature of lime.

Calma'ries.-From an old French word, calmar, an inkstand, or a pencase; this word is from the Latin, calamus, a pen. Name of a family of cephalopods (pages 23 and 29).

Calyptrés. -From the Greek, $k a$. luptra, a covering. Name of a genus of gasteropods (page 59).

CALYPTRE' E.-Plural of Calyptræ'a.

Cam'erines. - From the Latin, $c a-$ mera, chamber. Name of certain microscopic shells (page 32).

Capíllary.-From the Latin, capillus, a hair. Hair-like.

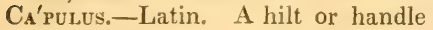
(page 58).

Ca'Pulor'pes.-From the Latin, capulus, and the Greek, eidos, resemblance (page 58 ).

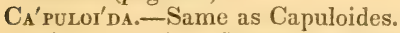

CAR'Dia.-Latin. Plural of cardium, a cockle. A genus of the family of Cardiacea (page 84).

CAR'DIAC.-From the Greek, kardia, the heart. Belonging or relating to the heart.
Cardia'cea,-From the Latin, car. dium, a cockle. Systematic name of a family of acephalous mollusks (page 83).

Cardiáces.-Plural of Cardiacea.

CAR'Dita.-Genus of the family of Cardiacea.

Cardinal (tooth).-From the Latin cardo, a hinge. Belonging or re. lating to the hinge (pages 99, $100)$.

Cardíum.-Latin, a cockle.

CAR'TILAGE.-Gristle.

Cartila'ginous. - Belonging or re. lating to cartilage.

Carina'rid.-From the Latin, carina, a keel. A genus of heteropodous gasteropods (page 66).

Ca'riNate.-From the Latin, carina, a keel. When a surface has a longitudinal elevated line like the keel of a boat.

Carni'vorous.-From the Latin, caro, in the genitive case, carnis, flesh, and voro, I eat. Flesh eating.

CAs'sis.-Latin. A helmet (page 54).

$\mathrm{CA}^{\prime}{ }^{\prime} \mathbf{A}$ (Vena). - A name given to the two great veins of the body, which meet at the right auricle of the heart.

CEPHa'LIC.-From the Greek, kephale, the head. Belonging or relating to the head.

Céphar opods (ke'f-a-lo-pods),-From the Greek, kephale, head, and pous, in the genitive case, podos, foot. A class of mollusks which have the head situated between the body and feet (page 19).

Ce'PHalopo'da.-Latin. Cephalopods. Cérita.

Ceríthium. $\}$ (See page 54.)

Chama (kama).-From the Greek, châ̂, I gape. A cockle.

Chama'cea (ka-ma'-cea)._-From cha$m a$, a cockle. Systematic name of a family of acephalous mollusks (page 81).

Chi'Ton (ky'-ton).-From the Greek, chiton, a garment. Name of a cy. clobranch gasteropod (page 62).

Chon'DRus (kon'drus).-From the Greek, chondros, cartilage. Name of a genus of gasteropods (page 40 ).

CHo' Rold (ko-royed). - From the Greek, 
chorion, chorion, and eidos, resemblance. Name of the membrane of the eye which lines the sclerotica.

CICA'TRIX.-From the Latin, cœcare, to conceal. The scar which remains after the healing of a wound. The "muscular impressions" or points where the adductor muscles are attached in bivalve shells are called cicatrices.

Cica'trices. - Plural of cicatrix.

Cíliaten.-From the Latin, cilium, eyelash. Fringed, like the eyelashes.

Cine'reus.-Latin. Like ashes; ashcolored.

Cirr'hopoda, or CIRRIPEdia.-From the Latin, cirrus, a tendril, a curl, and the Greek, pous (podos), foot. Systematic name of a class of mollusks. They are characterized by having a number of long, curled, articulated processes, analogous to the feet of the Crustaceans, which project from the central aperture of the multivalve shell protecting them. They are com. monly called barnacles. This class includes the genus Anatifa and Balanus.

Crausília.-From the Latin, clau. sus, closed. A genus of land shells, so named because the aperture of the shell is closed internally by a spiral lid (page 40 ).

Clavige' Lla. - From the Latin, clavis, a nail (page 88).

Cleodo'ra.-Name of a genus of pteropod mollusks (page 67).

Chio_-From the Greek, kleos, glory (page 67).

CECUn, or CÆCUM,-From the Latin, cœcus, blind. The blind-gut, so called from its being perforated at one end only.

Columétla.-Latin, a little column, or pillar. The axis of a shell from top to bottom (page 95).

Compo'sita. - Latin. Compounded.

Con'CHIFE'ra. - From the Greek, conche, shell, and the Latin, fero, I bear. Shell bearing. Applied to mollusks with bivalve shells.

Conchi'lan (kon-kil'-ean), - Belong- ing or relating to shells. The name of a dye (page 57).

Concho'Logy. - From the Greek, conche, a shell, and logos, a dis. course. The science of shells.

Co'nus.-Latin. A cone.

Cor.-Latin. The heart.

Corallíophaga. - Latin. Formed from the Greek, korallion, coral, and phagein, to eat. Coral-eating. Cor'bis. - Latin. A twig basket, or pannier. Name of a genus of acephalous mollusks which have the external surface of the shell marked by ribs and transverse lines, resembling basket-work (page 84).

COR'DIForM.-From the Latin cor, in the genitive case, cordis, heart, and forma, shape. Heart-shaped.

Con'NEA. - From the Latin, cornu, horn. One of the coats of the eye, so called because it has some resemblance to horn. It is the ante. rior, transparent part, through which light passes.

Cra'NIAL.-From the Latin, cranium, the skull. Belonging or relating to the skull.

Cre'Nulate. From the Latin, crenx,

Crénulate. a notch. Having

CRENULATED. rounded teeth.

Crenula'tion.-A rounded-tooth, or notch.

Crepínula. - Latin. A slipper (page 58).

Crepídula.-Plural of crepidula.

Crusta'CEa.-From the Latin, crus. ta, a hard covering. A class of free articulate animals, with articulated limbs, a branchial respiration and a dorsal or ventrical heart.

Crusta'ceef- Plural of Crustacea. Crusta'ceans.

Cry'stalline Lens.-The lens of the eye.

Cr'CLAS.-From the Greek, kuklos, a circle. A genus of fresh water gasteropods, so named from the circular form of the shell.

$\mathrm{Cx}^{\prime}$ CLADES.-Plural of cyclas.

Cy'Clobrancmíata.-From the Greek, kuklos, a wheel, and bragcriia, gills. Name of an order of mollusks (page 61). 
Crclo'stoma.-From the Greek, $k u$ klos, a circle, and stoma, mouth. A genus of gasteropods (page 48).

Cyclóstoma.-Plural of cyclostoma.

Сумви'Lia.-From the Greek, $k u m$ balon, hollow. A genus of pteropoda, commonly called the gondola.

CyPR $\mathbf{E}^{\prime} \mathbf{A}$ - From the Greek, kupris, Venus. Name of a genus of gasteropods. A cowry.

CyPr.E' TE.-Plural of Cypræa.

Cypricar'dia.-From the Greek, $k u$ pris, Venus, and cardium, a cockle. A genus of the family of Chama'cea.

Crprína. - A genus belonging to a group of Cy'clades.

Cyre'na.-A genus of the family of Chama'cea.

Delphínula.-Latin. A little dol. phin. Name of a genus of the family of Trochoides.

Den'sate. - From the Latin, dens, tooth. Marked with tooth-like projections.

Depressed shell.-When the spire is very flat.

Dı'APIRAGM.--Midriff.

Di'branchia'ta. - From the Greek, dis, two, and bragchos, gills-twogilled. Name of a division of cephalopods.

Dibra'nchial (di-bra'nk-eal).-Having double gills or branchiæ.

Drgita'tion.-From the Latin, digitus, finger. A process resembling a finger.

Driya'ria.-From the Greek, dis, two, and muôn, muscle. All those bivalves are so called which have two distinct and separate adductor muscles, and consequently two corresponding muscular impressions on each valve.

DIMYA'RIE.-Plural of dimyaria.

Diphyllídia.-From the Greek, dis, two, and phullon, leaf. Name of a division of gasteropods (page 62).

Dr'scoid.-From the Greek, diskos, a quoit, and eidos, resemblance. This term is applied to those univalve shells of which the whorls are disposed vertically on the same plane so as to form a disc; as in the Planorbis (page 44).

DoLA'BELLA. - Latin. A little axe.
Name of a genus of gasteropods (page 64).

Dólium.-Latin. A tun or tub. Name of a genus of gasteropods (page 53).

Do'NAX.-Latin and Greek. A reed; an arrow. Name of a genus of mollusks of the family of Chama'. cea (page 84).

Do'naCEs.-Plural of Donax.

Do'ris.-A sea goddess, the daughter of Ocean and Thetys. Name of a genus of nudibranch gasteropods (page 65).

Do'RSAL.-From the Latin, dorsum, the back. Belonging or relating to the back.

E'Dulis.-Latin. Edible; that which may be safely eaten.

Emargínula.-From the Latin, $e_{\text {, }}$ from, and margo, in the genitive, marginis, border or margin. A genus of gasteropods, character. ized by a shell of simple conical form, but having a narrow fissure, extending from the margin to near the summit (page 61).

Entire opening.-When the opening of a shell has neither a notch or canal on its margin, it is said to be entire (page 94, and page 50, fig. 51).

E'olidia. - Name of a genus of gasteropods (page 65).

E'olidie,-Plural of Eolidia.

Eride'rmis.-From the Greek, epi, upon, and derma, skin. The cu. ticle or searf-skin.

E'quivalve. - When the two valves of a bivalve shell are symmetrical they are said to be equivalve (page 97).

ETHE'RIA.-From the Greek, aithô, I shine. Name of a genus of the family of Ostracea (page 75).

Ethe'ri e.-Plural of Etheria.

ExCrE'TorY.-Applied to any vessel or duct which transmits the fluid secreted by a gland, either exter. nally or into the reservoir designed to receive it.

Extravasa'tion,-From the Latin, extra, out of, and vasa, vessels. Escape of fluids from vessels con taining them and the offusion of 
those fluids into the surrounding textures.

Fascrículus,-Latin. A bundle.

Fascículi.-Plural of fasciculus.

Fr'brous -Composed of fibres.

Fili'form.-From the Latin, filum, a thread. Thread-like.

Firo'LA.-Name of a genus of gasteropods (page 67).

FIRO'L $\varlimsup_{0}$-Plural of Firola.

Fissure' Lla.-From the Latin, findo,

I split. A genus of gasteropods having a split or opening in the top of the shell.

FisSuRE'Ll.E.-Plural of Fissurella.

Eistula'Na.-From the Latin, fistula,

a pipe. Name of a tribe of mollusks (page 88).

Fistula'NA.-Plural of Fistulana.

Fo'Llicle-From the Latin, follis, a bag. A little bag or sack.

Foraminife'ra. - From the Latin, foramen, a hole, and fero, I bear. Name of a tribe of very minute shells.

Eorma'тrov-A geological term applied to a group of deposits or strata apparently referable to a common origin or period.

Fo'ssa.-Latin. A pit, a hollow.

Fos's_E.-Plural of fossa.

FrA'Gris.-Latin.-Fragile; easily broken.

Fu'cus.-Latin. Sea-weed.

Fu'sus.-Latin. A spindle.

GALE'A.-Latin. A helmet.

Gan'GLIA.-Plural of ganglion.

GA'NGLION.From the Greek, gag. glion, a knot. An enlargement or knot in the course of a nerve is termed a ganglion.

GA'NGLIONIC.-Consisting of, or relating to ganglia.

GA'steropods. - From the Greek, gaster, belly, and pous, foot. Systematic name of a class of mol. lusks, comprehending those which have a ventral muscular disc, adapted for creeping.

GA'steropóda.-Latin. Gasteropods. $\mathrm{G}_{\mathrm{A}}$ 'steropo'dous.-Belonging or relating to gasteropods.

Gas'TRoch 'NA. - From the Greek, gaster, belly, and chainô, I gape. A genus of bivalve mollusks, in which a large hiatus or gape intervenes between the closed valves, on the ventral aspect of the animal (page 88).

GAS'TROCHE'NÆ.-Plural of gastro. chæna.

GE'NUS.-Latin. A kindred, breed, race, stock, lineage or family.

GE' Nera.-Latir. Plural of genus.

GLand.-An organ for the purpose of secreting a peculiar fluid, \&c.

GLA'NdULAR.-Relating to glands.

GLAU'CUs.-From the Greek, glaukos, blue. Name of a genus of mollusks (page 66).

GLo' Bos:-Globe-like; globular.

GLYCY'MERA, or GLYCI'MERIS:-Name of a genus of bivalve mollusks (page 86).

GRYPHE'A.-From the Greek, gru. pos, incurved. A genus of mol. lusks of the family of Ostracea (page 73).

HA'Liotis.-From the Greek, als, the sea, and ous, the ear. Name of a genus of gasteropods (page 60).

Halio'tides,-Plural of Haliotis.

HAR'PA.-Latin. A harp.

Helicína.-Name of a genus of gas. teropods.

HE'ux.-From the Greek, elix, a spiral, a whorl. Name of a genus of gasteropods (page 39).

Heli'ces.-Plural of Helix.

Hemícyclo'stoma.-From the Greek, emisus, half, kuklos, round, and stoma, mouth. Name of a tribe of gasteropods (page 49).

Herbívorous. - From the Iuatin, herba, plants, and voro, I eat. Plant-eating; applied to animals that feed on vegetables.

Her MA'PHRodite.-From the Greek, ermes, Mercury, and aphrodite, Venus. An organized body, com. bining in reality or appearance the characteristics of both sexes.

He'teropods.-From the Greek ete. ros, various, and pous, foot. The name of an order of gasteropods.

HE'TERopódA. - Latin. Heteropods (page 66).

HE'TERoPo' Dous.-Belonging or relat. ing to heteropods. Hia'tus. - Latin. A yawning,
gape. 
Hippo' ${ }^{\prime} x_{0}$ - From the Greek, ippos, a horse, and onux, nail. Name of a genus of gasteropods (page 58).

Hyaléa.-From the Greek, ualos, glass. A genus of beautiful ptero. pods, remarkable for the transparency and delicacy of the shell (page 67).

HYDA'TIS.-Latin. Formed from the Greek, udor, water. Specific name of a mollusk.

IM'BRICATE.-Placed like the tiles of a house.

INCLU'SA.-From the Latin, includo, I enclose. Name of a tribe of acephalous mollusks.

INCURV'ED.-When a part is turned inwards.

INE'QUILATERAL. -When the anterior and posterior sides make different angles with the hinge.

INE'QUIVALVE.-Where one valve is more convex than the other, or dissimilar in other respects, as in the common oyster.

IN'FEROBRANCHIA'TA.-From the Latin, inferus, below, and branchia, gills. Name of an order of gasteropods which have the branchiæ below the mantle (page 62).

InTE'GUMENT.-From the Latin, te. gere, to cover, the covering, the skin.

In'TERgangLio'NIC. - A pplied to nerves which are between ganglia.

IN'TER NoDE.-The space between one knot or joint and another.

INTERRU'PTED.-Divided, separated.

INTOR'TA.-Latin. 'Twisted inwards.

INVERTEBRA'TA.-Latin. Formed of in, without, and vertebra, a bone or joint of the spine or back-bone. A division of the animal kingdom, embracing mollusks, insects, and other animals which have no vertebræ, or internal bony skeleton.

INVE'RTEBRATF.-Without vertebræ.

In'volute.-Having the exterior lip turned inwards at the margin, as in the Cyprææ.

Involu'TION.-That part which in. volves or inwraps another.

Iso'CARDIA.-From the Greek, isos, like, and kardia, heart. Name of a genus of Chama'cea (page 82).

Iso'CARDIE.-Plural of Isocardia.
JANTHI'NA.-From the Greek, ianthon, violet colour. A genus of the family of 'Trochoides.

LA'BIAL.-From the Latin, labium, lip. Belonging or relating to the lips.

LACi'niate.-Jagged, or cut into irregular segments.

LA'CUNose. - Having the surface covered with pits.

LAME'LLA.-Latin. A little thin plate or piece.

LAME'LLE.-Plural of lamella.

Lame' Llibra'nchiata. - From the Latin, lamella, a thin plate, and branchia, gills. An order of aceph. alous mollusks.

LAME'LLIBRANCH.-Belonging to the lame'llibra'nchiata.

LA'mina -Latin. A plate, or thin piece of metal or bone.

LA'MINE.-Plural of lamina.

LA'MINATED.-Divided into distinct laminæ.

Lapíllus.-Latin. A little stone.

Lentícular.-From the Latin, lenticula, a little lens, a lentil. Shaped like a lens.

Li'ma.-Latin. A file. Name of a genus of the family of Ostracea.

Límax.-Latin. A slug, a snail.

LiMA'cEs. - Plural of limax.

Liмв.-The margin of bivalve shells.

LIMNE'A.-From the Greek, limne, a pool. Name of a genus of fresh. water snails.

Li'NEAR.-Composed of lines.

LI'NEATE.-Marked with lines.

Li'NGULA.-Latin. A little tongue. Name of a genus of bivalves (page 89).

Li'NGULA.-Plural of Lingula.

Lirho'dosus. - From the Greek, lithos, stone, and demô, I build. Name of a genus of bivalves found in rocks and stones, inhabiting cavities which they form for that purpose.

Liтно' DoмI.-Plural of Lithodomus.

LI'TTORaL.-Belonging to the shore.

LitTori'na.-From the Latin, litus, the sea-shore. A genus of the family of Trochoides (page 49).

LitTo'reus. - Latin. Belonging or relating to the sea-shore. 
Lo'BATED, - Rounded at the edges.

LOBE. - A round projecting part.

Lo'LIgo.-Latin. A calmary.

LoLIGo'Psis.-A calmaret; a little calmary.

Longitu'DinaL.-The length of the shell from the apex to the base.

Lubri'CITY.-Smoothness of surface, slipperiness.

LU'NATED,-Formed like a half-moon.

LUNU'LATED.-Crescent-shaped.

Lu'NULE.-A crescent-like spot or mark situated near the anterior and posterior slopes in bivalve shells.

LU'NIFORM.-In the shape of a cres. cent or half-moon.

LUTRA'RIA, - Genus of the family of Inclusa.

Mactra. - Latin. A kneadingtrough. Name of a genus of bi. valves.

MA'DREPORE.-A hybrid compound of the French madré, spotted, and. Latin, porus, a pore. Name of a genus of zoophytes.

MA'GILUs.-Name of a genus of gas. teropods.

MÁGus,-Latin. Magical.

MÁlleus,-Latin. A hammer. A genus of Ostracea.

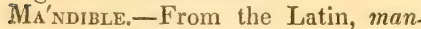
dibula, a jaw. The jaw of a bird.

MAN'TLE.-The external fold of the skin of mollusks.

Ma'rgaritífera.-Latin. From mar. garitum, a pearl, and fero, I bear. Pearl-bearing.

$M_{A^{\prime} \text { RGIN. - The whole circumference }}$ or outline of the shell in bivalves.

Márginated.-Having a prominent margin or border.

Mediterránea. - Latin. Belonging or relating to the Mediterranean.

Medu'llary.-From the Latin, medulla, the marrow. Belonging or relating to nervous matter.

Mela'nia-From the Greek, melas, black. Genus of fresh-water gas. teropods.

Meleagri'na.-From the Greek, meleagris, a guinea-hen. A genus of the family of Ostracea.

Men'branous,-Belonging or relating to membrane.

ME'SENTERY,-From the Greek, me- sos, in the middle, and enteron, in. testine. A membrane which serves to retain the intestines in their proper situation.

Metamo'rphosis,-From the Greek, $m e t a$, indicating change, and mor. phe, form. Transformation.

Microsco'pic-From the Greek, mikros, little, and skopeô, I view. Diminutive. Not easily seen without the aid of a magnifying-glass. Mítra-Greek. A head-band, or diadem. A genus of gasteropods. Modió'Lus, - Latin. A bucket. A genus of mussels.

Mo'LECULE.-An atom.

Mollu'sca.-From the Latin, mollis, soft. Name of the second branch of the animal kingdom.

Mo'Llusk.-A soft animal.

Mo'nonov.-From the Greek, monos, single, and odous, tooth. A genus of the family of Trochoides.

Mononon'ta.-Latin. Monodons.

Mono'mya'ria. - From the Greek, monos, single, and muôn, muscle. Bivalves which have only one ad. ductor muscle.

Mu'Cronate.-Ending in a sharp, rigid point.

Mu'Ltivalve. - From the Latin, multus, many, and valve, valves. Composed of several, or more than two calcareous pieces or valves.

Multilócular.-From the Latin, multus, many, and loculus, a lodge. Many-chambered; consisting of several divisions.

Mu'REx. - Latin. A shell-fish. A genus of gasteropods.

Mu'RiCES.-Plural of Murex.

Mu'ricated. - Clothed with sharp spines.

Mu'scLe.-Fleshy fibres capable of contraction and relaxation.

Mu'scular.-Belonging or relating to muscle.

Mu'SSEL - An acephalous mollusk.

$M \mathbf{y}^{\prime} \mathbf{A}_{\mathbf{A}}$-From the Greek, muôn, a musele. An acephalous mollusk.

Mytila'cea.-From the Greek, $m u$. tilos, a mussel. Name of a family of mollusks.

My'rilus.-Latin. A mussel.

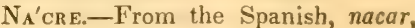
mother-of-pearl. 
$\mathrm{NA}_{\mathrm{A}}^{\prime}$ CREous.-Of the nature of motherof-pearl.

NA'ssa.-Latin. A net, a snare. genus of gasteropods.

NA'TICA,-Latin. Name of a genus of gasteropods (pages 34 and 51).

NAU'TILUS,-From the Greek, Nautilos, name of the Argonaut. genus of cephalopods.

NE'Moral. - From the Latin, nemus, a wood. Belonging or relating to a. wood or grove.

Neri'ts.-Latin. A shell-fish. genus of gasteropods (page 51).

Neriti'na.-Latin. Diminutive of Nerita. A genus of gasteropods (page 51).

Nerv'ous.-Belonging or relating to the nerves.

Nilo'ticus.-Latin. Belonging to the Nile.

Ni'TED.-From the Latin, niteo, I shine. Glossy.

Nodo'sE, -Knotty.

$\mathrm{Nu}^{\prime} \mathrm{CH}$ (nu-ka).-The nape of the neck.

Nu'Cleus, - A kernel. A centre around which matter has accumulated.

NU'DA.-Latin. Naked.

Nu'dibrancir.-Relating to the Nudibranchiata.

Nu'dibranchis'ta.-From the Latin, nudus, naked, and branchia, gills. Name of an order of gasteropods.

Numuldi'tes.-From the Latin nummus, money, and the Greek, lithos, stone. An extinct genus of cephalopods, of a thin lenticular shape, divided internally into small chambers. These occur so abundantly in some parts of the chalk formation, that the name of nummulite limestone is given to the strata so characterized.

OB'LONG-O'VATE.-Egg shaped, or oval.

OB'SOLE'rE.-Indistinct, not well defined.

O'Cellated.-From the Latin, oculus, an eye. Marked with eyelike spots.

$\mathrm{O}^{\prime}$ chreous $\left(o k^{\prime}\right.$-re-us), - Of the colour of yellow ochre.

O'cropus.-From the Greek, oktô, eight, and pous, foot. Name of a genus of cephalopods.
Octopo'dia. - A tribe of cephalopods.

Eso'phageal. - Belonging to the œsophagus.

Eiso'phagus.-Latin. The gullet.

Of'FusCaTED. - Darkened, clouded, dimmed.

OfFicina'lis. - Latin. Officinal. From officina, a shop. Applied to what is ready prepared.

Oli'va.-Latin. An olive. A genus of gasteropods.

Olivi'ceous,-Being of a greenish olive colour.

OnCHI'DIUM. - A genus of gasteropods (page 41).

OrA'QUE.-From the Latin, opacus, dark. Incapable of transmitting light.

Ope'rculur. - From the Latin, operio, I cover. The lid or door which covers anything.

O'PTIC.-From the Greek, optomai, I see. The principal nerve of vision. is so called.

Orbi'cula.-From the Latin orbis, a circle. A genus of brachiopod mollusks (page 90 ).

Orbícular. - Spherical, circular, round.

O'RGAN.-From the Greek, organon, an instrument. Part of an organized being, destined to exercise some particular function.

Organiza'tion.-A mode of structure.

Ostra'CEA.-Name of a family of bivalves.

Os'trea.-Latin. An oyster. Name of a genus of the family of $\mathrm{Os}$. tracea.

O'varies. - Female organs which contain the ova or eggs.

O'vate.-Shaped like the longitudi. nal section of an egg.

O'viduct.-From the Latin ovum, an egg, and duco, I conduct. The tube which conveys the ovum from the ovary.

Ovi'parous.-From the Latin, ovum, an egg, and pario, I produce. Ap. plied to animals whose young are produced by means of eggs.

O'vord,-Oval.

O'vula.-From the Latin, ovum, an egg. A genus of gasteropods.

O'vuLÆ,-Plural of ovula.

Pálatine. - Relating to the palate. 
PA'Llial.-Belonging or relating to the pallium.

PA'Lliurr.-Latin. A cloak. The mantle of mollusks is so called.

Paludína,-In the plural Paludina. From the Latin, palus, a marsh. Name of a genus of fresh-water gasteropods.

Pan'creas.-A gland situated in the abdomen.

PAPI'Lla.-Plural, papilla. Latin. A nipple. A nipple-like eminence. PÁpillous. Having the surface Pápillary. $\left\{\begin{array}{l}\text { covered with pimples } \\ \text { or dots. }\end{array}\right.$ PA'pillose.-Pimpled, dotted.

PApyra'ceous.-From the Latin, $p a$. pyrus, a sort of paper. Thin as paper.

PARI'Etes.-From the Latin, paries, a wall. A name given to parts that form the enclosures - the limits of different cavities of the body.

Parmace'lla. - From the Latin, parma, a round buckler. A genus of naked gasteropods.

Patélula. - In the plural patella. Latin. The knee-pan. A genus of gasteropods (page 61).

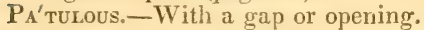
PE'́t'TEN. - In the plural pectenes. Latir. A comb. A genus of the family of Ostracea (page 73).

Pec'tinatea.-Latin. Pectinated.

Pectinated.-Resembling the teeth of a comb.

Pectínibranch,-From the Latin, pecten, comb, and branchia, gills. Relating to the Pectinibranchiata.

Pectinibranchia'ta. - Name of an order of gasteropods.

Pectu'nculus.-Latin. Name of a genus of the family of Ostracea (page 78).

PE'DICLE:-A support, A little foot.

PE'diform-Foot-shaped.

Pedu'NCle-A foot-stalk or tube on which anything is seated.

Pedu'nculate.-Having a peduncle.

Pela'Gic.-Belonging to the deep sea.

PE'Llicle-A thin skin or film.

Penu'Ltimate.-Next to the last.

PE'rna.-In the plural perna. Latin. A gammon. A genus of the family of Ostracea (page 75).
Pericn'rdium,-The sack which con. tains the heart.

Petraco'la. - From the Latin, petra, a stone, and colo, I inhabit. Name of a family of Ostracea (page 85).

Phasiane'lla. - From the Greek, phasianos, a pheasant. A genus of gasteropods (page 50).

Phary'nx-The swallow. The su. perior opening of the gullet.

Pho'LAs. - In the plural pholades. From the Greek, pholeos, a lurking. place. A genus of the family of Inclusa (page 87).

Phosphóric. Emitting light Phosphore'scent. $\}$ in the dark.

Phyllitida. - From the Greek, phullon, a leaf. Name of a tribe of mollusks (page 62).

Phy'sa.-From the Greek, phusa, a bubble. A genus of fresh-water snails (page 42).

Pi'ca._Latin. Black as pitch.

Pileo'rsis.-From the Greek, pilos, a hat. A genus of gasteropods (page 58).

Pr'LLAR. - The internal continuation of the columella, and extends from the base to the apex.

Pinna.-Latin. In the plural pinne. A fin, a wing. A genus of the family of Ostracea.

PínNated.-Winged.

Plano' rbis.-From the Latin, planis, flat, and orbis, an orb, a circle. A genus of marsh-snails (page 42).

Puíca,-Latin. A fold.

Plícate.-Folded or plaited, as in the pillar of the Volute tribe.

Pleurobra'nchus (plu-ro-bran'-kus). -From the Greek, pleura, side, and bragchia, gills. A genus of gasteropods (page 63).

Pleurobra'nchi- (plu-ro-bran'-ki). Plural of Pleurobranchus.

Plumo'se. - Having a feathery appearance.

Po'LyPI,-Plural of Polypus.

Po'LYPus.-From the Greek, polus, many, and pous, foot. A genus of radiate animals.

Polytua'lamous,-From the Greek, polus, many, and thalamos, cham. ber. Having many chambers.

Por'cste. - Marked with raised longitudinal lines. 
Porcella'na.-Latin. Porcelain.

Porrécted.-Projecting.

Post-ersopha'Geal. - Situate behind the œsophagus.

Pounce.-A powder to prevent ink from spreading after erasures.

Prehe'nsion.-The act of laying hold of and conveying the food to the mouth.

Probo'scis.-A trunk, a prolongation of the nose.

Produ'CED.-Lengthened out.

Psammo'bia.-From the Greek, psam. mos, sand. A genus of bivalves.

Prerócera. - From the Greek, pteron, wing, and keras, a horn. A genus of gasteropods (page 55).

PteróPoda. - From the Greek, pteron, a wing, and pous, foot. Name of a class of mollusks (page 67).

Punc'ruated.-From the Latin, punctum, a point. Having small hollows like the punctures of a thimble.

Púlmonary.-Belonging or relating to the lungs.

Pulmonéa.-Latin. Pulmonary.

Pu'PA.-Latin. A puppet. A genus of snails.

Pur'rura.-Latin. Purple. A genus of the family of Buccinoides (page $53)$.

Pylo'rus.-The right orifice of the stomach.

Py'riform. Pear-shaped.

Pyrosóna. In the plural pyrosoma. From the Greek, pur, fire, and soma, body A genus of mollusks (page 92).

QUADRA'NGULAR. - Having four angles.

QUA'DRIPLICATED,- Having four plaits.

RADIA'TA.-Latin. Name of a class of Zoophytes.

RA'DIATE. - From the Latin, radius, a ray. Furnished with rays.

RE'ctuM.-The terminating portion of the intestine.

Recu'rved.-Bowed back.

REFLE'CTED.-Bent backwards.

ReFRA'CTED.-Abruptly bent, as if broken.

RE'NIForír.-Kidney-shaped.

REPA'ND.-With a serpentine margin.
RE'PLICATED.-Folded so as to form a groove or channel.

RESPIRA'TION.-The act or function of breathing.

Respíratory.-Relating to respira. tion.

Retículated.-Formed like a piece of net-work.

Retra'ctile.-Susceptible of being drawn back.

RETrofle'Cted.-Bent backwards.

Retrou'sse.-Backed up, turned up.

RETROVE'RTED. - Turned back.

RETU'SE.-Ending in an obtuse sinus.

Rerun'Dated.-Blunted or turned at the edge.

RE'volute.-Rolled backwards.

$\mathrm{RI}^{\prime}$ Ma.-The interstice between the valves when the hymen is removed.

Ros'trum.-The beak. The extension of that part of the shell in which the canal is situated.

RотU'ND.-Round, eircular, spherical.

Ru'rous.-Of a reddish colour.

Ru'fus,-Latin. Reddish.

Ru'Gose.-Rugged, full of wrinkles.

SaLI'va.-The fluid secreted in the mouth by the salivary glands.

Sa'Livary.-Relating to saliva.

SANGUI'NOLA'RIA.-From the Latin, sanguis, blood. Name of a genus of acephalous mollusks.

SANGuina'Ceous.-Of a blood colour, or resembling blood.

Sca'brous.-From the Latin, scaber, rough. Rough, harsh, rugged, or like a file.

SCALA'ria.-From the Italian, scala, a ladder, or series of stairs. Name of a genus of gasteropods.

SCA'LLOPED.-Indented at the edges.

ScLERo'TICA.-From the Greek, skleros, hard. One of the external membranes of the eye-ball.

Scorbi'culate. Pitted, having the surface covered with holiows.

$\left.\begin{array}{l}\text { SCU'TELlated: } \\ \text { SCU'TIForm. }\end{array}\right\}$ Shield-shaped.

Scutibranchia'ta.-From the Latin, scutum, a shield, and branchia, gills. An order of gasteropods.

SEAM.-The line formed by the union of the valves. 
stratified rocks with certain characters by which they are distinguished from the primary rocks. By the term formation geologists understand a series of rocks of the same age. Those rocks which were first formed are called primary; those formed next in succession are secondary; and so on.

Secre'tion.-From the Latin, secernere, to separate. The process by which organic structure is enabled to separate from the fluids circulating in it, other different fluids. These separated fluids are also called secretions.

SECRE'TORY.-Belonging or relating to secretion.

Semicor'neous. - From the Latin, semi, half, and cornu, horn. Half or partly horny in its nature.

SE'PIA. - Latin. A cuttle-fish. kind of paint made from this ani. mal. A genus of cephalopods.

SE'Prifory.-From the Latin, septum, a partition. In the shape of a partition.

Se'rrated.-From the Latin, sera, a saw. Like the teeth of a saw.

Sérrulated, - Very minutely serrated.

SE'TA.-Latin. A bristle.

Seta'ceous. / Bristly; covered with Se'tose. $\}$ bristles.

Sigare'tus.-A genus of gasteropods.

Siliqua'ria.-From the Latin, si'li$q u a$, a pod. A genus of gasteropoda tubulibranchiata.

Si'Nister. - The left.

Si'NUS.-A groove or cavity.

Sirhona'ria.-From the Greek, siphôn, a tube. An order of cephalopods.

Sipun'nculus. - A cylindrical canal perforating the partitions in polythalamous shells.

So'LAR.-From the Latin, sol, the sun. Belonging or relating to the sun.

Sola'rium.-Latin. A sun-dial. A genus of the family of Trochoides. (page 46).

SolemY'A. A genus of the family of Inclusa.

So'LEN.-From the Greek, solen, a tube. A genus of acephalous mol. lusks (page 86).
Spa'tulate.-Rounded and broad at one end, and becoming narrow like a battledore or spatula.

SpheroídaL.-Resernbling a sphere or globe.

SPI'NAL. - Belonging or relating to the spine.

Spi'nous. / Covered with thorn-like

SPI'NY. $\{$ processes or spines.

SPIRE.-All the whorls of univalve shells, except the one in which the aperture is situated, which is term. ed the body.

Spi'ral.-T'wisted like a corkscrew.

SPLEEN.-An organ of the body, the use of which is not known: it is vulgarly called the melt.

SPon'DyLus,-In Greek, spondulos, a vertebra. A genus of bivalves, in which the teeth of the hinge lock into each other, like the vertebræ of the spine.

SQUA' Mose.-From the Latin, squama, a scale. Scaly.

S'TE'LLATED.-Consisting of star-like figures.

Stra'ta.-Latin. Plural of stratum.

Strátum.-Latin. A bed, a layer.

Strría.-Latin. In the plural striæ.

A diminutive channel or crease.

S'TRI'ATED.-Scored, or covered with fine thread-like lines.

Strómbus.-Latin. In Greek strombos, a shell-fish. A genus of gas. teropods.

STY'LET.-A small style or slender process.

Subar'cuated. - Somewhat arched.

Subco'NIC.-Somewhat conical.

Subesopha'gEaL.-Placed beneath the œsophagus.

SuB'rotund.-Nearly globular.

Sub'ulate.-Awl-shaped.

Succi'nea.-From the Latin, suc. cinum, amber. A genus of gaste. ropods, so called from the transparent texture and amber colour of the shell.

Su'LCATED.-Furrowed.

$\mathrm{Su}^{\prime}$ LCr.-Plural of sulcus.

Su'LCUS.-Latin. A furrow.

Su'mut, - The tip or apex.

Su'PER Ficres. - From the Latin, super, above, and facies, face. The surface.

SuPERPo'sed.-From the Latin, super, 
above, and pono, I place. Land one upon another; lying above.

Su'ture.-The seam, or fine spiral line which separates the whorls or wreaths.

Sy'PHon-—From the Greek, siphon, a tube.

TACT.-The sense which gives the perception of touching. 'Touch is active; tact passive.

Tectibranchia'ta. - From tego, I cover, and branchia, gills. Name of an order of gasteropods.

Tegume'ntary,-Relating to the tegument or covering.

Tellína. - In the plural tellina. From the Greek, telline, a species of mussel. A genus of acephalous mollusks.

Tev'tacle. A feeler.

Tenta'cula.-The feelers of snails.

TEnTA'CULAR_-Belonging or relating to tentacles.

Tenta'culuar.-Latin. A feeler.

Tere'bra.-Latin. From terebro, I bore. A genus of gasteropods.

'Terebra'tula. - Plural, terebratula. A genus of acephalous mollusks (page 89).

Tere'do.-Latin. A ship-worm.

Tere'dines.-Plural of teredo.

Terréstria.-Latin. Terrestrial.

Ter'tiary forma'tion, or strata.-A series of sedimentary rocks which lie above the primary and second. ary strata, and distinguished from them by their arganic remains.

Te'sselated. - Chequered like a chess-board.

Tessera'tus.-Latin. Tesselated.

Testa'cea.-From the Latin, testa, a shell. An order of acephala covered with a testaceous shell.

Testa'ceous,-Consisting of carbonate of lime and animal matter.

Testace'lla. - A genus of snails (page 39).

Tétrabranch,-Having four branchiæ.

Tetrabranchin'ta.-From the Greek, tetteres, four, and bragchia, gills, Name of an order of gasteropods.

TE'Tragonal.-Four cornered.

THORA'CIC.-Belonging to the thorax.

'Tho'rax.-Latin. The chest.

Transve'rse. - Placed crosswise.
When the breadth of a shell is greater than its length, it is termed transverse.

TrAPE'ZIForM.-Shaped like a trape. zium.

'Trida'Cna.-A genus of the family of Chama'cea.

Trico'rnis.-From the Latin, tres, three, and cornu, horn. Three horned.

Trigo'nia.-From the Greek, trigonôs, three-cornered. A genus of the family of Ostracea.

Trigo'NaL.-Three-cornered.

TRITo'NIA. - A genus of gasteropods.

'Trocho'IDEs.-From the Greek, tro. chos, a wheel, and eidos, resem. blance. Name of a family of gas. teropods.

Tro'chi._Plural of trochus.

'T'ro'chus (tro-kus).-A genus of gasteropods.

Trunk.-The body.

Trun'cate.-Stunted, cut short or abruptly off at the end.

Tu'Bercle.-A little knot or pimple.

Tube'rculated. - Knotted or pim. pled.

Tubero'sities.-Prominent knobs or excrescences.

Tu'buLar.-In shape of a hollow tube

Tu'bulate.-Hollow.

Tubulibranchin'ta. - From the Latin tubus, tube, and branchia, gills. An order of gasteropods which have the branchiæ lodged in a tube (page 59).

Tunica'TA,-Name of an order of acephalous mollusks.

Tu'NICATE.-From the Latin, tunica, a tunic. Coated.

Tur'binated.-Shaped like a top or pear.

Tu'RaID.-Swollen.

TU'RRETED. - Resembling a tower with turrets.

Tu'nвo.-Latin. A whirling or twisting. A tribe of gasteropods (page 47).

Turritéles,-Latin. A turret. A genus of gasteropods.

Umbili'cus.-The aperture or depression in the centre, round which the shell is convoluted.

UMBILI'CATED.-Having a depression in the centre like an umbili'cus. 
U'мво.-Latin. A protuberance or boss. The round part of a bivalve shell which turns over the hinge.

Un'BONES.-Plural of umbo.

UM'BONATE.-Bossed; having a raised knob in the centre.

Unartículated.-Not jointed.

UNDA'TUm.-Latin. Waved.

Un'Dulated. - Waved, having a waved surface.

Unilo'cular. - From the Latin, unus, one, and loculus, partition. Having a single chamber or compartment.

Unío.-Latin. A pearl. A genus of mussels (page 81).

UNIO'NES.-Plural of Unio.

U'NIVALVE.-Consisting of one piece or valve.

UR'CEOLATE, - Swelling in the middle like a pitcher.

VAGI'NULA.-Latin. A little sheath or scabbard. A genus of naked gas. teropods (page 39). It is the same as vaginu'lus.

VALVA'TA.-A genus of fresh-water snails (page 48).

V $_{\mathbf{A}}$ 'RICEs, - Longitudinal ribs in univalve shells.

VA'scular.-Composed of numerous vessels.

VAU'LTED.-Arched like the roof of the mouth.

VE'NA.-Latin. A vein.

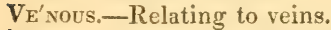

VE'NTER.-Latin. Belly. The most prominent part of the shell when the aperture is turned towards the observer.

VE'ntral. Relating to the belly.

VEN'TRICOSE. Inflated; swelled in the middle.

Vex'Tricle.-A little belly. A part of the heart.
Veneru'pis. A genus of Cardiacea (page 85).

VE'NUS. A genus of the family of Cardiacea.

VERME'TUS. A genus of gasteropods (page 59).

VE'RMIFORM. Worm-shaped.

VE'rRUCOSE. From the Latin, verru$c a$, a wart. Warted.

VER'TEBRA.-From the Latin, verlere, to turn. A joint or bone of the back-bone or spine.

VER'TEBRAL. Relating to the verte. bræ.

Vertebra'ta. Name of the first branch of the animal kingdom.

VER'tebrate. Having vertebræ.

Vertículated, Whorled.

VE'SICLE. A diminutive bladder.

Vesícular. Relating to vesicles.

VI'scus. Any internal part, as the heart, intestine, \&c.

Víscera. Plural of viscus.

VÍsceral. Relating to viscera.

VI'scid. Glutinous, sticky.

Vi'treous. Resembling glass. humour of the eye is so termed.

Vitrína. From the Latin, vitrea, glass. A genus of fresh-water gasteropods.

Volu'ta. Latin. A whorl. A genus of gasteropods.

Vulga'ris. Latin.' Common.

Whorl. A wreath, or turning of the spire of univalve shells.

ZONED. Surrounded with one or more girdles.

Zoo'LOGY. From the Greek, zôon, animal, and $\log o s$, discourse. The science of animals.

Zoo'pнyтe. From the Greek, zôn, animal, and phuton, plant. An animal belonging to the fourth $\mathrm{di}$ vision of the animal kingdom. 


\section{NEW AND IMPORTANT SCHOOL BOOKS.}

\section{TO TEACHERS, PRINCIPALS AND CONTROLLERS OF SCHOOLS, ACADEMIES AND COLLEGES}

We take the liberty of calling your attention to a Series of Books on the subject of Natural History, which, in the opinion of many of the most eminent men in our country, is second to no branch of knowledge now taught in schools. We ask your attention to these books, because we believe them to be superior to any works of the kind ever offered to the American public. They are small in size, extremely cheap, as accurate in scientific arrangement as the most voluminous works on similar subjects, and in every respect, such as parents and teacliers would wish to place in the hands of their children. In confirmation of this opinion of the worth of these works, we respectfully invite your attention to the following testimonials.

Very respectfully, your obedient servants, GRIGG \& ELLIOT, No. 9 North Fourth Street, Philad'a.

These books have been introduced into the Public Schools of Pennsylvania and Ohio, and no doubt will, ere long, be introduced into all the public schools of our other States.

"We regard the introduction of these works into our public schools, among the highest compliments they have received; for we feel sure that the gentlemen who constitute the committee for selecting books, possess too much discernment and general knowledge, to pass favourably upon works of inferior pretensions. The following gentlemen composed the Committee for selecting books for the use of Public Schools."

George M. Wharton, Esq.

Thomas H. Forsyth, Esq.

George Emlen, Jr., Esq.

Francis Lyons, Esq.

Philadelphia.

John C. Smith, Esq.

In addition to the following flattering notices of the American Press, the pubsishers have received upwards of one hundred recommendations from the most prominent professors and distinguished teachers of our country, to the superior claims of these works, and urging their introduction as Class Books into all the Schools, Academies, \&c., throughout the United States. 


\section{FIRST BOOKS}

oF

\section{NATURAL H I T T RY.}

fuR SCIIOOLS, COLLEGES, AND FAHILIES.

1. ELEMENTS OF

\section{ANATOII AND PIISIOLOGY.}

2. ELEMENTS OF

\section{A MI MI A L O G Y,}

The Natural History of $Q$ uadrupeds.

3. ELEMENTS OF

\section{R N I T H O L O G Y,}

The Natural History of Birds.

4. ELEMENTS OF

HERPETOLOGY AND ICHTHYOLOGY,

The Natural History of Reptiles and Fishes.

5. ELEMENTS OF

C. 0 N C H O L O GY,

The Natural Ilistory of Shells and Mollusca.

6. ELEMENTS OF

\section{ENTOMOLOGY,}

The Natural History of Insects.

7. ELEMENTS OF

B 0 T A N Y,

The Natural History of Plants.

8. ELEMENTS OF

\section{G E 0 L 0 G Y,}

The Natural History of the Earth's Structure.

This interesting series of books has already met with the most flattering reception ever extended to any work issued from the American press. Introduced into the Public Schools of Pennsylvania, and in nearly all the first class seminaries of learning in the United States. 


\section{RECOMMENDATORY NOTICES.}

"Rusclisenberger's Series of Boo's on Natural Hi:tory, are among the most valuabe and useful wo ks, fir the use of Schools that have ever been pullished. A knıwledge of Natural History, is not only valu be, but deeply $\mathrm{i}$ teresting; and $\mathrm{n}$, one's educati $\mathrm{n} \mathrm{c}, \mathrm{n}$, with such facili ies as these works afford, be comidered co np'ete without it."-National Intelligencer.

"These are the mo-t valuatle additions of the day to vur stock of Sehool Books. T'he ividity with which they liave been seized upon is unprecedersted. I'hough the first vol. wis published for the first time ouly a few month: : go, it h:s already gone through its fifth edition; the second is fol. L,wing c:o-e upon its heels; and the third promi es even to be more popular than either of the other two. These books have been adopted by the 'koyal Cousicil of Public Instruction,' for the use of Schoo's throughout France. They are recommended and have been adopted by some ol the most emi nent teachers in the United States."-Southern Literary Messenger.

From 'The Ladies' Companion, a Monthly Magazine." June, 184:-New York. W. Enowden, 109, Fuiton street.

“Ruschenbirger'y Ornithology: Grigg \& Elliot. This is an excellent book, by one who shows himself perfectly qualified for the task he has undertaken, which is the publishing of a series of works on the different branches of education, for the use of schools and colleges. The present issue is a gencral and synoptical view of Ornithology, one of the most interesting subjects in Natural History, and will be found of great service, both to teacher and student."

"This is a compendious, and, as it seems to us, a judiciously compiled treatise on Ornithology, and one well calculated for the use of Schools; fur which object it is intended." $-N$. Y. Courier and Enquirer.

"In the work before us, the plan is happily carried out. In its small compass it embraces an immense amount of useful and interesting infor. mation."-Buffalo Adv. and Journal.

"Ornithology.-This is evidently, like its predecessors, an excellent work of instruction; and has been, in all respects well got up by the publishers." -Pennsylvanian.

"A valuable little work, and is divided up and classified admirably. The glossary, giving the deriv tion of the names of birds, is of itself worth the price of the volume."-New York Aurora.

"An exceedingly interesting, and very instructive bouk, and one which possesses special attraction for ycung ladies."-Baltimore Sun.

"Ruschenberger's SrRies: Second Book.-A highly useful and instructive school book. Third Bouk-This we consider as decidedly an acquisition to our list of school books, the subject is treated of in such a plain style as to be adapted to the simplest capacity. Altogether we think the above Eeries as worthy to take a high and permanent place among our school books."-Buffulo Democrat.

"We wish we could induce our teachers generally to examine this, as wcll as the earlier works of Dr. Ruschenberger; they are admirably arranged, and just the very books needed for schools. The work before us on the Nitural History of Birds is an admirable one, and no tencher should neglect to introduce the series. '-Cincinnati Gazelte.

"It is an excellent text book of an interesting science, comprising much knowledge in a brief space, presented in a clear style and with lucid arrangement. Dr. Ruschenberger, who has already achieved a high charac. ter in the literary world, is acquiring additional clains by his exertions in the ficld of Natural Science.-Spectalor, Washington City. 


\section{RECOMMENDATORY NOTICES.}

"Ruschenberger's Series.-These volumes are constructed upon a new and admirahle plan, combining great simplicity of arrangement, with a perspicuity and sententiousiess of style seldom found in works of this class; ind which has elicited the highest encomiums of upwards of thirty of the leading professors of the country, whose opinions have again been endorsed by most of the public ptints." - U. Siutes $A d v$.

"The developement of the principles of classification, is among the very best we hive ever scen. Science is here dressed in her own native sim. plicity and beanty, so that the philosopher may admire, while the child may acquire it.-Medical Reporter.

"It is a choice, and well digested work."-Atlas.

"An excellent publication adapted to the youthful mind, and a great help to the mure matured."-Mercury.

"The study of Natural History though generally neglected in schools, is of undoubted use: the present work contains a great amount of infor. mation within a small compass, and properly contenses it for the young mind." - N. Y. Journal of Commerce.

"Ruschenberger's Series.-The subjerts are well treated, and from the exceedi.g cheapness, and admirable arrang mel $f$ of these clementary works, they are well fitted for general use in public sithuls and academies." New York American.

"We do not hesitate to say, that this is the best work of the kind and dimensions, that has even fallen under our notice. We hope all will embrace the first oppurtunity of procuring a copy, as we are sure they will prize it highly."-Botanic Recorder.

" A well dige-ted and carefu'ly arranged abstraet of the most interesting parts of Natural Science."-Philadelphia Gazrtte

"Admirably adapted to convey an elementary knowledge on the subject of which it treats; and will be found an excellent book for the student." Public Ledger.

"Valuable in every respect,-it contains a vast amount of information, condensed into an available form, for the use of schools."-Spirit of the Times.

"Just such a work as is wanted for elementary instruction, in this pleas. ing branch of science."-New York Evening Post.

"We reg:ird this series as eminently useful, supplying adequately the instruction in natural history necessary to a proper school education." North American.

"It is an excellent little work for the purpose designed, written in a cl ar and familiar style, and will not fail to facilitate the studies of those who wish to make themselve: acquainted with the subject."-Suturday Courier.

"Admirably adapted for elementary instruction." - Saturday Chronicle.

"We have great pleasure in recommending it as an excellent elenientary manual on the subject "-Medical Examiner.

"Ornithology-'This book is equal in merit to the first and second, and is a most valuable work. It is intended for the use of schoo's and academies, and we would call the attention of parents and others to the series of books to which this belongs, assuring them at the same time, that it will answer the purpose for whici it is intended, better than any other work of the kind that we ever saw, or, in our opinion, that was ever published in this conntry. It is divided into questions and answers, contains an exten. sive and valuabie Glossary, end is illustrated by eight Plates; and what is more the price is so very low that every person can aftord to purchase it.New Lork New Era. 
It has been justly observed, that " the double effect of the study of Natural Ifistory is to impart certainty to the mind, and religion to the heart," and the christian no less than the man of science, must rejoice in every effort to throw more widely open the sublime and boundless ficld which it presents. This is the design of Dr. Ruschenberger, in a series of First Books of Natural History, which he is preparing for the Lse of schools and colleges.-Banner of the Cross.

The series have uct a demand and sale in France almost unparalleled, and the rvords are well adapted, not only for schons, but for popular reading and instruction. Thig work is from the French of Edwards and Comte, and has received the warm commen. dation of many of the best physicians and scholars in this country $-\mathcal{N}$. Y. Eve. Tattler.

It is highly commended by the very best authorities,-N. Y. Tribune.

This book is highly commended by competent judges, and we therefore give our so. lemn opinion that it is an excellent work.-Boston Daily Times.

\section{A small, but very valuable work.-Boston Evening Transcript.}

We have examined this new hook for schools and collezes, with peculiar gratification. The style is succinct and clear, and the subject illustrated by appropriate drawings. We should be glad to see this work introduced into all the schools. It teiches knowledge the most important, which has been, however, strangely overhoked in our school and college system. It is a book which should not be confined to seminaries alone it may be used with advantage by all individuals in society. We repeat, it is in all respects a most excellent work, and we hope will receive the attention and patronage it unerits.Broolilyn Evening vitar.

\section{A valuable work; we have read it with profit.- $\mathcal{N}$. I: Mcrcury.}

We are highly pleased with this work. For elementary instruction in families, schools, and colleges, it is decidedly superior to any thung of the kind we have seen. It gives much valuable information in a very small space, and in style it is grenteral!y fiee from obstruse technicalities It has already received the highest recommindatuns frum a large number of professional men in ditierent parts of the country; and it mist have, we think. a general circulation. It gives that kind of kuowledge which should be dif. fused among the mass of the people, and it must and will be patronised as far as it: merits are known.-Zion's Watchman.

This is a fine litule book, containing the elements of much useful learning, illustra. ted by anatomical plates of the human figure, its organs and their fumctions. It is a highly useful work to the student-indeed to every cinzen it shows liow fearfully and wonderinlly we are made, and what slight causes may derange and utterly destroy the complicated machine:-The Olive Branch

\section{A very useful little work.- $\mathcal{N}$. $\boldsymbol{Y}$. Atlas.}

As far as we are competent to determine, it may safely be welcomed as an important addition to the means of elementary instruction in natural science,- The Friend.

$$
\text { We recommend it as a highly instructive publication.-N. Y. Times and Eve. Star. }
$$

This is a most valunble work, by Dr. Ruschenberger, and most admirably are the plates, representing a'l the different paris of the body, done. It is cheap, and every pa rent should place one in the hands of their chldren.- $\mathcal{N}$. Y. Herald.

We have examined this little volume with much pleasure, and think it admirahly adapted to the purpose for which it is intended. Auimal Mechanism, as a study, has generally been neglected, excupt by the few, whose profession requires a knowledge of it, and who have time to spare in acquiring that knowledge. A prominent cause of the neglect of this useful and interesting science by the general student, is, the want of a suitable treatise upon the subject, those extant beung too voluminous, techmical, and expensive for general tise. The little work before us is happly calculated to sup. ply this want. It will, we think, be introduced into our schools ant colleges as a text. book, but its circulation nught not to be confined theie. Evury private hibrary shou!d be cousidered incomplete without it. $-\mathcal{N}$. $Y$. Mechanic.

It seems to us to be well suited for the ohject for which it is designed, and it wi!? doubtless be introduced into many of our elementary schools. - The -American. Juurnab of the Acdical Sciences. 


\section{OPINION OF THE PUBLIC PRESS.}

"Such a little treatise is just the thing for our schools and academies and no time should be lost in introducing it." -New York Mirror.

"This is a most excellent work, and we would most respectfully recommend it to our cominon school tru tees, as worthy of introduction into the temples of learning under their supervision."-New York New Era.

"The plan and arrangement of the work are admirable, and eminently calculated to facilitate the progress of the pupil.-We recommend it to teachers and heads of families."-Philadelphia Sat. Chronicle.

"We know of nu books better calculated to convey elementary instruction than these, and heartily recomm nd those which have appeared." - Brother Jonathan.

"We cannot too arnes!ly recommend it to public attention."-Cincinnatz Enquirer.

"Decidedly one of the best elementary works on the subject with which we have ever met."-New York Lancet.

"The information it contains is at once lucid, intelligible, and satisfuctory: i: forms an excllent text.book for classes in schools, and cannot fail to infuse into the young mind a knowledge and love of Nitural History. It is concise : nd comprehensive, and must if adopted in seminaries of learning, be exceedingly useful in inculcating a correct knowledge of the elements of Znolngy. The plan is excel'ent, and must be found eminently useful." Alexanilria Gazette.

"It is one of the most valuable works of the kirid we have ever read.Such are the bosks we like to see disseminated among the people." - New Orleans American.

"The reputation of the author is a guarantec that the work is a gond one. On examination we find it to be so. It is an ad nirable compend of the subjects of which it treats:-we should think, indeed, that it would attract the attention of teachers, both from its cheapness, and the admirable manner in which it is arronged."-Cincinnati Gazette.

"The Second Book:- this number treats of all animals that in infancy feed on the milk of their mothers; from the human being down to the mus. quito-catching b.t - Like the "First Book," it is divided into questions and answers, and a glossary; and is illustrated by six plates. It is as cheap as dirt; and contains an abundance of useful information. There are thousands of persons in this country, and millions in Europe, who do not know that whales give milk."-New York Era.

"We do not know a more useful set than this promises to be:-and IS." New York Aurora.

"We liesitate not to say that it is a valuab'e work, and fully entitled to the high enconiuns bestowed upon it; taken as a whole the work may be jusily regarded as invaluable to schools." - New Furk Standard.

"It is a most valuable work, and one which we believe has no superior in our seminaries, - we know of nothing equal to it. It is very flatteringly recommended by the most distinguished men in France and in the United States, and deserves it."-New York Courier and Enquirer.

Ruschenberger's Second-Book of Natural History.- "This is another on those useful volumes, which Dr. Ruschenbeı ger is so beneficially in editing. $\mathrm{His}$ former volume has already been received $\mathrm{i}$ to some of our public schoo's, and we hope both it and the present may find th ir way into all."-American Medical Intelligencer.

The present work, is in our opinion quite a desideratum, and abounds with information of the most useful and, at the same time, most necessary character, every parent should place it in the hands of his children, and no public instructor should neglect to give it a place in his academy.-Philu. delphia Spirit of the Times. 





\section{R US C F I I B F FIRST 39088000739904 \\ NATURAL HISTORY, FOR SCHOOLS, COLEEGES, AND FAMILIES. \\ 1. ELEMENTS OF \\ ANATOMY AND PHYSIOLOGY. \\ 2. ELEMENTS OF \\ M A M M A L 0 GY, \\ The Natural History of Quadrapeds. \\ 3. ELEMENTS OF \\ 0 R N I T H 0 L 0 G Y, \\ The Natural History of Birds. \\ 4. ELEMENTS OF \\ HERPETOLOGY AND ICHTHYOLOGY, \\ The Natural History of Reptiles and Fishes.

$$
\begin{aligned}
& \text { 5. ELEMENTS OF } \\
& \text { C O N C H O I O G Y }
\end{aligned}
$$

The Natural History of Shells and Mollasea.

6. ELEMENTS OF

E N T 0 M 0 L 0 G Y,

The Natural History of Insects.

7. ELEMENTS OF

BOTANY,

The Natural History of Plants.

8. EIIEMENTS OF

$$
\mathrm{G} \mathrm{E} O \mathrm{~L} O \mathrm{G} \mathrm{Y}
$$

The Natural History of the Earth's Structure.

Six numbers have been issued, and have alveady met with the $m$ si flatering reception ever extended to any work issued from the Amorican press. Introduced into the Public Schools of Pernsylvamia, ard in nearly all the first class seminaries of learning in the United States. 